MECHANISMS OF ENDOCRINOLOGY

\title{
Mechanisms of disease: the endocrinology of obstructive sleep apnoea
}

\author{
Aikaterini Lavrentaki ${ }^{1}$, Asad Ali' ${ }^{2}$, Brendan G Cooper ${ }^{3,4}$ and Abd A Tahrani ${ }^{1,5,6}$
}

${ }^{1}$ Institute of Metabolism and Systems Research, University of Birmingham, Birmingham, UK, ${ }^{2}$ Department of Respiratory Medicine, University Hospitals of Coventry and Warwickshire NHS Trust, Coventry, UK, ${ }^{3}$ Department of Respiratory Medicine, University Hospitals of Birmingham NHS Foundation Trust, Birmingham, UK, ${ }^{4}$ Institute of Clinical Sciences, University of Birmingham, Birmingham, UK, ${ }^{5}$ Centre of Endocrinology, Diabetes and Metabolism, Birmingham Health Partners, Birmingham, UK, and ${ }^{6}$ Department of Endocrinology, University Hospitals of Birmingham NHS Foundation Trust, Birmingham, UK

Correspondence

should be addressed

to A A Tahrani

Email

a.a.tahrani@bham.ac.uk

\begin{abstract}
Obstructive sleep apnoea (OSA) is a common disorder that is associated with serious comorbidities with a negative impact on quality of life, life expectancy and health costs. As OSA is related to obesity and is associated with sleep disruption, increased inflammation and oxidative stress, it is not surprising that OSA has an impact on the secretion of multiple hormones and is implicated in the development of many endocrine conditions. On the other hand, many endocrine conditions that can affect obesity and/or upper airways anatomy and stability have been implicated in the development or worsening of OSA. This bidirectional relationship between OSA and the endocrine system has been increasingly recognised in experimental and epidemiological studies and there are an increasing number of studies examining the effects of OSA treatment on endocrine conditions and vice versa. In this review article, we will critically appraise and describe the impact of OSA on the endocrine system including obesity, dysglycaemia, the pituitary, the thyroid, the adrenals, the reproductive system and the bones. In each section, we will assess whether a bidirectional relationship exists, and we will describe the potential underlying mechanisms. We have focused more on recent studies and randomised controlled trials where available and attempted to provide the information within clinical
\end{abstract} context and relevance.

\section{Invited Author's profile}

Abd A Tahrani is a National Institute for Health Research (NIHR) Clinician Scientist at the University of Birmingham (UoB), an Honorary Consultant Endocrinologist at the UniversityHospitals of Birmingham NHS Foundation Trust, the lead for weight management research and diabetic neuropathy services at Birmingham Heartlands Hospital, the lead for translational research in the Centre of Endocrinology, Diabetes and Metabolism (CEDAM), Birmingham Health Partners and the communication co-lead in the Institute of Metabolism and Systems Research (IMSR) at the UoB. He obtained his PhD in 2013 from UoB, which was focused on the impact of obstructive sleep apnoea (OSA) in patients with type 2 diabetes and was awarded a SCOPE National Fellowship in 2014 from the World Obesity Federation. Abd's research has the following themes: the metabolic consequences of sleep-related disorders, obesity management and complications, diabetes-related neuropathy and the pharmacology of type 2 diabetes and obesity.

(c) 2019 European Society of Endocrinology Printed in Great Britain
Published by Bioscientifica Ltd. 


\section{Introduction}

Obstructive sleep apnoea (OSA) is a common disorder that affects $13-33 \%$ of men and $6-19 \%$ of women (1). OSA is characteried by instability in the upper airways (UAs) leading to recurrent episodes of the UA obstruction, particularly during the transition to sleep and rapid eye movement (REM) sleep (characterised by low-amplitude, mixed-frequency theta EEG waves, pronounced eye activity and low muscle tone (2)) (Supplementary data, see section on supplementary data given at the end of this article) $(3,4,5,6)$. These repeated obstructions are associated with recurrent episodes of oxygen desaturation/ re-saturation, cyclical changes in blood pressure (BP), heart rate, sympathetic activity and intrathoracic pressure, brief microarousals and changes to sleep architecture, such as the loss of REM and slow wave sleep (SWS or deep sleep is stage N3 of NREM sleep characterised by high-amplitude slow waves, further decrease in muscle tone, possible eye movement cessation and is a restorative sleep stage decreasing though with age (2)) (Fig. 1 and Supplementary data) $(3,5,7)$.

The interactions between OSA and the endocrine system have attracted much attention and they often can be bidirectional, which is not surprising considering the diurnal secretion pattern of many hormones. In addition, OSA treatment (namely continuous positive airway pressure CPAP) has an impact on the endocrine system (such as insulin resistance, cortisol secretion) while treating endocrine disorders (such as obesity, hypothyroidism or acromegaly) can also improve OSA. Moreover, the well-established higher OSA risk in men
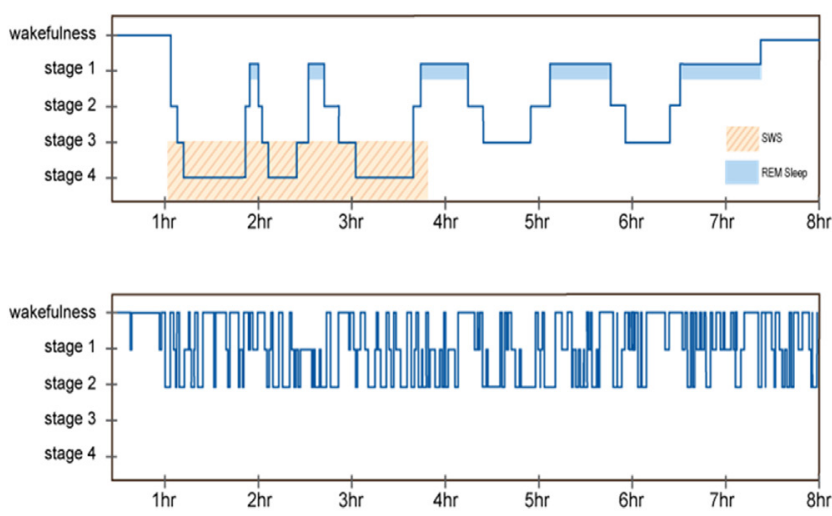

\section{Figure 1}

Hypnograms and sleep stages of a healthy individual (top) and a patient with OSA (bottom). Please note how the patient with OSA has disrupted sleep architecture with loss of REM and SWS. REM, rapid eye movement; SWS, slow wave sleep. vs women also emphasises the potential relationship between sex hormones and OSA pathogenesis. Hence, it is important to understand the links between OSA and the endocrine/metabolic system in order to improve our understanding of the pathogenesis and the comorbidities and mortality associated with OSA and a variety of endocrine disorders (8)

In this article, we will review the interactions between OSA and the endocrine system, and we will highlight the underlying mechanisms underpinning this bidirectional relationship when exists, as well as explore the potential impact of OSA treatment on the endocrine disorders and vice versa. Some aspects of this article require some understanding of the pathogenesis of OSA; hence, we have provided an overview of OSA and its pathogenesis in the Supplementary data.

\section{OSA and obesity interplay}

Obesity is a major risk factor for the development of OSA $(9,10,11)$, which is driving the increase in OSA prevalence $(1,12)$. Obesity prevalence in patients with OSA (approx. 70\%) is also higher than that of the general population (13).

\section{The impact of weight change on OSA}

Weight changes have significant impact on OSA and its severity. In a longitudinal study of randomly selected patients from Wisconsin, a 10\% weight gain over 4 years was associated with $32 \%$ (95\% CI 20-45\%) increase in the apnoea-hypopnoea index (AHI: the average number of apnoea and hypopnea events per hour of sleep) and six-fold higher risk of developing moderate-to-severe OSA (95\% CI 2.2-17) compared to weight stability (11). On the other hand, $10 \%$ weight loss was associated with $26 \%$ (95\% CI 18-34\%) decrease in the AHI compared to weight stability (11), partly due to a reduction in UAs collapsibility observed with weight loss (14). The favourable impact of weight loss on OSA and its severity seems to be evident regardless of the method of losing weight such as lifestyle interventions, pharmacotherapy or bariatric surgery as has been shown by several studies among them and randomised controlled trials (RCTs) (14, $15,16,17,18)$.

In a RCT, of 60 patients with obesity and moderateto-severe OSA, laparoscopic adjustable gastric banding (LAGB) resulted in greater weight loss (5.1 vs $27.8 \mathrm{~kg})$ and greater reductions in AHI (based on PSG) (-14.0 vs -25.5 
events/h; between-group difference was -11.5 events $/ \mathrm{h}$ $95 \%$ CI -28.3 to $5.3 ; P=0.18$ ) over 2 years compared to lifestyle intervention (dietary, physical activity and behavioural conventional programme) (15). In a recent post hoc analysis of this RCT, patients who achieved a normal supine AHI (i.e. AHI $<5 / \mathrm{h}$ ) lost significantly more weight than those who had persistently elevated AHI (weight change $-23.0(-21.0$ to -31.6$) \%$ vs -6.9 (-1.9 to -17.4$) \%, P=0.001)$ (19). Other studies also showed significant improvements in the AHI and a high proportion of OSA resolution following sleeve gastrectomy and gastric bypass $(16,17)$. A meta-analysis confirmed the positive impact of bariatric surgery on OSA severity, by showing a significant reduction of $\mathrm{AHI}$ post surgery (by 38.2 events/h, 95\% CI: 31.9-44.4) (20). A more recent systematic review and meta-analysis by Wong et al. showed that bariatric surgery was associated with a reduction in the AHI (WMD -25.1 events/h (95\% CI $-29.9,-20.2)$ ); with the pooled mean pre- and post-surgery AHI of $39.3 \pm 15.1$ and $12.5 \pm 5.6$ events $/ \mathrm{h}$ respectively; however, OSA persisted in most patients and there was high between-studies heterogeneity mostly due to baseline AHIO and duration of follow-up (21). Hence, RCTs remain needed to address the impact of bariatric surgery on OSA, although these might be challenging to conduct. In another RCT, liraglutide $3 \mathrm{mg}$ daily combined with lifestyle intervention resulted in greater reductions in weight $(-5.7 \%$ vs $-1.6 \%, P<0.0001)$ and AHI $(-12.2$ vs -6.1 events $/ \mathrm{h}$, estimated treatment difference: -6.1 events/h; 95\% CI -11.0 to $-1.2, P=0.015)$ compared to lifestyle intervention only over 32 weeks (18). The degree of weight loss correlated significantly with improvements in OSA in this trial (18).

Obesity can affect multiple aspects of OSA pathogenesis, as summarised in Fig. 2 (22, 23, 24, 25, 26, $27,28,29,30,31,32,33,34,35,36)$.

\section{The impact of OSA on weight}

The impact of OSA on obesity is controversial. One possibility is that OSA could lead to worsening obesity via multiple mechanisms such as increased excessive daytime

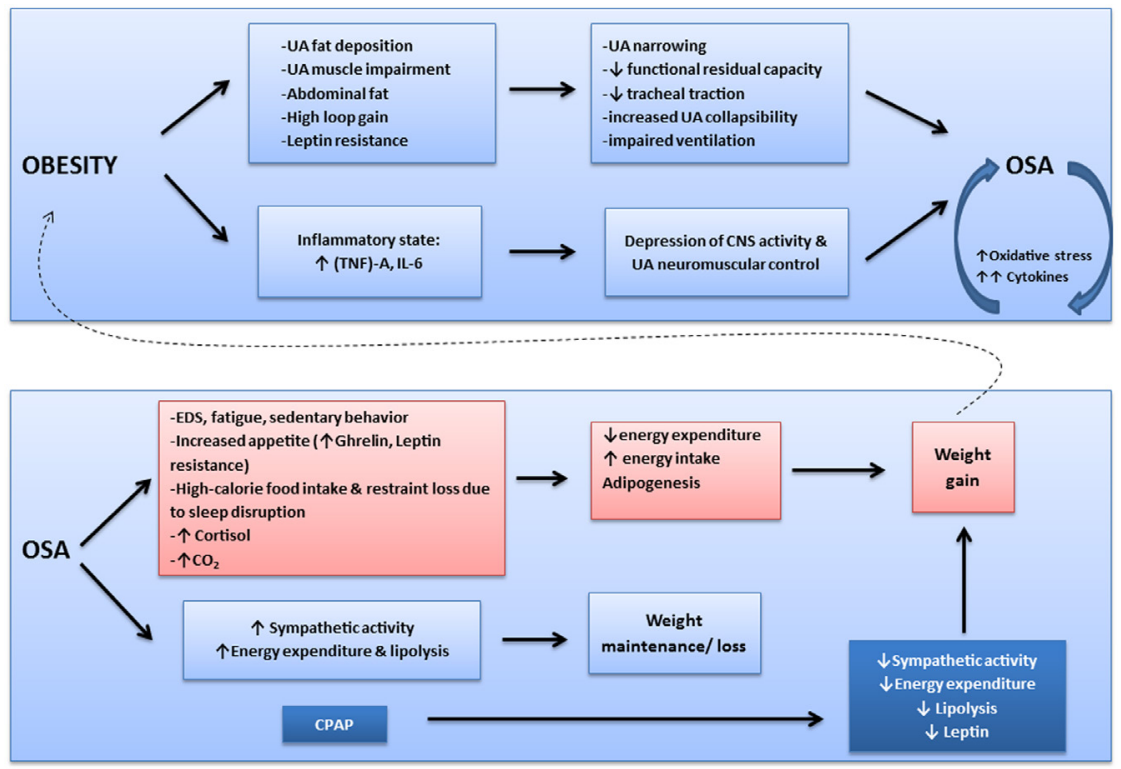

\section{Figure 2}

OSA and obesity interplay. (A) The potential mechanisms linking obesity to obstructive sleep apnoea. (B) The potential impact of obstructive sleep apnoea and its treatment on weight and the underlying mechanisms. Pink boxes are the mechanisms of OSA that might lead to weight gain and the blue boxes are the mechanisms of possible weight loss in OSA. UA, upper airways; TNFA, tumour necrosis factor-alpha; IL6, interleukin-6; CNS, central nervous system; EDS, excessive daytime sleepiness; CPAP, continuous positive airway pressure. Obesity can lead to increased UA collapsibility via increased parapharyngeal fat deposition, UA narrowing, intramuscular fatty deposits leading to reduced UA muscles activity and increased UA muscle fatigability and reduced lung volume resulting in reduced tracheal caudal traction $(19,20,21,22,23,24,25,26,27)$. In addition, the low lung volume in obesity can lead to hypoxaemia and ventilatory instability in the presence of increased whole body oxygen demand due to obesity (high loop gain) (28). 
sleepiness (EDS) leading to a reduction in physical activity, sleep disruption leading to changes in hunger and satiety hormones $(37,38,39)$ (leptin resistance, increased ghrelin, increased orexin and neuropeptide $Y$ levels), changes to sleep duration and architecture (40, 41, 42, 43, 44). Sleep restriction was associated with increased activation of the brain regions related to emotional response to stimuli and motivation and reward system based on functional MRI, which was similar to what observed following energy deprivation resulting in corrective behaviour of seeking food $(45,46)$. This is supported by cross-sectional studies showing that the AHI was significantly associated with increased preference of calorie-dense foods independent of the severity of obesity in adolescents and children (47, 48) and that visceral obesity was increased in patients with OSA and short sleep duration ( $<5 \mathrm{~h} /$ night) (OR, 4.40, 95\% CI 1.80-10.77), compared to those who slept $\geq 7 \mathrm{~h} /$ night (49). In addition, disruption of sleep architecture (suppression of SWS as happens in OSA) without affecting sleep duration in young healthy men, increased hunger for high-calorie food in the afternoon and evening (50). OSA could also contribute to increased fat mass by activation of the HPA axis and increased cortisol secretion and by hypercapnia-induced adipogenesis $(51,52)$. However, despite the above-mentioned plausible mechanisms, epidemiological evidence for an impact of OSA on weight longitudinally is lacking. One small $(n=53)$ prospective study of patients with newly diagnosed OSA showed $7.4 \pm 1.5 \mathrm{~kg}$ weight gain over 12 months, but these patients had also a history of weight gain in the year preceding OSA diagnosis (53), hence quantifying the impact of OSA is difficult without an appropriate control group (Fig. 2B).

Nonetheless, if OSA is a cause of obesity, then it would be expected that OSA treatment will lead to weight loss. However, a systematic review of 3181 patients from 25 RCTs showed that CPAP resulted in a modest but statistically significant increase in BMI and weight compared to control (BMI change: $-0.018 \pm 0.243 \mathrm{~kg} /$ $\mathrm{m}^{2}$ for controls vs $0.134 \pm 0.273 \mathrm{~kg} / \mathrm{m}^{2}$ for CPAP; weight change: $-0.096 \pm 0.718 \mathrm{~kg}$ for controls vs $0.417 \pm 0.718 \mathrm{~kg}$ for CPAP) (54). The mechanisms behind the weight gain after CPAP are not fully elucidated. However, CPAP reduces leptin (satiety hormone), intermittent hypoxia and sympathetic activity leading to reductions in lipolysis and energy expenditure and hence can cause weight gain $(55,56,57,58,59,60,61)$.

Furthermore, it is plausible that OSA can lead to weight loss via increased sympathetic activity leading to increased energy expenditure and lipolysis via lipoprotein lipase inhibition and sympathetic activation $(62,63)$. The net effects of the above-mentioned opposing mechanisms/ impacts of weight gain and weight loss is potentially weight maintenance in patients with OSA. CPAP treatment tilts the balance between these opposing mechanisms towards weight gain by inhibiting sympathetic activity (Fig. 2), but this might be opposed to a certain degree by the impact of CPAP on increasing growth hormone (GH) levels leading to lipolysis (64). The above, however, is only a hypothesis that requires further investigations.

\section{OSA and dysglycaemia}

As obesity is a major risk factor for OSA, much of the research in this field has focused on pre-diabetes/T2D. However, it is now increasingly recognised that OSA is common in patients with T1D as well. In this section, we will focus mostly on pre-diabetes/T2D but we will also summarise the evidence regarding T1D.

\section{Epidemiology}

In general population studies, OSA has been shown to be associated with various comorbidities, including T2D (9), which is not surprising since obesity is a common risk factor for OSA and T2D $(7,65)$. Several crosssectional studies showed a high prevalence of OSA (mild: $5 \leq \mathrm{AHI}<15$; moderate: $15 \leq \mathrm{AHI}<30$; severe: $\mathrm{AHI} \geq 30$ ) in patients with T2D (8.5-86\%, 23.8-70\% moderate-tosevere OSA), and a high prevalence of T2D in patients with OSA $(15-30 \%)(7,66)$. This variation in prevalence estimates is due to different diagnostic methods and criteria used to define OSA and differences in study populations $(67,68,69,70,71)$.

Longitudinal studies have also shown that OSA is an independent risk factor for the development of T2D. A recent meta-analysis of eight studies (63,647 participants) showed that OSA was an independent risk factor for T2D after adjustment for age, sex and BMI (adjusted RR: 1.49, 95\% CI: 1.27-1.75), which remained significant even in studies that defined OSA as AHI $\geq 5$ (adjusted RR: 1.42; $95 \%$ CI 1.02-1.99) (72). A small RCT of 12 weeks in 80 patients with obesity (BMI $>45 \mathrm{~kg} / \mathrm{m}^{2}$ and mostly with metabolic syndrome) suggested that CPAP resulted in improvements in impaired glucose tolerance status compared to no CPAP and that CPAP lowered the 2-h glucose levels following OGTT (73). However, there remains a need for large RCTs of long duration to assess the impact of CPAP, on its own or in combination with lifestyle intervention, on T2D prevention. 


\section{OSA and insulin resistance and $\beta$-cell function}

The impact of OSA on incident T2D is likely to be mediated by the effects of OSA on insulin resistance (IR) and $\beta$-cell dysfunction (7). Studies that examined the relationship between OSA and IR had conflicting results, due to variations in the definitions of OSA and IR, but most of the studies showed an association (65). The association between OSA and IR was present in lean men, suggesting that the relationship is not dependant on obesity $(74,75)$. Variation in EDS might contribute to the variation in the associations between IR and OSA observed in the different studies as Barcelo et al. showed that the association between OSA and IR was only evident in patients with EDS vs without EDS despite being matched for BMI (76). In support of the relationship between OSA and IR, a recent meta-analysis of six RCTs of adults without diabetes showed a favourable effect of CPAP on IR vs no CPAP (mean difference in HOMA-IR: -0.43 ; $95 \%$ CI: -0.75 to $-0.11, P=0.008)(77)$.

The impact of OSA on $\beta$-cell function is much less examined in the literature. In one study of patients without diabetes, patients with moderate-to-severe OSA had a lower $\beta$-cell function (measured using the disposition index during frequent sampling intravenous glucose tolerance test (IVGTT)) compared to healthy controls; and higher AHI was associated with lower $\beta$-cell function despite adjustment for obesity (78). Similar results were found in a more recent study (79) and in another study in patients with T2D (80). Similar to IR, CPAP improved $\beta$-cell function in compliant patients with moderate-tosevere OSA without diabetes (uncontrolled trial) (81) or with pre-diabetes (RCT) (82).

\section{Mechanisms: OSA leading to dysglycaemia and T2D}

There are several putative mechanisms linking intermittent hypoxia (IH) and sleep fragmentation to IR, $\beta$-cell dysfunction and dysglycaemia (33) summarised in Fig. 3.

In rodent models, IH has been shown to increase $\beta$-cell death (83) and impair $\beta$-cell function (84). Results from experimental studies in healthy adults showed that $5 \mathrm{~h}$ of IH ( 24.3 events/h, average oxygen saturation $90.6 \%$, range 75.4-98\%) resulted in blunted, rather than increased, insulin secretion despite reductions in insulin sensitivity (based on IVGTT) (85). Chronic IH can lead to $\beta$-cell dysfunction and IR via increased oxidative stress (86), which pancreatic $\beta$-cells are less able to handle compared to other tissues $(87,88,89)$, and increased inflammation (increased $\mathrm{CD}^{+}$cytotoxic T-cells recruitment, shift to M1-proinflammatory macrophages in crown-like structures, IL and TNFA) $(90,91)$. In addition, chronic IH can increase free fatty acid (FFA) release leading to ectopic fat deposition in the liver and muscle rusting in IR (90). The impacts of chronic IH and oxidative stress on IR could also be mediated by hypoxia-inducible factor (HIF) tissue effects (92). In rodents, 35 days of chronic IH decreased insulin receptor expression and phosphorylation in skeletal muscle and adipose tissue, but not in the liver which was accompanied by upregulation of HIF1a in the liver and downregulation of HIF1a and HIF2a in skeletal muscle (93).

Changes in sleep architecture can also contribute to the effects of OSA on glucose metabolism (94). In an experimental study of young healthy adults, all-night suppression of SWS (without awakening the subjects, changing sleep duration or REM sleep) was achieved via acoustic stimuli of varying intensity and frequency for three nights (94). This resulted in a reduction in insulin sensitivity (by $25 \%$, which is similar to a weight gain of $8-13 \mathrm{~kg}$ ) without a compensatory increase in insulin release (based on IVGTT) (94). These changes in insulin sensitivity and $\beta$-cell function were associated with increased sympathetic activity and in some cases changes in cortisol levels $(94,95)$. In addition, several other neurohormonal mechanisms are involved in the links between OSA and T2D, which are summarised in Fig. 3 $(30,39,51,65,96,97,98,99,100,101,102,103,104$, $105,106,107,108,109,110,111,112,113)$.

\section{The impact of dysglycaemia on OSA}

While the impact of OSA on glucose metabolism has been widely studied, the impact of $\mathrm{T} 2 \mathrm{D}$ and dysglycaemia on OSA has not received much attention. Many cross-sectional studies showed a high prevalence of OSA in patients with T2D as we detailed above, but whether this prevalence is higher than an age- and obesity-matched population without T2D remains unclear. Recently, a populationbased study of 151,194 participants with T2D showed a hazard risk of incident OSA 1.53 (95\% CI: 1.32-1.77) and further patients treated with insulin had higher risk of OSA, especially if they were women $(1.43 ; 95 \%$ CI: 1.11 1.83) (114). In addition, the incidence and natural history of OSA in patients with T2D are currently unknown. One longitudinal study assessed the relationship between IR and possible OSA prospectively and showed that HOMA-IR was an independent predictor for incident witnessed sleep 


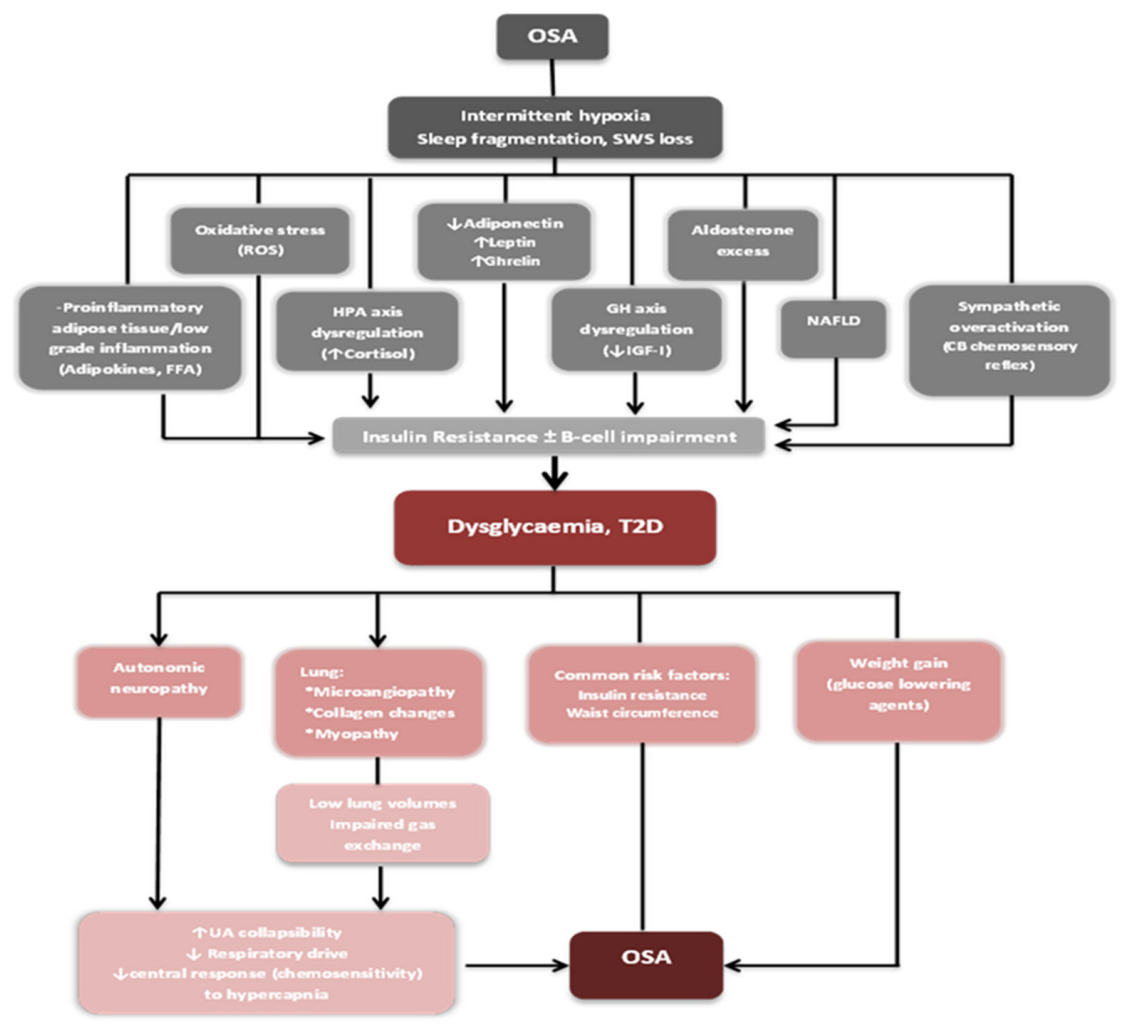

\section{Figure 3}

The potential bidirectional relationship and the underlying mechanisms between obstructive sleep apnoea and type 2 diabetes. SWS, slow wave sleep; CB, carotid body; FFA, free fatty acid; ROS, reactive oxygen species; NAFLD, nonalcoholic liver disease; HPA, hypothalamic-pituitary-adrenal axis; T2D, type 2 diabetes. IH and sleep disruption result in increased oxidative stress and inflammation leading to IR an $\beta$-cell dysfunction. In addition, OSA can lead to dysglycaemia via activation of the hypothalamuspituitary-adrenal (HPA) axis, changes in the growth hormone (GH)/IGF axis, hyperaldosteronism (via hypokalaemia, increased oxidative stress and inflammation), increased ghrelin, increased leptin and reduced adiponectin (40, 48, 90, 91, 92, 93, 94, 95). Interestingly, CPAP treatment can interrupt most of the above-mentioned pathways which might explain the favourable effects of CPAP on IR (96). However, the impact of CPAP on leptin and adiponectin has not been consistent between the different studies $(97,98,99,100,101)$. Furthermore, patients with OSA (due to recurrent microarousals, the loss of SWS and the IH (59)) have increased sympathetic activity which can contribute to the increased IR $(30,102)$. The IH, via oxidative stress and its impact on HIF signalling, results in carotid body chemosensory reflex and hence to increased sympathetic activity (103), that is reversible by CPAP $(104,105)$. Another mechanism that links OSA to dysglycaemia is the increased risk of nonalcoholic fatty liver disease (NAFLD) and progression to steatosis in those patients, due to ectopic fat accumulation and hepatic inflammation, with subsequent effects on insulin sensitivity $(106,107)$. A recent meta-analysis of nine cohort studies showed that OSA was a predictor of the development and progression of NAFLD (107). On the other hand, dysglycaemia could lead to OSA. One plausible mechanism in patients with pre-diabetes or diabetes is autonomic neuropathy, which might impact on UA innervation (6), ventilatory drive and central respiratory responses to hypercapnia $(109,110)$. In addition, T2D is associated with reduced pulmonary volumes and functions compared to healthy individuals which could affect UA stability $(111,112,113,114,115,116$, $117,118,119,120,121)$ and diffusion capacity for carbon monoxide $(112,113,122,123)$. The impact of T2D on the lungs seems to be related to the severity of hyperglycaemia independently of obesity and smoking (123), which raises the possibility that improvements in glycaemic control might have a favourable impact on OSA. Furthermore, treatment intensification in patients with T2D is often associated with weight gain (124), which could lead to the development or worsening of OSA (10, 125). Other independent predictors of incident witnessed apnoeas such as HOMA-IR, hypertriglyceridaemia and smoking are also common in patients with T2D and thus can have a negative impact on OSA $(6,108)$. 
apnoea (not formally diagnosed OSA) over 6 years (OR: 1.31; 95\% CI 1.13-1.51) (115).

Several possible mechanisms make it plausible that dysglycaemia/diabetes can lead to the development or worsening of OSA as summarised in Fig. $3(7,11,115,116$, $117,118,119,120,121,122,123,124,125,126,127,128$, $129,130,131,132)$.

\section{OSA in patients with T2D}

OSA and glycaemic control in T2D

Several cross-sectional studies in patients with T2D showed that patients with OSA had worse fasting plasma glucose, glycaemic variability and HbA1c compared to patients without OSA despite adjustment for confounders (difference in HbA1c between patients with and without OSA $0.7-3.7 \%)(7,133,134,135)$. In addition, OSA severity is correlated with worse glycaemic measures (7). Interestingly, one study showed that the relationship between AHI and HbA1c was only evident for the AHI during REM sleep and not during NREM sleep (after adjustment for confounders) (136). This raised the possibility that OSA treatment might improve glycaemic parameters in patients with T2D.

Several uncontrolled trials showed that CPAP improved glycaemic variability, postprandial glucose levels and HbA1c over the short term $(65,137)$. However, three RCTs showed conflicting results. Two of these RCTs showed that CPAP had no impact on HbA1c $(138,139)$, while another RCT showed that CPAP for 6 months lowered HbA1c by $-0.4 \%$ (95\% CI: $-0.7 \%$ to $-0.04 \%$; $P=0.029)$ while there was no change in HbA1c in the control group (140). These conflicting results could be due to differences in studies population ( $\beta$-cell reserve), baseline glycaemic control (for example one of the negative RCTs had a baseline HbA1c of $7.3 \%$, while the RCT that showed positive effects of CPAP had baseline HbA1c of 7.6\%) (139) or study duration (3 vs 6 months) (138). There were no significant changes in weight or anthropometrics measures in these RCTs between the CPAP and the control arm to explain the conflicting results. However, an important difference between these RCTs was compliance with CPAP; the positive RCT showed CPAP usage of $5.2 \mathrm{~h}$ per night compared to below $4 \mathrm{~h} / \mathrm{night}$ in the trial by West et al. $(138,140)$. Longer CPAP duration per night might have an important impact on glycaemic control as REM tends to occur later during sleep and the AHI during REM correlated with HbA1c better than the AHI during NREM $(82,136)$. Hence, there is still a need for well-designed
RCTs of longer CPAP duration to answer the question whether CPAP can (or cannot) improve glycaemic control in patients with T2D.

\section{OSA and vascular complications in patients with T2D}

Several plausible mechanisms have led to the hypothesis that OSA could lead to the development or progression of macro- and microvascular complications in patients with T2D as shown in Fig. 4 (141, 142, 143, 144, 145, 146).

The relationship between OSA and CVD in patients with T2D has not been studied widely. A retrospective observational study showed that in patients with T2D and newly diagnosed OSA, CPAP for 9-12 months lowered systolic (mean change: $-6.81,95 \%$ CI: -9.94 to -3.67 ) and diastolic $(-3.69,-5.53$ to -1.85$)$ BP (147). Similar reductions in BP levels were observed after 3 months of CPAP in an RCT in which patients with T2D and OSA were randomised to early ( $<1$ week) or late (1-2 months) CPAP (148). The sleep AHEAD study showed an association between AHI and a history of stroke (adjusted OR: 2.57; 95\% CI: 1.03-6.42) but not with coronary artery disease (149). In a longitudinal study in 132 patients with T2D and a normal baseline exercise echocardiography test, OSA predicted incident coronary artery disease (adjusted HR: 2.2; 95\% CI: $1.2-3.9 ; P=0.01$ ) and heart failure (3.5; $1.4-9.0 ; P<0.01)$ over a median follow-up of 4.9 years (150). In another recent study of 1311 patients who had percutaneous coronary intervention (PCI), OSA was associated with increased risk of major adverse cardiac and cerebrovascular events (MACCEs) over 3 years in patients with diabetes mellitus (adjusted HR: 2.03, 95\% CI: 1.10 3.74, $P=0.023$ ) after adjustment for age, sex, ethnicity, BMI and hypertension (151). There is no interventional RCT published regarding the impact of CPAP on CVD in patients with T2D.

OSA has been shown to be associated with diabetesrelated microvascular complications including peripheral neuropathy, chronic kidney disease (CKD), retinopathy and autonomic neuropathy (71). Most of these studies were cross-sectional and no interventional studies have been published although several are ongoing.

A recent systematic review of 15 cross-sectional studies concluded that there was no convincing evidence that OSA was associated with diabetic retinopathy (DR), but that there was some evidence to suggest that OSA was associated with greater DR severity (152). The systematic review also suggested that OSA was associated with maculopathy (152). It is plausible that the impact of OSA on DR is more related to disease progression rather 
A

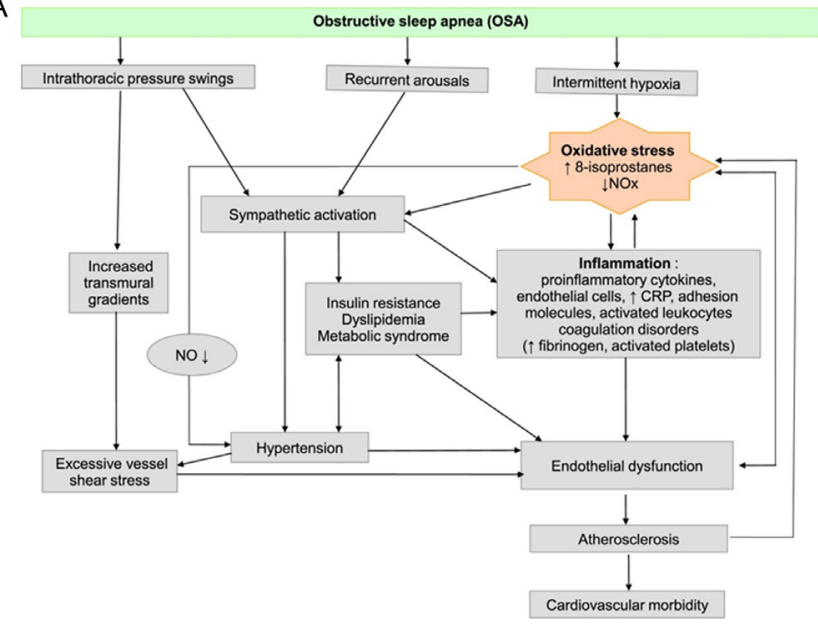

B

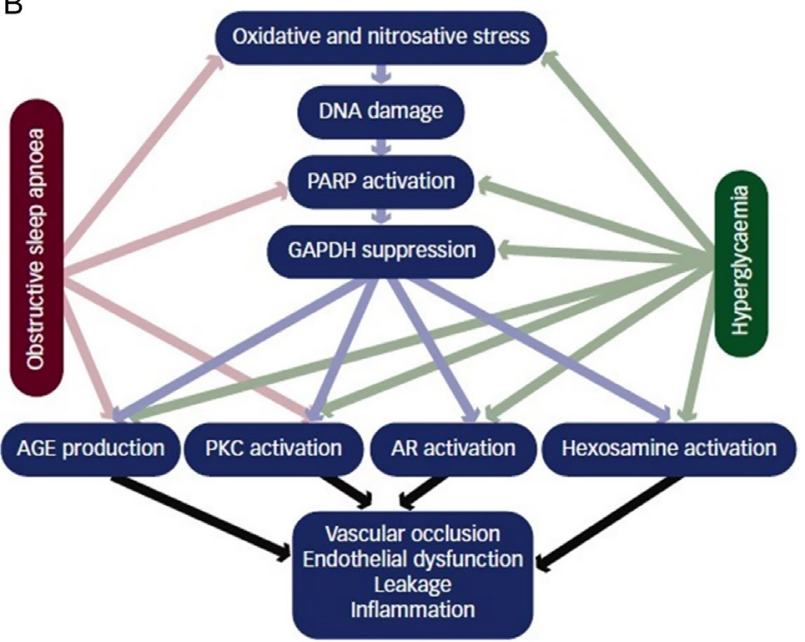

\section{Figure 4}

(A) Mechanisms relating OSA to cardiovascular disease (A) - Adapted with permission from Jullian-Desayes et al. (145) and microvascular complications (B) - Adapted with permission from Tahrani et al. (131) in patients with type 2 diabetes. CRP, C-reactive protein; IH, intermittent hypoxia; NO, nitric oxide; NOx, total nitrate and nitrite; OSA, obstructive sleep apnoea; PKC, protein kinase C; AGE, advanced glycation end product; PARP, poly ADP ribose polymerase; AR, aldose reductase; GAPDH, glyceraldehyde 3-phosphate dehydrogenase. (A) Obstructive sleep apnoea and its cardiometabolic consequences. IH, oxidative stress and inflammation play a key role in OSA and the development of associated cardiometabolic morbidities. Oxidative stress induces inflammation, while increased proinflammatory cytokines, adhesion molecules and procoagulant activities can exacerbate oxidative stress. This vicious circle leads to cardiovascular morbidity. Sympathetic overactivity and the decrease in NO induced by oxidative stress lead to hypertension. Both hypertension and inflammation promote endothelial dysfunction responsible for atherosclerosis, which in turn can also exacerbate oxidative stress (140). In addition, intrathoracic pressure swings and the increase in transmural pressure gradients over vessel walls could also contribute to the endothelial dysfunction observed in OSA. Recurrent arousals also activate the sympathetic nervous system and thus lead to endothelial dysfunction (140). (B) Both OSA and hyperglycaemia share similar molecular consequences including oxidative stress, PKC activation and AGE production. Our own work has shown that patients with OSA and type 2 diabetes have increased oxidative and nitrosative stress increased PARP activation and impaired microvascular function compared with patients with type 2 diabetes only (141).

than the development of disease (which is a function of hyperglycaemia) (7). The increased retinal oxygen demands overnight will make the retina particularly vulnerable to the effects of the IH that occur in patients with T2D and OSA. This is supported by a recent longitudinal study in patients with T2D in which OSA was not associated with the development of DR but was associated with progression to pre-proliferative and proliferative DR (153). In this longitudinal study, OSA was associated with sight threatening DR (STDR) (adjusted OR: 2.3 ; 95\% CI: $1.1-4.9 ; P=0.035)$ and maculopathy (adjusted OR: 2.7, 95\% CI: 1.2-5.9, $P=0.01$ ) at baseline (153). After a median follow-up of 43.0 (IQR: 37.0-51.0) months, patients with OSA were more likely than patients without OSA to develop pre-proliferative/proliferative DR $(18.4 \%$ vs $6.1 \% ; P=0.02)$, which remained significant after adjustment for potential confounders (adjusted
OR: 5.2; 95\% CI: 1.2-23.0; $P=0.03$ ) (153). Interestingly in this study, patients with moderate-to-severe OSA who were compliant with CPAP were significantly less likely to develop pre-proliferative/proliferative DR compared to non-compliant patients (153). This finding was supported by another proof-of-concept study that showed that CPAP treatment $\geq 2.5 \mathrm{~h} /$ night CPAP over 6 months in individuals with OSA and significant macular oedema was associated with improvement in visual acuity but without improvement in the oedema (154). Currently, RCTs assessing the impact of CPAP on DR are ongoing.

In a systematic review of two longitudinal and ten cross-sectional studies, there was an association between OSA and CKD in patients with T2D (pooled OR: 1.73, 95\% CI: 1.13-2.64) (155). In a longitudinal study in patients with T2D, CKD prevalence was higher in patients with OSA vs without OSA (49.3 vs $23.8 \%, P<0.001)$, which 
remained significant after adjustment for confounders (adjusted OR: 2.64, 95\% CI: 1.13-6.16, $P=0.02$ ). OSA was also associated with lower eGFR and more micro- and macro-albuminuria (156). After an average follow-up of 2.5 (0.7) years, eGFR decline was greater in patients with vs without OSA (median: $-6.8 \%$; IQR: -16.1 to 2.2 vs $-1.6 \% ;-7.7$ to $5.3 \%), P=0.002$ ) (156). After adjustment, having OSA $(B=-3.8, P=0.044)$ and higher AHI $(B=-4.6$, $P=0.02$ ) were predictors of lower study-end eGFR (156).

The relationship between OSA and peripheral neuropathy in patients with T2D was examined in a crosssectional study, which showed that OSA is associated with peripheral neuropathy based on the Michigan Neuropathy Screening Instrument (MNSI) vs patients without OSA (60 vs $27 \%, P<0.001$ ), which remained significant after adjustment (OR: 2.82; 95\% CI: 1.44-5.52; $P=0.003$ ) (143). In addition, OSA was associated with lower intraepidermal nerve fibre density (based on skin biopsies), and a history of foot ulceration in patients with T2D (141). These studies suggest that OSA was associated with both large and small fibre neuropathy in patients with T2D. Cohort studies and RCTs assessing the relationship between OSA and CPAP on diabetes-related neuropathy and its complications are ongoing.

\section{OSA and T1D}

As patients with T1D tend to be lean or leaner than patients with T2D, examining OSA in T1D received much less attention than in T2D (157). However, there is increasing interest in OSA in patients with T1D, particularly that some recent studies suggest that OSA in T1D might be more related to autonomic neuropathy rather than obesity (158). In addition, epidemiological studies suggest that obesity prevalence is increasing in patients with T1D which might further increase their risk of developing OSA (159).

In a systematic review of four studies ( $n=186$ patients), the prevalence of OSA (defined as AHI $\geq 5$ ) was $51.9 \%$ among adult patients with T1D, but the $95 \%$ CI was wide (31.2-72.6) reflecting the small sample size the variation between studies (160). The prevalence of moderate-tosevere OSA (AHI $\geq 15$ ) in the same meta-analysis was 16.7\% (95\% CI: 1.1, 34.5) (160).

Autonomic neuropathy was suggested as one potential mechanism for the high prevalence of OSA in T1D as shown in a cross-sectional study of 199 patients with T1D in which OSA was present in $32 \%$ of the patients with normal BMI (161). And another study showed a higher prevalence of OSA in patients with T1D and cardiac autonomic neuropathy compared to patients with T1D but without neuropathy (67 vs $23 \%$ ) (162). Other factors might contribute to the high prevalence of OSA in children and adolescents with T1D including lower mean lung volumes (FVC, PEF, MMEF) $(163,164)$ and impaired gas exchange with lower diffusing capacity for carbon monoxide (165). There are similar findings of impaired pulmonary function in adult patients with T1D (166, $167,168)$. The natural history, impact and pathogenesis of OSA in patients with T1D remain poorly explored and large well-designed studies are needed.

\section{OSA and the renin-angiotensin-aldosterone system (RAAS)}

The links between OSA and RAAS activation are potentially bidirectional (Fig. 5). Hyperaldosteronism might also play an important role in the well-established links between OSA and hypertension (particularly resistant hypertension-RH) (Fig. 5) (9, 169, 170, 171, 172, 173).

The pathophysiology of hyperaldosteronism in patients with OSA is mainly attributed to the activation of the RAAS due to cyclical/IH (172). In addition, some studies suggested a higher prevalence of primary aldosteronism (PA) in patients with OSA compared to patients without OSA (173).

A recent meta-analysis has examined the relationship between OSA and RAAS activation (174). The metaanalysis included 14 studies, all but one were case-control studies and they included a relatively small sample size (mostly $<100$, range: 12-120) (174). The studies generally included middle age men and eight of them included patients with hypertension (174). The meta-analysis found no significant relationship between OSA and plasma renin activity (PRA) (mean difference: $0.17 \mathrm{ng} / \mathrm{mL}$ per hour $(95 \%$ CI: -0.22 to $0.55, P=0.40)$ ) or plasma renin concentration (PRC) (mean difference $0.95 \mathrm{ng} / \mathrm{mL}$ (95\% CI: -0.58 to 2.48, $P=0.23$ ) (174). However, angiotensin II levels were significantly higher in patients with OSA compared to those without OSA (mean difference of $3.39 \mathrm{ng} / \mathrm{L} ; 95 \%$ CI: 2.00-4.79, $P<0.00001)$ (174). There was a trend towards higher plasma aldosterone concentration (PAC) in patients with OSA vs no OSA (mean difference: $0.95 \mathrm{ng} /$ dL; 95\% CI: -0.16 to $2.07, P=0.09$ ) (174). However, when examined in patients with and without hypertension separately, patients with hypertension and OSA had significantly higher PAC vs patients with hypertension but without OSA (mean difference: $1.32 \mathrm{ng} / \mathrm{dL} ; 95 \% \mathrm{CI}$ : 0.58-2.07, $P=0.0005)(174)$. 


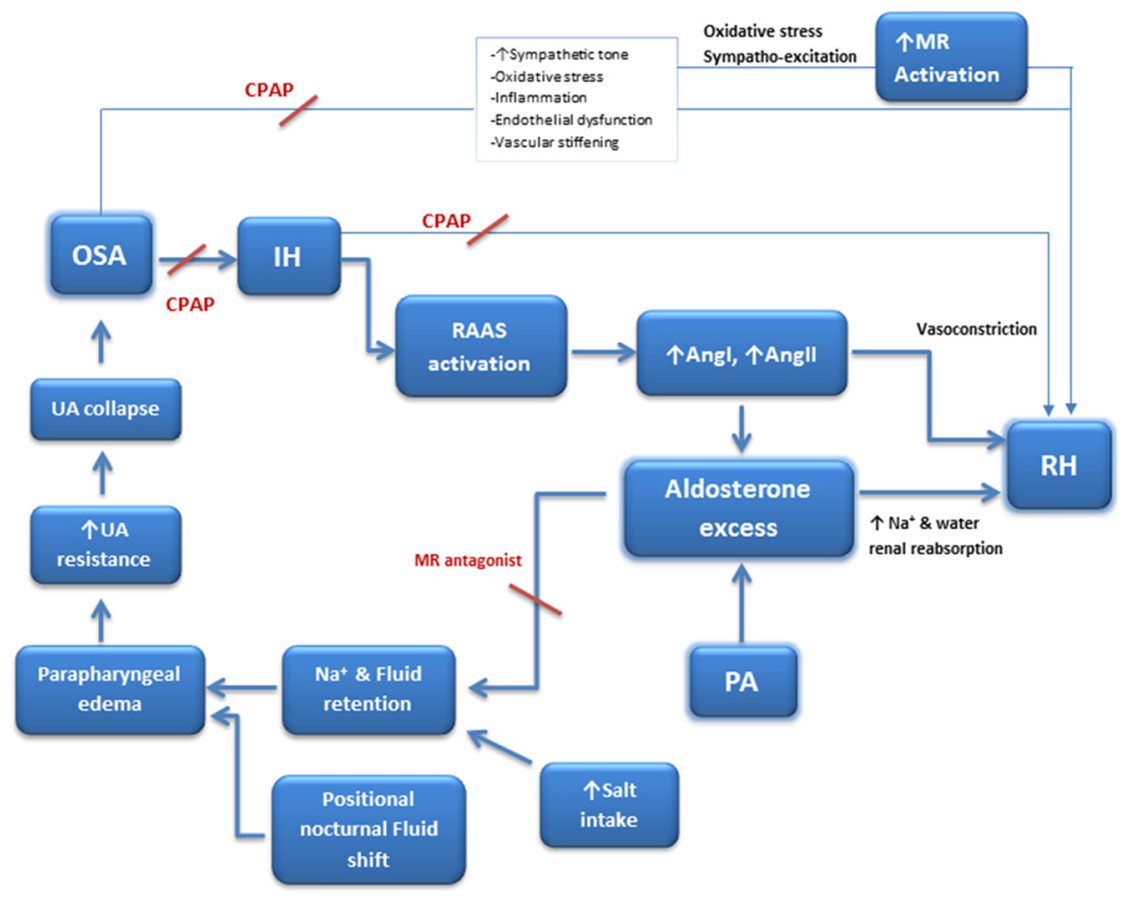

\section{Figure 5}

The potential bidirectional relationship between obstructive sleep apnoea and hyperaldosteronism and the plausible linking mechanisms. IH, intermittent hypoxia; RAAS, renin-angiotensin-aldosterone system; $\mathrm{RH}$, resistant hypertension; PA, primary aldosteronism; MR, mineralocorticoid receptors. In rodent studies, IH promoted angiotensin I and AT1 expression, increased the activation of the carotid body by angiotensin II and resulted in increased renin and aldosterone levels leading to increased BP $(159,169,170)$. In addition, oxidative stress has been shown to increase the activation of the mineralocorticoid receptors (MR) in rodent models (171). Whether OSA is associated with renin activations remains to be explored as the current studies show a non-significant trend. The increased risk of OSA in patients with hyperaldosteronism is plausible due to increased sodium and fluid retention resulting in UA oedema, increased UA resistance and collapse $(159,176,177,178)$. This might have been worsened further by oedema due to fluid displacement during recumbency overnight particularly in patients with RH (159, 178).

The above-mentioned meta-analyses had high heterogeneity, which could be due to variations in the definition of OSA (174). The heterogeneity can also be attributed to the medication used prior to RAAS measurements; however, a meta-regression showed that anti-hypertensives did not affect the relationship between OSA and PAC (174). Supporting the findings of this metaanalysis, another study showing that the AHI correlated significantly with PAC and urinary aldosterone levels ( $r=0.568, P=0.0009 ; r=0.533, P=0.002$, respectively) in patients with RH and hyperaldosteronism (175).

Several uncontrolled studies in patients with hypertension (mostly RH) showed that CPAP lowered angiotensin II and aldosterone levels (176, 177, 178, 179). One RCT in which 117 patients with $\mathrm{RH}$ were randomised to CPAP $(n=57)$ vs no CPAP $(n=60)$ showed that 6 months of CPAP resulted in greater reduction in aldosterone excretion (based on $24 \mathrm{~h}$ urine) compared to the control group in the per-protocol analysis (mean difference: $-3.3 \mu \mathrm{g} / 24 \mathrm{~h}$; $95 \% \mathrm{CI}$ : -6.1 to $-0.4 \mu \mathrm{g} / 24 \mathrm{~h}$; $P=0.027$ ) (180). However, the intention-to-treat analysis showed only a trend $(P=0.07)$. The impact of CPAP on lowering aldosterone was particularly evident in those with uncontrolled hypertension, nondipping in nocturnal BP, not using spironolactone and with patients with worse hypoxia (180). A recent meta-analysis of three observational studies and two RCTs (did not include the above-mentioned RCT) showed that CPAP lowered aldosterone levels compared to no/sham CPAP (mean difference: -0.236 , 95\% CI: -0.45 to $-0.02, P=0.034$ ) (181).

Chronic IH seems to play an important role in the impact of OSA on the RAAS and the mechanistic pathway is shown in Fig. 5 (172, 176, 177, 178, 182, 183, 184, 185).

On the other hand, RAAS activation and hyperaldosteronism might lead to or worsen OSA 
via multiple mechanisms as detailed in Fig. 5. In a retrospective cohort registry-based study, the risk of developing OSA was higher in patients with hypertension and hyperaldosteronism compared to those without hyperaldosteronism after adjustment for age, sex, BMI, diabetes mellitus and heart failure (adjusted OR: 1.8; 95\% CI: 1.3-2.6) (186). Moreover, in a cross-sectional study of patients with RH, spironolactone treatment was associated with lower AHI (187). In another uncontrolled study in patients with $\mathrm{RH}$, spironolactone (25-50 mg daily for 8 weeks) improved OSA severity (based on PSG) (AHI: $39.8 \pm 19.5$ vs $22.0 \pm 6.8$ events $/ \mathrm{h} ; P<0.05)(188)$. A recent systematic review and meta-analysis found three studies (one RCT) and concluded that spironolactone reduced the AHI by a mean of -21.12 (95\% CI: -27.47 to -14.77 , $P<0.00001)$ (175). Furthermore, in a small study of 20 patients with PA who had PSGs, having MR antagonists $(n=13)$ or adrenalectomy $(n=7)$ resulted in AHI reduction from 22.5 (14.7) to $12.3(12.1)(P=0.02)(185)$. These studies support the notion that hyperaldosteronism could worsen OSA and suggest that aldosterone antagonists can be useful in patients with hypertension or PA and OSA.

Finally, due to the links between OSA and PA the recent guidelines of the Endocrine Society on the management of PA recommend that patients with hypertension and OSA are screened for PA (173). Furthermore, well-designed RCTs assessing the impact of MR antagonists on OSA are needed, particularly that OSA is associated with increased CVD risk and that CPAP compliance is often not optimal.

Although not directly related to RAS activation, it is important to note that patients with OSA can present with hypertension and the clinical and biochemical features of phaeochromocytoma without the presence of a catecholamine secreting tumour (i.e. pseudophaeochromocytoma) $(110,189,190,191)$. These cases are rare but have been reported in multiple case reports and series, and the clinical and biochemical features usually resolve with CPAP treatment or weight loss (110, $189,190,191)$.

\section{OSA and hypothalamic-pituitary-adrenal (HPA) axis}

Cortisol secretion has a well-described circadian rhythm and is closely related to sleep stages (192, 193). Sleep onset and SWS are associated with a decline in cortisol levels followed by increased cortisol secretion in late sleep (which is consistent with the rise in early morning) (194). On the other hand, cortisol might impact on sleep architecture, for example, HPA axis hyperactivity inhibits SWS and promotes nocturnal awakening (193).

\section{OSA and HPA axis activation}

The impact of OSA on HPA axis is controversial with conflicting results due to the confounding effects of obesity, the sampling frequency (single time point vs 24-h profile), variability in matching between patients with and without OSA, small sample sizes and short CPAP duration with variability in compliance. Some studies showed no relationship between OSA and the HPA axis, while some even suggested that OSA might inhibit the HPA axis (AHI and ODI correlated negatively with morning cortisol levels: $r=-0.444, \quad P=0.002$ and $r=-0.381, \quad P=0.011$ respectively) $(195,196,197,198)$. In a systematic review of studies that compared cortisol levels in patients with OSA to either obese or lean control, there was no evidence of HPA activation in patients with OSA in 6/7 studies (199). However, only two of these studies had plasma cortisol measurements over $24 \mathrm{~h}$, while the rest had single time point measurements (199). The two studies that measured 24-h cortisol profile reported contradicting results as one showed no difference in mean 24-h plasma cortisol between patients with OSA and obese controls (200), while the other showed that OSA was associated with HPA activation compared to obese controls (201).

However, the impact of OSA on HPA axis may not necessarily be consistent over the 24 -h period, as the study by Vgontzas et al. showed that mean plasma cortisol levels between 23:00 $\mathrm{h}$ and 07:00 $\mathrm{h}$ were higher in patients with OSA and obesity vs obese controls, consistent with nocturnal HPA activation when there is IH and disruption of the sleep architecture (201) (Fig. 6). Another important aspect is that the impact of OSA on HPA axis may not be simply related to basal or 24-h cortisol profiles but might be related to the dynamic responses to HPA inhibition or stimulation. Carneiro et al. showed that although basal salivary cortisol was not different between patients with OSA vs obese controls, the salivary cortisol inhibition following overnight dexamethasone suppression test (ONDST) was significantly less pronounced in patients with OSA compared to obese controls (196). Interestingly, this deficit was corrected after 3 months of CPAP (196). Another study also showed that ACTH responses to CRH stimulation were higher in patients with OSA compared to obese and lean controls (202).

In the same above-mentioned systematic review, eight uncontrolled studies assessed the impact of CPAP on cortisol levels (blood or salivary) (199). Five studies 
A
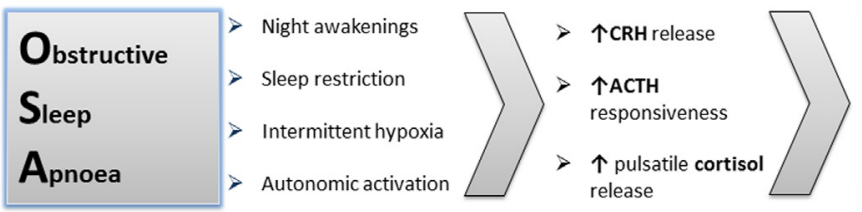

\section{HPA}

Axis (up) dysregulation
$B$

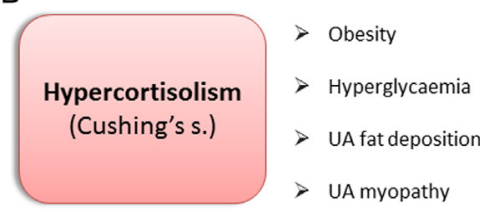

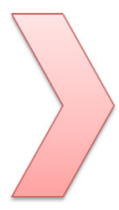

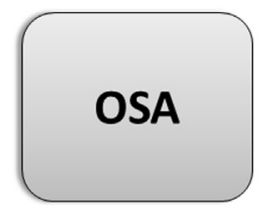

\section{Figure 6}

OSA and HPA axis dysregulation. (A)

Possible underlying mechanisms linking OSA to HPA axis dysregulation. (B) Possible mechanisms linking hypercortisolism with OSA development. $\mathrm{CRH}$, corticotropin-releasing hormone; ACTH, adrenocorticotropic hormone. showed no impact $(76,196,203,204,205)$, while three studies showed that CPAP lowered cortisol levels (blood and salivary) (201, 206, 207). The studies that showed favourable impacts of CPA measured cortisol more frequently during the $24 \mathrm{~h}$ compared to the negative studies (199). However, a recent in-laboratory study showed that $8 \mathrm{~h}$ of CPAP per night did not have any effect on 24-h cortisol profile (208). Nonetheless, this study was over a 1-week period, unlike the studies that showed positive impact of CPAP on cortisol which were over 3-month period. A slightly longer study of 14 days, showed that CPAP can lower morning salivary cortisol in men and women with obesity and OSA (209). The confounding effects of obesity and gender on the relationship between OSA and HPA axis were addressed in a recent study of nonobese men and postmenopausal women which showed that OSA patients had higher 24-h blood cortisol levels compared to controls, which were lowered after 2 months of CPAP (51).

Overall, while the studies showed conflicting results there is evidence that OSA is associated with HPA activation particularly nocturnally and that CPAP (14 days to 3 months) can lower cortisol 24-h profile rather than cortisol levels at single time points. The effects of OSA on the HPA axis can be mediated via mechanisms related to night awakenings (even when brief), sleep restriction and IH (51, 210, 211, 212, 213, 214, 215, 216) as shown in Fig. 6.

\section{OSA in patients with Cushing's syndrome}

Several studies have shown that OSA is common in patients with Cushing's syndrome (CS) (whether endogenous or exogenous) (217). The prevalence of OSA (based on PSG) was higher in women with active CS $(n=35)$ compared to age-, gender- and BMI-matched controls $(n=30)(50 \%$ vs $23 \%, P=0.003$ ) (218). After controlling for BMI and HOMA score, serum cortisol remained independently associated with AHI $\left(R^{2}: 77.8 \%, P<0.001\right)$, suggesting that the relationship between CS and OSA are not only related to obesity (218). A recent Taiwanese population-based cohort study showed that patients with CS $(n=53)$ were at increased risk of developing OSA compared to matched controlled (matched for age, sex and comorbidities including obesity, T2D and hypertension) (4.11 vs 1.70 per thousand person/year; HR 2.82, 95\% CI: 1.67-4.77), with slightly higher risk in men vs women (219). Interestingly in this study, the survival curves for OSA development starting separating clearly from the first year after the diagnosis of CS (219). Similarly, in patients without OSA $(n=17)$ who had PSG before and after 3 months of prednisolone (10 mg daily or more), AHI worsened by $56 \%$ compared to controls (with mild OSA but no steroid treatment) (220). This increase in AHI did not correlate with changes in weight and neck circumference suggesting mechanisms other than adiposity responsible for the worsening in AHI (220).

While obesity might play an important role in the relationship between CS and OSA, it is clear from the above-mentioned studies that obesity is not the only factor. In addition to obesity, hyperglycaemia, IR and ectopic fat (in the peritoneum, mediastinum and parapharyngeal spaces) may also play a role in the increased risk of OSA in patients with CS $(217,221)$. Moreover, hypercortisolism can induce UA myopathy leading to compromised UAs (Fig. 6) $(217,219,222)$.

Future studies need to assess the impact of CS treatment on the incidence and severity of OSA and to examine whether the increased OSA risk in patients with CS is lifelong or simply related to the period where CS is active. In addition, endocrinologists, surgeons and anaesthetists need to be aware of the high risk of OSA in patients with CS when considering surgical treatment (both pituitary and adrenal) in order to ensure the safety of the surgical intervention. 


\section{OSA and GH/IGF axis}

Summary of OSA impact on GH/IGF axis as well as the relation of $\mathrm{GH}$ excess and deficiency to OSA development or worsening can be found in Fig. 7 .

\section{OSA and the dysregulation of GH/IGF axis}

OSA-associated chronic IH and disruption of sleep architecture can lead to dysregulation of the GH/IGF axis as GH secretion is increased after sleep onset and during SWS (both of which are disrupted in patients with OSA) $(223,224)$. Overall, studies in rodents and humans suggest that OSA is associated with suppression of basal and stimulated GH and IGF1 levels, which are improved by CPAP (225).

In rodents, IH was shown to cause a recoverable dosedependent suppression of $\mathrm{GH}$ release and $\mathrm{GH}$ mRNA expression, possibly due to modulation of somatostatin activity (226). In humans, OSA was shown to be associated with a marked reduction in $\mathrm{GH}$ blood levels, which increased following one night of CPAP (64). In addition, fasting IGF1 levels correlated negatively with the ODI in men with OSA, but increased following 3 months of CPAP (195). Sleep disruption also plays a role in the relationship between OSA and the GH/IGF1 axis. In an experimental study of patients with OSA who were examined for one night without CPAP and one night with CPAP, GH plasma levels and secretion rate (bloods were collected every 10 min overnight) were reduced and increased after CPAP treatment; this improvement correlated with the improvement in SWS (227).

In support of the impact of OSA on the GH/IGF axis, a recent RCT in 65 middle-aged men with moderate-tosevere OSA showed that CPAP vs sham CPAP increased IGF1 levels, total and pulsatile GH secretion, mean $\mathrm{GH}$ concentration, mass of $\mathrm{GH}$ secreted per pulse and pulse frequency after 12 weeks of treatment with further increases in IGF1 levels and a decrease in IGFBP1 levels by week 24 (228). Furthermore, other treatments that can

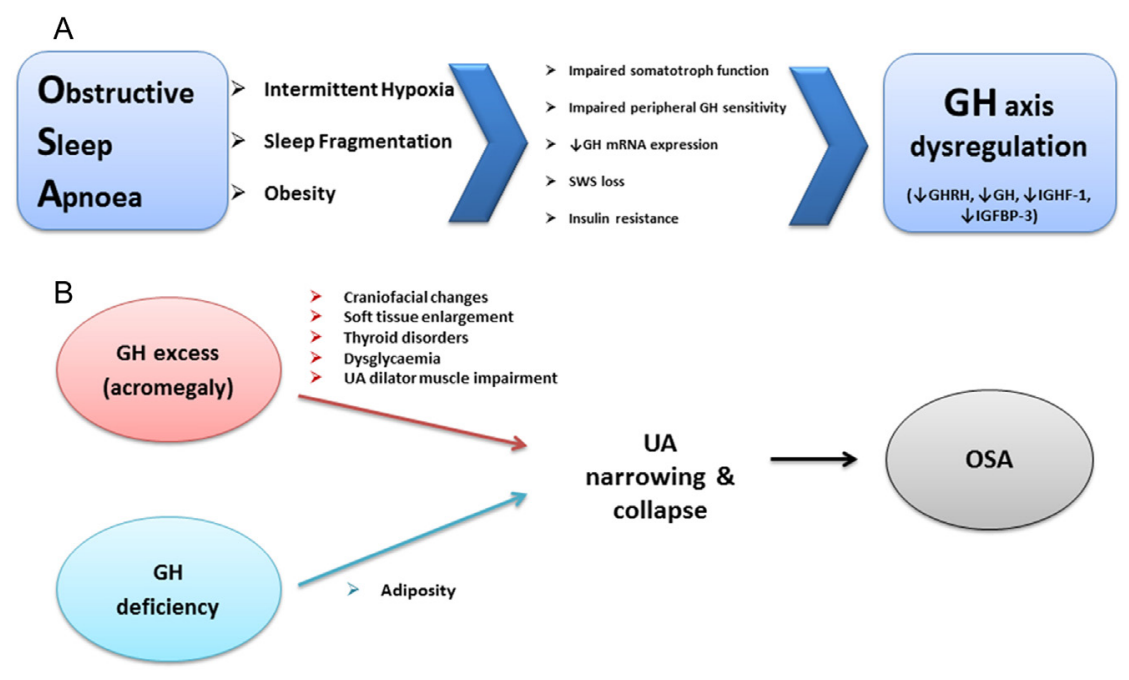

\section{Figure 7}

OSA and GH/IGF axis. (A) Possible underlying mechanisms for OSA leading to GH/IGF axis dysregulation. (B) Possible mechanisms linking GH excess (red arrows) and GH deficiency (blue arrows) with OSA development. The main causal mechanisms linking acromegaly to OSA are related to the anatomical changes that occur as a result of GH excess leading to narrower and more collapsible UAs. Patients with acromegaly have vertical growth of the mandible, which leads to pharyngeal obstruction due to the retroposition of the tongue base with caudal displacement of the hyoid (225). In addition, soft tissue thickening/swelling, secondary to increased glycosaminoglycan deposition, collagen and tissue oedema and macroglossia contribute to the compromise of UAs in patients with acromegaly $(226,227,228,229,230,231,232,233,234)$. This is supported by a study using MRI and nasopharyngoscopy that showed the tongue base and uvula to be the main site of UA obstruction in patients with OSA and acromegaly (216). In addition, the uvula diameter correlated to the severity of the UA collapse and tongue measurements correlated to the AHI and IGF1 levels $(216,230)$. The weakness of UA muscles (sternohyoid muscle) also contributes to the increased risk of UA collapsibility in patients with acromegaly (235). Other factors include hypothyroidism, large goitres (detailed later) $(219,236,237)$, IR and dysglycaemia $(219,224,238)$. 
improve OSA, such as adenotonsilectomy in children, have also been shown to improve IGF1 and IGFBP3 levels (229).

Obesity is a potential confounder for the relationship between OSA and GH/IGF1 dysregulation as obesity (particularly visceral) is linked to a reduction in $\mathrm{GH}$ secretion, IGF1 levels and peripheral GH sensitivity, which can recover with weight loss (230). However, IGF1 levels were lower in patients with OSA compared to the weightmatched control despite that both these groups had lower IGF1 levels compared to the lean control (96).

\section{OSA and acromegaly}

Many cross-sectional studies showed that OSA is highly prevalent in patients with active acromegaly (45-80\%) (231), with an average prevalence of 69\% in PSG-based studies (232). Although lowering GH/IGF1 improves OSA, up to $40 \%$ (range: $21-58 \%$ (231)) of those with controlled acromegaly have persistent OSA that required evaluation and the consideration of CPAP $(233,234)$. 'Although clinicians seem to be aware of the links between acromegaly and OSA (as shown by a survey in Italy), only few patients undergo PSG in clinical practice (235).

In addition, OSA contributed to the adverse outcomes of acromegaly, despite that there were no differences in $\mathrm{GH}$ or IGF1 levels between patients with OSA + acromegaly vs acromegaly alone (236). The presence of impaired glucose tolerance or T2D was higher in patients with acromegaly and OSA vs acromegaly only ( $n$ : $10 / 17$ vs $5 / 19$ ) (236), although this was not adjusted for obesity. In addition, OSA contributed to IR in patients with acromegaly, which improved by CPAP in a RCT (237). Furthermore, OSA might play an important role in other acromegaly-related comorbidities such as hypertension and heart failure/ cardiomyopathy (238).

As a result of the high prevalence of OSA and its impact on acromegaly-related comorbidities, the 2014 Endocrine Society Clinical Practice Guideline for acromegaly recommended evaluating all patients for OSA (234). In addition, the guidelines recommended that patients with severe pharyngeal thickness and OSA should be treated with somatostatin receptor ligands preoperatively to reduce the OSA-related surgical risks (234).

On the other hand, a recent study of 507 patients with OSA showed that ten patients (1.97\%) had elevated IGF1 levels, of which nine patients suppressed GH levels on OGTT giving an acromegaly prevalence of $0.2 \%$ (1/507) (239). These findings suggest that screening for acromegaly in OSA should not be routinely performed. However, if in addition to OSA, there are other features of acromegaly or acromegaly-associated conditions (such as T2D, debilitating arthritis, carpal tunnel syndrome, hyperhidrosis and hypertension), then measurement of IGF1 levels is recommended as per the Endocrine Society Clinical Practice Guideline for acromegaly (239). Finally, although we have focused here on OSA, central sleep apnoea (SA) can also occur in the context of acromegaly (240), but far less common than OSA (236).

The mechanisms leading to the high prevalence of OSA in patients with acromegaly are summarised in Fig. 7 (231, 234, 240, 241, 242, 243, 244, 245, 246, 247, 248, $249,250,251,252,253,254)$.

\section{The impact of acromegaly treatment on OSA}

Considering that OSA is driven by the excess of GH/IGF1 in patients with acromegaly, it is not surprising that treating acromegaly can improve OSA, but it is also common for OSA to persist or even worsen after acromegaly is brought under control (234). In a small study of six patients with SA syndrome (obstructive or central with EDS) and acromegaly, trans-sphenoidal adenomectomy resulted in resolution of the SA syndrome in all patients regardless of whether acromegaly was cured or not (255). In another study of 24 patients with acromegaly (20 with OSA) who had remission following trans-sphenoidal surgery, at 1 month post surgery, the tongue area declined while the airway volume increased significantly, accompanied with improved OSA (256). The prevalence of severe OSA was reduced from 45.8 to $28 \%$ by 6 months with significant improvements in AHI but the average AHI remained in the moderate OSA range (256). Similar results were observed in patients with acromegaly following treatment with somatostatin analogues $(246,249,257,258,259,260)$ and pegvisomant $(261,262)$.

The above-mentioned studies clearly show that curing acromegaly or significant improvements in $\mathrm{GH} /$ IGF1 levels can improve OSA, but many patients with acromegaly have persistent moderate-to-severe OSA that might require CPAP. In fact, OSA might occur in patients with acromegaly following achieving normal IGF1 levels even when OSA was not present at baseline as shown by Chemla et al. (OSA cured in 57\%, new OSA that was not present at baseline 22\%) (263). Similarly, Castellani et al. showed that AHI increased in $55.5 \%$ of patients with acromegaly after complete/partial biochemical control (either after surgery, radiotherapy and/or medical therapy) 
(231). OSA persistence following acromegaly treatment is probably due to multiple factors including increased BMI and/or irreversible craniofacial-skeletal deformities/ fibrosis (231). Hence, OSA evaluation is needed post acromegaly treatment regardless of the normalisation of GH/IGF1 (264).

\section{OSA in adults with GH deficiency (GHD)}

OSA is much less examined in GHD in comparison to acromegaly. OSA is very common in adults with GHD with a prevalence of $63 \%$, which is mainly due to the increased obesity either due to GHD or hypothalamic obesity as a result of surgical or radiotherapy treatment delivered to the underlying pituitary or hypothalamic pathology (265).

\section{GH replacement and OSA}

GH replacement in patients with GHD might improve OSA due to a reduction in adiposity (strong lipolytic properties of GH $(266,267)$ ) or it could worsen OSA if the replacement was excessive. The studies in the literature show a mixed picture. In a small study of five men who received GH replacement (median dose: $2 \mathrm{U} /$ day; median serum IGFI: $351 \mu \mathrm{g} / \mathrm{L}$ ) for 1-2 years post pituitary surgery GHD showed that 6 months after stopping GH treatment the median obstructive AHI decreased significantly from 4.4 to $0.1(P=0.03)$, whereas the central AHI increased from 6.3 to $14.6(P=0.03)$, suggesting that $\mathrm{GH}$ replacement worsened the OSA but improved central SA (268). However, another study of 19 patients with GHD showed that GH replacement for 6 months had no impact on AHI (pre vs post treatment: 28.2 /h vs $28 / \mathrm{h}$ ), regardless of baseline OSA status (265). Still, in a large observational longitudinal study of GH-treated $(n=1988)$ and- untreated $(n=442)$ patients with GHD showed that after a mean follow-up of 2.3 years the SA incidence was greater in the group that received GH replacement (3.3 vs 0.9\%, $P<0.05$ ), despite that the GH-treated vs -untreated groups had similar BMI at baseline and the GH-treated group were younger (269). However, the GH-treated group had higher baseline IGF1 levels $(108 \pm 61$ vs $90 \pm 51 \mu \mathrm{g} / \mathrm{L}, P<0.001)$ and serum IGFBP3 levels $(2.4 \pm 0.9$ vs $2.1 \pm 1.0 \mu \mathrm{g} / \mathrm{L}, P<0.001)$ (269). In a 12-month double-blind RCT of 40 men with obesity and dysglycaemia who were randomised to either GH or placebo, GH treatment increased IGF1 from $168 \pm 72$ to $292 \pm 117 \mu \mathrm{g} / \mathrm{L}$, the AHI from $31 \pm 20$ to $43 \pm 25$ and the
ODI from $18 \pm 14$ to $29 \pm 21$ (all $P$ values $\leq 0.001$ ) (270). Interestingly, $\mathrm{GH}$ treatment in this study increased neck transverse diameter, circumference and total crosssectional area, while reduced abdominal visceral adipose tissue (based on CT) (270).

Hence, more data are required to assess the impact of GH replacement on pre-existing OSA and the development of new OSA. However, GH replacement might result in the development or worsening of pre-existing OSA via increasing IGF1 levels or via affecting adipose tissue distribution (increasing neck circumference).

\section{OSA in Prader-Willi syndrome}

Children and patients with Prader-Willi syndrome (PWS) are also at high risk of having OSA (prevalence: 1:10,000-25,000 live children), and as a result, screening for OSA in this population has been recommended (271). The high prevalence of OSA in patients with PWS is likely to be multifactorial due to GH deficiency, increased viscosity of UAs secretions, craniofacial abnormalities with small airways, UAs muscles hypotonia and secondary alveolar hypoventilation (obesity and scoliosis causing lung volume restriction) all leading to airway collapsibility (271).

The impact of GH replacement on OSA in children with PWS is debatable. Salvatoni et al. showed that shortterm treatment with rhGH (6 weeks) did not worsen the AHI, and there was no difference in AHI between the treatment and control group at baseline or study end (272). Nonetheless, in this study, the AHI increased (i.e. OSA worsened) in 50\% of the cases following $\mathrm{GH}$ replacement (272). Similar results were shown in another study suggesting that the AHI worsens in a subgroup of patients following $\mathrm{GH}$ replacement over the short run (273), which in part could be due to the development of adenotonsillar hyperthophy following $\mathrm{GH}$ treatment (273). However, longer term follow-up (2 years) showed that $\mathrm{GH}$ replacement did not worsen AHI during the follow-up except in those who worsened shortly after $\mathrm{GH}$ initiation $(274,275)$. As a result, the 2013 consensus guidelines considered untreated severe OSA as an exclusion criteria for rhGH initiation, till the patient is treated with CPAP $(276,277)$. This is particularly important considering that sudden death early in the course of GH replacement in patients with PWS, associated with sleep-disordered breathing/OSA, have been reported in the literature (278, $279,280)$ 


\section{OSA and hypothalamic-pituitary-thyroid (HPT) axis}

\section{OSA in patients with hypothyroidism}

A recent systematic review of one observational and five interventional studies (501 patients in their 4th-5th decade of life) found that $25-50 \%$ of patients with overt hypothyroidism $(\mathrm{OH})$ had nocturnal breathing abnormalities (snoring, choking, apnoea periods), which improved with levothyroxine 4 (LT4) treatment (281). In one study, $30 \%$ of patients with recently diagnosed $\mathrm{OH}$ had evidence of OSA (AHI $\geq 5$ based on PSG) and LT4 improved the AHI (from a median of 14.3 (7.4-33.6) to $2.1(0.8-4.6))$ (282). In addition, in the later study LT4 treatment improved hypoxaemia and sleep architecture $\left(\mathrm{TpO}_{2}\right.$ sat $<90 \%: 14 \%(2.2-19.9)$ vs $0.2 \%(0-1.7), P<0.05$; SWS\%: 18.4 (7.2-25.2) vs 28.2 (15-33.4), $P<0.05)(282)$. This suggests that hypothyroidism can lead to/worsen OSA, which improves with LT4 treatment. However, larger studies including RCTs are needed before confirming this relationship.

There is lack of good-quality data regarding the relationship between OSA and subclinical hypothyroidism (SH); one small observational study $(n=108)$ showed that $53 \%$ of patients with untreated SH had OSA (based on PSG) (283). However, these results are likely to represent selection bias as the prevalence of OSA in healthy controls with normal thyroid functions was higher $(75 \%)$ than that in patients with untreated $\mathrm{SH}$ despite that $\mathrm{SH}$ patients were heavier and the patients are recruited from the respiratory department (283). Hence, currently we cannot be certain about the relationship between OSA and SH.

\section{Hypothyroidism in patients with OSA}

While studies are not consistent, overall, there is no evidence that hypothyroidism is more common in patients with OSA compared to patients without OSA $(284,285)$. A recent study also supported this conclusion as it showed that the prevalence of raised TSH in 813 patients with severe OSA was $4.7 \%$ which is similar to the general population (286). Some studies showed that the prevalence of SH was higher in OSA vs control, but these studies have potential selection bias as the population was recruited from sleep clinics and the control group was younger and leaner $(287,288,289)$. Other studies did not show a high prevalence of $\mathrm{SH}$ in patients with OSA (290). In a study of 245 euthyroid patients with suspected OSA, the prevalence of Hashimoto's thyroiditis was $32.2 \%$ in patients without OSA vs $46.8 \%$ in patients with OSA (based on PSG) $(P=0.03)(291)$. The prevalence of Hashimoto's increased with worsening severity of OSA (291).

\section{Mechanisms linking OSA and thyroid disorders}

Hypothyroidism can lead to the development or worsening of OSA via multiple mechanisms summarised in Fig. 8 (232, 281, 282, 284, 291, 292, 293, 294, 295, 296, $297,298,299,300)$.

\section{OSA and non-thyroidal illness syndrome (NTIS)}

A recent cross-sectional study showed that patients with moderate-to-severe OSA $(n=125)$ had a higher prevalence of NTIS (defined as normal TSH and low FT3) compared to controls ( $n=60)$ (10.4 vs 0\%), but the control group was lean, and there were more men in the OSA group (301). Within the OSA group, patients with NTIS had worse nocturnal hypoxemia compared to patients without NTIS (301). This suggests that IH could play a role in the high prevalence of NTIS in patients with OSA, possibly via downregulation of deiodinase 1 and enhancing deiodinase 3-inactivating T3 and T4 (302). In addition, oxidative stress and low-grade inflammation, resulting from OSA, can also contribute to the association between OSA and NTIS (303, 304). CPAP for 5 months has been shown to improve FT3 levels in patients with NTIS supporting the notion that OSA might lead to NTIS, but this study was not controlled (301). However, it is important the clinicians take into account the possibility of NTIS when interpreting thyroid function results in patients with OSA.

In summary, SA and thyroid specialists need to have a low threshold to test for thyroid disorders if indicated clinically. In addition, OSA can be associated with NTIS and clinicians interpreting the thyroid function results need to take the presence of OSA into consideration. However, cohort studies with well-matched control groups and RCTs are needed to enable us to understand the complex relationship between OSA and HPT axis and the impact of treating one or the other.

\section{OSA and the hypothalamic-pituitary- gonadal (HPG) axis}

The interaction between sex hormones and OSA was initially brought to attention by the consistently reporting a higher prevalence of OSA in men vs women. 


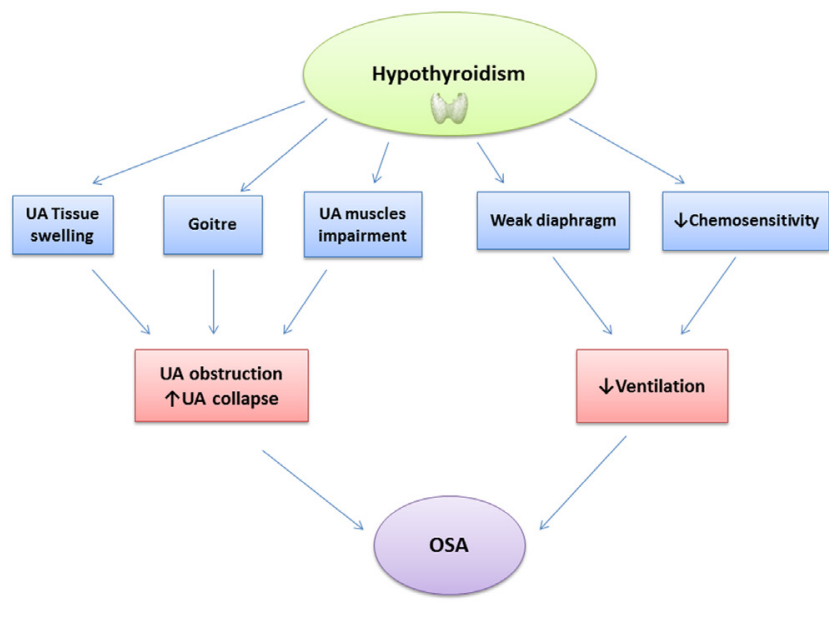

\section{Figure 8}

Mechanisms linking OSA and hypothyroidism. Hypothyroidism can lead to increased UA collapsibility due to soft tissue swelling (in tongue, neck, and pharynx) caused by mucopolysaccharides infiltration (myxoedema in the more severe form) (256). In support of this mechanism, LT4 treatment reduced soft tissue swelling and improved $\mathrm{AHI}$, nocturnal hypoxaemia and sleep architecture in an uncontrolled study (254). Goitre (regardless of thyroid status) can cause UA obstruction and collapse (256, 263). It causes narrowing of the UA by direct mechanical obstruction, especially in supine position, and by increasing laryngeal oedema due to reduced venous return; both of which can be resolved following thyroidectomy or LT4 in some cases (256, 264, 265, 266). Hypothyroidism (especially when severe) can also result in blunted ventilatory drive and impaired chemosensors' response to hypoxia/hypercapnia in animal and human studies (256). This is possibly due to decreased dopamine receptor (D1) expression in the brain stem and the CB in rodents with hypothyroidism (267), and can be reversed with LT4 treatment (256). Impaired UA dilator muscle function in hypothyroidism, due to altered myosin heavy chain expression in rodent studies and neuropathy in humans, has also been reported $(217,268)$. Furthermore, the diaphragm has been shown to be weaker in rodents and human studies in hypothyroidism, which result in a reduction in lung volumes contributing to OSA development/worsening $(253,256,269)$. The diaphragm weakness can be improved by LT4 treatment (253). Finally, obesity could be potentially another link between $\mathrm{OH}$ and OSA as studies have shown that patients with $\mathrm{OH}$ are about 5-7 kg heavier compared to euthyroid matched controlled (270). However, this weight-increase in $\mathrm{OH}$ seems to be related to expanded water compartment rather than fat mass. In addition, LT4 treatment causes weight loss by reducing lean mass rather than fat mass (based on DXA) (271, 272).
This relationship was further emphasised by several observations including that testosterone replacement in men worsens/increases the risk of having OSA, the prevalence of OSA in postmenopausal women was higher than that in premenopausal women; hormone replacement therapy reduced the risk of OSA in postmenopausal women and oral contraceptives were associated with lowered OSA risk in women with polycystic ovarian syndrome (PCOS) $(65,305)$.

\section{In men}

OSA is associated with hypogonadotropic hypogonadism due to altered gonadotropin synthesis and release (306). In a cross-sectional analysis of a prospective study of healthy older men ( $n=1312$, $\geq 65$ years old), lower testosteronelevels (based on quartiles) were associated with significantly less SWS, higher AHI (based on PSG) and more sleep time spent with $\mathrm{O}_{2}$ sat $<90 \%$ after adjustment for age and race (307). However, adjustment for BMI made these associations non-significant (307). Other studies showed that patients with OSA had lower area under the curve and mean levels for $\mathrm{LH}(24.9 \pm 10.2 \mathrm{IU} / \mathrm{L}$ vs $43.4 \pm 9.5 \mathrm{IU} / \mathrm{L}, P<0.005)$ and testosterone $(67.2 \pm 11.5 \mathrm{nmol} / \mathrm{L}$ vs $113.3 \pm 26.8 \mathrm{nmol} / \mathrm{L}$, $P=0.003)$ compared to healthy controls, but the control group was leaner numerically (308). Similar findings were found in other studies $(309,310,311)$.

\section{Testosterone replacement and OSA}

Patients receiving testosterone replacement are at increased risk of developing OSA. In a cohort study, 3422 of US military service members, aged 40-64 years, who were free of OSA at baseline and received testosterone replacement, were matched based on age and comorbidities to men who did not receive testosterone treatment (312). The absolute 2 -year risk of incident OSA was greater in patients who received testosterone replacement vs those who did not (16.5\% (95\% CI: $15.1-18.1)$ vs $12.7 \%$ (95\% CI: $11.4-14.2)$, $P<0.001)$ (312). Interestingly, the increased risk of OSA was greater for those who used injectable vs topical testosterone (312). This is also supported by a small RCT in which healthy ambulatory men aged $>60$ years were randomised to receive three injections of weekly intramuscular testosterone esters (500, 250 and $250 \mathrm{mg}$ ) or matching oil-based placebo and then crossed over to the other treatment after 8-week washout. Testosterone replacement in this RCT resulted in worsening RDI (approximately by seven events per hour), mainly 
during non-REM (NREM) sleep and worsened nocturnal hyoxaemia measures, while placebo had minimal effects on RDI and hypoxia parameters (313). Several other studies suggested a link between testosterone replacement and incident or worsening OSA $(314,315,316,317)$. As a result, the Endocrine Society clinical practice guidelines recommended against the use of testosterone replacement in men with untreated severe OSA (318). It is unclear whether different methods of testosterone replacement have a differential impact on the risk of developing or worsening OSA due to the variations in the pharmacokinetics profiles of these agents.

The effects of testosterone can be time limited as shown in a RCT of 67 men who received hypocaloric diet and were randomised to intramuscular injections of $1000 \mathrm{mg}$ testosterone undecanoate or placebo (319), in which testosterone replacement worsened the ODI by 10.3 events/h (95\% CI, $0.8-19.8$ events/h; $P=0.03$ ) and on nocturnal hypoxaemia at 7 weeks but not at 18 weeks (319). This time-dependent effects might be as a result of time-dependent changes in hyperoxic ventilatory recruitment threshold following testosterone replacement (320).

\section{Mechanisms}

Low testosterone in men can lead to loss of muscle mass and increased visceral adiposity, which can contribute to the increased/worsening OSA in men with hypogonadism $(321,322)$. It is unclear how testosterone replacement leads to OSA, but postulated mechanisms include altered ventilator responses such as increased response to hypoxaemia (leading to $\mathrm{CO}_{2}$ levels below apnoea threshold), reduced sensitivity to hypercapnia or anabolic effects (leading to UA narrowing) and an effect on the neuromuscular control of UA $(323,324)$. However, these mechanisms are not well proven with multiple studies showing conflicting results. In one interesting mechanistic study, androgen blockade with flutamide did not influence chemo-responsiveness to hypoxia/ hypercapnia (325).

In addition, OSA can impact the HPG axis via several mechanisms including $\mathrm{IH}$, sleep fragmentation and obesity $(306,310,326)$. Testosterone levels peak during REM (fewer REM sleep episodes and REM sleep latency are related to lower testosterone concentrations (323)); hence, the disruption of sleep architecture in OSA (loss of REM) might explain the link between OSA and low testosterone (193).
The impact of OSA treatment on the HPG axis

CPAP effects on the HPG axis in men remains controversial with a limited number of studies in the literature. A meta-analysis in 2014 found only two RCTs and five observational studies with a total sample size of 232 men showing the paucity of available data (327). In this meta-analysis, an average of 6 months of CPAP treatment had no effects on testosterone levels despite good CPAP compliance (standardised mean difference $(\mathrm{SMD})=-0.14$, 95\% CI: -0.63 to 0.34) (327). CPAP also had no effects on free testosterone or SHBG levels (327).

Summary of the trials assessing the impact of OSA treatment (CPAP and surgical) on HPG axis can be found in Table $1(195,205,328,329,330,331,332,333$, $334,335)$. The two RCTs showed no effect of CPAP on testosterone levels, but the study participants did not have hypogonadism at baseline and the CPAP duration was short. The uncontrolled studies mostly showed no effects of CPAP on testosterone levels except two studies, which showed that CPAP increased testosterone levels (Table 2). In one of these studies, the increase in total testosterone was associated with increased SHBG, which suggests that the impact of free testosterone was rather limited. In the other study, patients had hypogonadism at baseline and CPAP improved testosterone levels along with LH, but the impact on SHBG was not reported (Table 1). Hence, the impact of CPAP on HPG axis in men remains unclear but future trials need to consider the potential difference in response between men with and without hypogonadism and need to ensure adequate CPAP treatment duration and the impact on free testosterone.

It is important to note that CPAP might still have beneficial impacts on scores for sexual and erection function despite the lack of impact of hormonal measurements $(332,333)$. However, in two RCTs sildenafil was superior to CPAP in regards to $\mathrm{ED}(336,337)$.

\section{In women}

OSA impact on the HPG axis in women is less well studied compared to men. Based on animal studies sex hormones can influence breathing not only via androgens but also via the effects of progesterone and oestradiol on $\mathrm{CB}$ and the brainstem (338). In addition, lack of progesterone receptor in rodent led to reduced hypoxic ventilator response (339) and lower UA resistance was found in the luteal phase in healthy premenopausal women with the peak in progesterone secretion (340). On the other hand, 
OSA has a negative effect on female sex hormones and on sexual function and is associated with PCOS.

In a cohort of 53 women (24-72 years old), AHI $>10 / \mathrm{h}$ was associated with lower morning levels of 17-OH-progesterone, progesterone and oestradiol (341). However, hormone replacement therapy (HRT) in postmenopausal women was associated with lower prevalence of moderate-to-severe OSA compared to women not taking HRT and less time spent in oxygen saturations $<90 \%$, particularly in women who received combined oestrogen-progesterone vs oestrogen alone (342). The impact of CPAP on the HPG axis in women remains to be explored in large studies, and since one small uncontrolled study showed no effect (330) RCTs in this area are needed.

Similar to men, OSA has been associated with sexual dysfunction (FSFI score: desire, arousal, lubrication, orgasm, satisfaction and pain) in pre- and postmenopausal women compared to matched controls $(343,344)(345)$. Unlike in men, evidence for CPAP's impact on sexual dysfunction in women is lacking (346). In this review we did not discuss the impact of OSA on pregnancy.

\section{OSA and polycystic ovarian syndrome (PCOS)}

OSA is highly prevalent in women of reproductive age with PCOS. A recent systematic review and meta-analysis from our group (15 studies, $n=568$ ) showed that $36.1 \%$ (95\% CI: 22.4-51.0) of women with PCOS had OSA regardless of the PCOS definition used (347). In addition, OSA prevalence was significantly higher in obese women with PCOS compared to lean (OR: 3.96, 95\% CI: 1.2912.13) and in adult women compared to adolescents, both of which are expected since obesity and age are main risk factors of OSA, and thus, PCOS precedes OSA development (347). However, in this meta-analysis, there was significant heterogeneity among studies, most studies came from the United States in women with obesity (class II), and there is a high level of selection bias since controls came from general population while exposed cohorts were recruited from specialised clinics (347). It is plausible that in some cases the OSA could precede PCOS development as detailed in a recent study showing that $1 / 3$ of adolescent girls with PCOS had previous tonsillar enlargement/tonsillectomy (348).

It is also interesting that although androgens are considered to impact OSA pathogenesis, contributing to the higher OSA prevalence in women with PCOS, three studies showed that women with PCOS and increased androgens did not have higher prevalence of OSA 


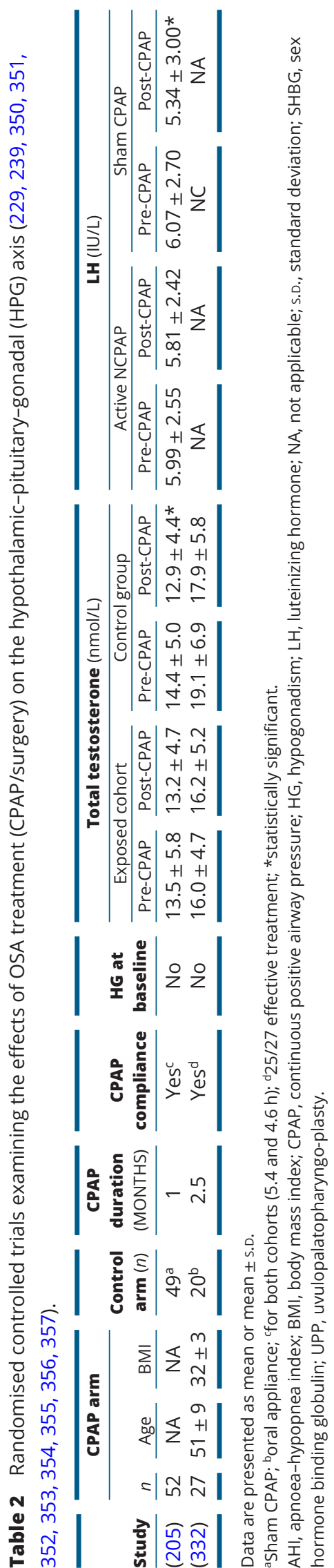

compared to controls, and the relationship between OSA severity and hyper-androgonaemia were not consistent across the studies (347). This could be due to the low circulating androgen levels in women with PCOS compared to men.

In another meta-analysis from our group comparing women with PCOS and OSA vs women with PCOS only showed that the earlier group had higher BMI (mean difference: $6.01 \mathrm{~kg} / \mathrm{m}^{2}, 95 \% \mathrm{CI}: 4.69-7.33$ ), waist circumference (MD: $10.93 \mathrm{~cm}, 95 \%$ CI: 8.03-13.83), IR (HOMA-IR: $\mathrm{MD}=2.23$, 95\% CI: 1.41-3.06; $I^{2}=0 \%$ ), systolic BP (10.8 mmHg 95\% CI: 6.21-15.39), diastolic BP $(4.63 \mathrm{mmHg} 95 \% \mathrm{CI}: 1.06-8.21)$, impaired glucose tolerance ( $2 \mathrm{~h}$ plasma glucose on OGTT: $\mathrm{MD}=2.23,95 \%$ CI: $0.67-2.11, I^{2}=0 \%$ ) and worse lipids profile (higher total cholesterol, LDL and triglycerides and lower HDL) compared to the alter group (349). The androgen levels were not different between the two groups but hirsutism was worse in the OSA group (349). However, these studies included were relatively small, at high risk of selection bias, and did not account for important potential confounders such as obesity (349).

Several mechanisms link PCOS to OSA as summarised in Fig. 9 (350).

\section{OSA and bone metabolism}

Although cross-sectional studies assessing the relationship between OSA and bone mass density (BMD) showed conflicting results $(351,352,353,354)$; longitudinal studies showed an increased risk of osteoporosis in patients with OSA $(355,356)$. In a large retrospective cohort study of 1377 patients with newly diagnosed OSA and 22,655 matched controls (age, sex and index date), the risk of osteoporosis was greater in patients with OSA vs control in both men and women (incidence rate: 2.52/1000 personyears vs 1.00/1000 person-years, adjusted HR: 2.74, 95\% CI: 1.69-4.44) over the 6-year follow-up (355). The HR in this study was adjusted for age, gender, diabetes status, obesity, CVD risk factors, CKD, CVD, gout and social demographics.

Consistent with the increased risk of osteoporosis in patients with OSA, several studies suggested that OSA might increase the risk of fractures, although these studies examined conditions that are related to OSA rather than OSA per se. In a study of 2911 men older than 67 years, men who spent $\geq 10 \%$ of their sleep time with $\mathrm{O}_{2}$ saturations $<90 \%$ had increased risk of incident nonspinal fractures compared to men spent $<1 \%$ of sleep time 


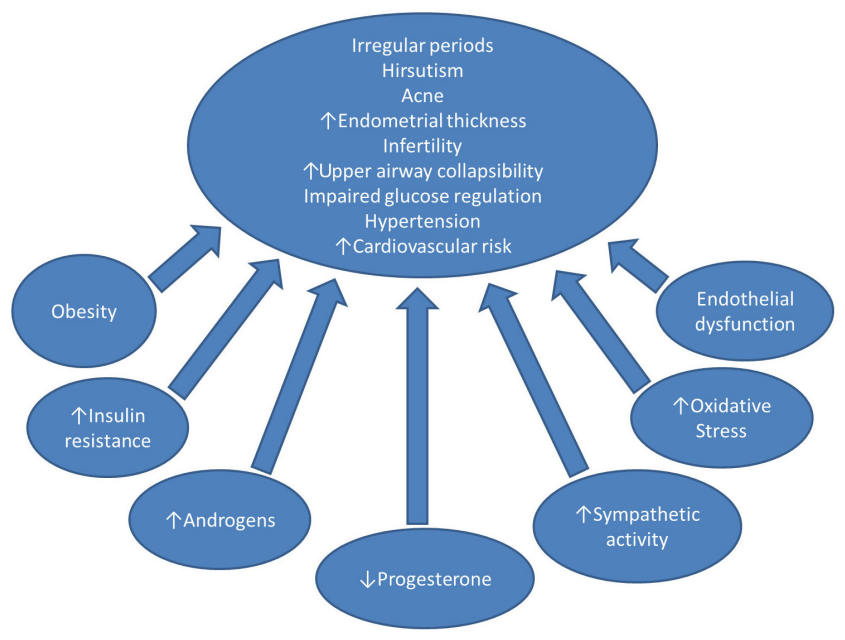

\section{Figure 9}

Obstructive sleep apnoea and polycystic ovary syndrome; clinical interactions and underlying pathophysiology. Adapted from Kahal et al. with permission. Sex hormones are thought to play a role in this bidirectional relationship, as in women with PCOS androgens excess along with lower progesterone (as a result of anovulation) can increase UA collapsibility and/ or lead to blunted ventilator chemo-responsiveness (322). While, IH and sleep fragmentation can impact HPG axis and can influence $\mathrm{GnRH}$ and gonadotropins pulsatility, leading to causing/or worsening PCOS phenotype (322). In addition, IR and dysglycamia in women with PCOS can contribute to worsening or the development of OSA (322). Obesity is common in both disorders and can contribute to the associations between OSA and PCOS. Other common comorbidities are oxidative stress, endothelial dysfunction and sympathetic activation all of which can lead to a vicious cycle of OSA and PCOS entities (322).

with $\mathrm{O}_{2}$ saturation $<90 \%$ over 7 years follow-up (adjusted relative hazards: $1.42,95 \% \mathrm{CI}: 0.94-2.15, P=0.047)(357)$. In the same study, the relative risk of having $\geq 1$ fall was also higher in the group with nocturnal hypoxaemia (relative risk: 1.25, 95\% CI: 1.04-1.51) (357). Another longitudinal study that followed up 8101 women aged 69 years or older for 6 years found that self-reported daily napping was associated with increased risk of incident hip fractures compared to women who did not nap daily (age-adjusted HR: 1.29, 95\% CI: 1.02-1.65; fully-adjusted HR: 1.33 , 95\% CI: 0.99-1.78) and similar to the previous study there was an increased risk of falls in women who napped daily (358). In a recent cohort study, women $(n=3220)$ and men $(n=2969)$ aged 40 years and older, severe snoring (a common OSA symptom) was associated

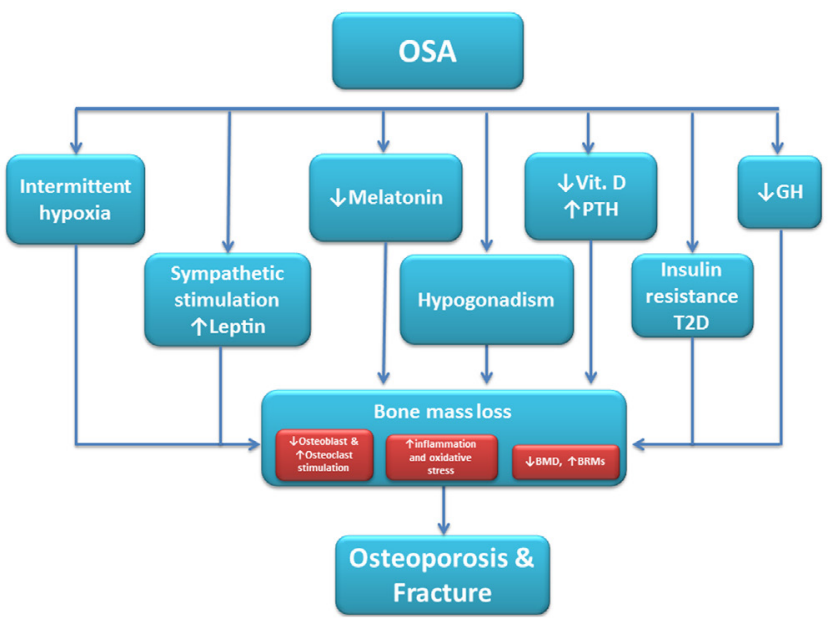

\section{Figure 10}

OSA and bone metabolism. GH, growth hormone; PTH, parathormone; BMD, bone mineral density; BRMs, bone resorption markers. As with other endocrine consequences of OSA, hypoxaemia plays an important role as has been shown by Cauley et al. and IH in human cell cultures and rodents can increase osteoclasts and inhibit osteoblasts' growth and differentiation via HIF transcription factor family (HIF1a and HIF2a) and VEGF $(333,334,335,336,337)$. In addition, IH can result in increased inflammation and oxidative stress that can lead to higher risk of osteoporosis and fractures $(338,339,340)$. Other mechanisms including hyperleptinaemia and sympathetic activation increase bone resorption and inhibit bone formation leading to bone mass loss $(341,342)$. Changes in melatonin profile could also contribute to the impact of OSA on bones, as patients with OSA might have changed melatonin profile and lower melatonin serum levels compared to people without OSA due to frequent nocturnal awakening and light exposure (343). Melatonin has been shown to increase BMD in a RCT (344). Furthermore, serum 25-hydroxyvitamin $D$ was found to be lower $(19.34 \pm 9.54 \mathrm{ng} / \mathrm{mL}$ vs $32.83 \pm 16.93 \mathrm{ng} / \mathrm{mL}, P<0.0001)$ and PTH levels higher $(62.57 \pm 29.97 \mathrm{pg} / \mathrm{mL}$ vs $40.05 \pm 31.12 \mathrm{pg} / \mathrm{mL}$, $P<0.0001$ ) in patients with OSA compared to healthy controls (345). CPAP for seven nights increased 25-hydroxyvitamin D concentrations $(19.21 \pm 9.45$ vs $21.03 \pm 9.50, F=8.32, P<0.01)$ but had no effect on PTH (345). The suppression of the gonadal axis and GH in OSA and the associated IR could also contribute to the impact of OSA on bone metabolism (342). T2D in particular can have detrimental effects on bone mass and fracture risk (374, $375,376,377)$, and as OSA increases the risk of T2D, then T2D is a potential mechanism between OSA and bone disease.

with increased risk of fractures over 10-year follow-up in women (adjusted HR: 1.68, 95\% CI: 1.16-2.43, $P=0.006$ ), with similar non-significant trend in men (359). 
Consistent with the increased risk of osteoporosis and fractures in patients with OSA, bone resorption markers (such as serum C-terminal telopeptide of type I collagen CTX) has been shown to be higher in patients with OSA compared to controls in men and the AHI was independently associated with urinary CTX independently of age, BMI and other variables $(352,360)$. Furthermore, CPAP for 3 months lowered the creatinineadjusted urinary CTX levels significantly (211 \pm 107 vs $128 \pm 59 \mu \mathrm{g} / \mathrm{mmol} /$ creatinine; $P<0.01)(360)$.

Several mechanisms might explain the impact of OSA on bone turnover, bone density and fracture risk summarised in Fig. 10 (361, 362, 363, 364, 365, 366, 367, 368, 369, 370, 371, 372, 373).

\section{Summary and conclusion}

In this review we have demonstrated that there are multiple bidirectional interactions between OSA and the endocrine system although the observed relationships varied depending on the endocrine system examined. The impact of OSA on the endocrine system was mostly mediated by intermittent hypoxaemia, sympathetic activation, the elevated BP and the increased inflammation and oxidative stress. While the impact of the endocrine system on OSA was mostly mediated via increased upper body adiposity, narrowing of the UAs, weakening of upper airway muscles, changes to chemosensitivity and ventilatory drive as well as autonomic dysfunction.

Our review also shows that there are multiple knowledge gaps in the field at a mechanistic level and also due to the lack of well-designed cohort and interventional studies in many areas. This is further complicated by the difficulty in achieving good compliance with CPAP in clinical studies, the diurnal nature of the endocrine system and the interaction between OSA and other sleep disorders such as short sleep duration and misalignment in the circadian rhythm. In particular, our review found the following need to be explored in future studies due to either no, minimal or inconsistent evidence currently available: the impact of OSA and CPAP on weight, the impact of diabetes treatment on OSA as well as the impact of OSA on diabetes-related outcomes, the impact of PA treatment on OSA, the effects of OSA on the HPA axis and the natural history of OSA and its response to treatment in patients with $\mathrm{CS}$, the long-term impact of $\mathrm{GH}$ replacement on OSA as well as central SA, the impact of thyroxine replacement on OSA in patients with hypothyroidism, the relationship between OSA and $\mathrm{SH}$, the impact of long-term testosterone replacement and the different methods of replacement on OSA, the impact of OSA and CPAP in women with PCOS and men with hypogonadism and the impact of CPAP on bone metabolism.

Finally, clinicians treating patients with endocrine conditions should not assume that OSA would recover by curing the underlying endocrine disorder (such as Cushing's, acromegaly or hypothyroidism) and that OSA status need to be clarified by formal testing following the successful treatment of the endocrine condition. Furthermore, clinicians, surgeons and anaesthetists involved in the treatment of the endocrine conditions that are associated with OSA need to be aware of this association and treat the OSA in order to improve the safety of the general anaesthesia and surgical procedures.

\section{Supplementary data}

This is linked to the online version of the paper at https://doi.org/10.1530/ EJE-18-0411.

\section{Declaration of interest}

The authors declare that there is no conflict of interest that could be perceived as prejudicing the impartiality of this review.

\section{Funding}

This research did not receive any specific grant from any funding agency in the public, commercial or not-for-profit sector. But A A Tahrani is a NIHR Clinician Scientist receiving funding from the National Institute for Health Research in the UK (CS-2013-13-029; 2013).

\section{Acknowledgements}

A A Tahrani is a clinician scientist supported by the National Institute for Health Research in the UK. The views expressed in this publication are those of the author(s) and not necessarily those of the National Health Service, the National Institute for Health Research or the Department of Health.

\section{References}

1 Senaratna CV, Perret JL, Lodge CJ, Lowe AJ, Campbell BE, Matheson MC, Hamilton GS \& Dharmage SC. Prevalence of obstructive sleep apnea in the general population: a systematic review. Sleep Medicine Reviews 201734 70-81. (https://doi. org/10.1016/j.smrv.2016.07.002)

2 Chokroverty S, Thomas RJ \& Bhatt M. Atlas of Sleep Medicine E-Book. Elsevier Health Sciences: Philadelphia, PA, USA, 2013.

3 McNicholas WT. Diagnosis of obstructive sleep apnea in adults. Proceedings of the American Thoracic Society 20085 154-160. (https:// doi.org/10.1513/pats.200708-118MG)

4 Epstein LJ, Kristo D, Strollo PJ Jr, Friedman N, Malhotra A, Patil SP, Ramar K, Rogers R, Schwab RJ, Weaver EM et al. Clinical guideline for the evaluation, management and long-term care of obstructive sleep apnea in adults. Journal of Clinical Sleep Medicine 20095 263-276. 
5 Deegan P \& McNicholas W. Pathophysiology of obstructive sleep apnoea. European Respiratory Journal 19958 1161-1178. (https://doi. org/10.1183/09031936.95.08071161)

6 Horner RL. Pathophysiology of obstructive sleep apnea. Journal of Cardiopulmonary Rehabilitation and Prevention 200828 289-298. (https://doi.org/10.1097/01.HCR.0000336138.71569.a2)

7 Tahrani AA. Obstructive sleep apnoea in diabetes: does it matter? Diabetes and Vascular Disease Research 201714 454-462. (https://doi. org/10.1177/1479164117714397)

8 Young T, Palta M, Dempsey J, Peppard PE, Nieto FJ \& Hla KM. Burden of sleep apnea: rationale, design, and major findings of the Wisconsin Sleep Cohort study. WMJ 2009108 246-249.

9 Young T, Peppard PE \& Gottlieb DJ. Epidemiology of obstructive sleep apnea: a population health perspective. American Journal of Respiratory and Critical Care Medicine 2002165 1217-1239. (https:// doi.org/10.1164/rccm.2109080)

10 Young T, Peppard PE \& Taheri S. Excess weight and sleep-disordered breathing. Journal of Applied Physiology (1985) 200599 1592-1599. (https://doi.org/10.1152/japplphysiol.00587.2005)

11 Peppard PE, Young T, Palta M, Dempsey J \& Skatrud J. Longitudinal study of moderate weight change and sleep-disordered breathing. JAMA 2000284 3015-3021. (https://doi.org/10.1001/ jama.284.23.3015)

12 Tufik S, Santos-Silva R, Taddei JA \& Bittencourt LR. Obstructive sleep apnea syndrome in the Sao Paulo Epidemiologic Sleep Study. Sleep Medicine 201011 441-446. (https://doi.org/10.1016/j. sleep.2009.10.005)

13 Vgontzas AN, Tan TL, Bixler EO, Martin LF, Shubert D \& Kales A. Sleep apnea and sleep disruption in obese patients. Archives of Internal Medicine 1994154 1705-1711. (https://doi.org/10.1001/archi nte.1994.00420150073007)

14 Schwartz AR, Gold AR, Schubert N \& Stryzak A. Effect of weight loss on upper airway collapsibility in obstructive sleep apnea. American Review of Respiratory Disease 1991144 494-498. (https://doi. org/10.1164/ajrccm/144.3_Pt_1.494)

15 Dixon JB, Schachter LM, O'Brien PE, Jones K, Grima M, Lambert G, Brown W, Bailey M \& Naughton MT. Surgical vs conventional therapy for weight loss treatment of obstructive sleep apnea: a randomized controlled trial. JAMA 2012308 1142-1149. (https://doi. org/10.1001/2012.jama.11580)

16 Sharples AJ, Charalampakis V, Daskalakis M, Tahrani AA \& Singhal R. Systematic review and meta-analysis of outcomes after revisional bariatric surgery following a failed adjustable gastric band. Obesity Surgery 201727 2522-2536. (https://doi.org/10.1007/s11695-0172677-7)

17 Priyadarshini P, Singh VP, Aggarwal S, Garg H, Sinha S \& Guleria R. Impact of bariatric surgery on obstructive sleep apnoea-hypopnea syndrome in morbidly obese patients. Journal of Minimal Access Surgery 201713 291-295. (https://doi.org/10.4103/jmas.JMAS_5_17)

18 Blackman A, Foster GD, Zammit G, Rosenberg R, Aronne L, Wadden T, Claudius B, Jensen CB \& Mignot E. Effect of liraglutide 3.0 $\mathrm{mg}$ in individuals with obesity and moderate or severe obstructive sleep apnea: the SCALE Sleep Apnea randomized clinical trial. International Journal of Obesity 201640 1310-1319. (https://doi org/10.1038/ijo.2016.52)

19 Joosten SA, Khoo JK, Edwards BA, Landry SA, Naughton MT, Dixon JB \& Hamilton GS. Improvement in obstructive sleep apnea with weight loss is dependent on body position during sleep. Sleep 201740 zsx047. (https://doi.org/10.1093/sleep/zsx047)

20 Greenburg DL, Lettieri CJ \& Eliasson AH. Effects of surgical weight loss on measures of obstructive sleep apnea: a meta-analysis. American Journal of Medicine 2009122 535-542. (https://doi. org/10.1016/j.amjmed.2008.10.037)

21 Wong AM, Barnes HN, Joosten SA, Landry SA, Dabscheck E, Mansfield DR, Dharmage SC, Senaratna CV, Edwards BA \& Hamilton GS. The effect of surgical weight loss on obstructive sleep apnoea: a systematic review and meta-analysis. Sleep Medicine Reviews 201842 85-99. (https://doi.org/10.1016/j.smrv.2018.06.001)

22 Schwab RJ, Gupta KB, Gefter WB, Metzger LJ, Hoffman EA \& Pack AI. Upper airway and soft tissue anatomy in normal subjects and patients with sleep-disordered breathing. Significance of the lateral pharyngeal walls. American Journal of Respiratory and Critical Care Medicine 1995 152 1673-1689. (https://doi.org/10.1164/ajrccm.152.5.7582313)

23 Shelton KE, Woodson H, Gay S \& Suratt PM. Pharyngeal fat in obstructive sleep apnea. American Review of Respiratory Disease 1993 148 462-466. (https://doi.org/10.1164/ajrccm/148.2.462)

24 Horner R, Mohiaddin R, Lowell D, Shea S, Burman E, Longmore D $\&$ Guz A. Sites and sizes of fat deposits around the pharynx in obese patients with obstructive sleep apnoea and weight matched controls. European Respiratory Journal 19892 613-622.

25 Wolk R, Shamsuzzaman AS \& Somers VK. Obesity, sleep apnea, and hypertension. Hypertension 200342 1067-1074. (https://doi. org/10.1161/01.HYP.0000101686.98973.A3)

26 Watson RR. Modulation of Sleep by Obesity, Diabetes, Age, and Diet. Academic Press, Elsevier: USA, 2016.

27 Carrera M, Barbé F, Sauleda J, Tomás M, Gómez C, Santos C \& Agustí AGN. Effects of obesity upon genioglossus structure and function in obstructive sleep apnoea. European Respiratory Journal 200423 425-429. (https://doi.org/10.1183/09031936.04.00099404)

28 Ray CS, Sue DY, Bray G, Hansen JE \& Wasserman K. Effects of obesity on respiratory function. American Review of Respiratory Disease 1983 128 501-506. (https://doi.org/10.1164/arrd.1983.128.3.501)

29 Schwartz AR, Patil SP, Laffan AM, Polotsky V, Schneider H \& Smith PL. Obesity and obstructive sleep apnea: pathogenic mechanisms and therapeutic approaches. Proceedings of the American Thoracic Society 20085 185-192. (https://doi.org/10.1513/ pats.200708-137MG)

30 Heinzer RC, Stanchina ML, Malhotra A, Fogel RB, Patel SR, Jordan AS, Schory K \& White DP. Lung volume and continuous positive airway pressure requirements in obstructive sleep apnea. American Journal of Respiratory and Critical Care Medicine 2005172 114-117. (https://doi. org/10.1164/rccm.200404-552OC)

31 Eckert DJ \& Malhotra A. Pathophysiology of adult obstructive sleep apnea. Proceedings of the American Thoracic Society 20085 144-153. (https://doi.org/10.1513/pats.200707-114MG)

32 Polotsky M, Elsayed-Ahmed AS, Pichard L, Harris CC, Smith PL, Schneider H, Kirkness JP, Polotsky V \& Schwartz AR. Effects of leptin and obesity on the upper airway function. Journal of Applied Physiology 2012112 1637-1643. (https://doi.org/10.1152/ japplphysiol.01222.2011)

33 Dempsey JA, Veasey SC, Morgan BJ \& O'Donnell CP. Pathophysiology of sleep apnea. Physiological Reviews 201090 47-112. (https://doi. org/10.1152/physrev.00043.2008)

34 Phipps P, Starritt E, Caterson I \& Grunstein R. Association of serum leptin with hypoventilation in human obesity. Thorax $2002 \mathbf{5 7}$ 75-76. (https://doi.org/10.1136/thorax.57.1.75)

35 Carter R \& Watenpaugh DE. Obesity and obstructive sleep apnea: or is it OSA and obesity? Pathophysiology 200815 71-77. (https://doi. org/10.1016/j.pathophys.2008.04.009)

36 Arnardottir ES, Maislin G, Schwab RJ, Staley B, Benediktsdottir B, Olafsson I, Juliusson S, Romer M, Gislason T \& Pack AI. The interaction of obstructive sleep apnea and obesity on the inflammatory markers C-reactive protein and interleukin-6: the Icelandic Sleep Apnea Cohort. Sleep 201235 921-932. (https://doi. org/10.5665/sleep.1952)

37 Phillips BG, Kato M, Narkiewicz K, Choe I \& Somers VK. Increases in leptin levels, sympathetic drive, and weight gain in obstructive sleep apnea. American Journal of Physiology: Heart and Circulatory Physiology 2000279 H234-H237. (https://doi.org/10.1152/ ajpheart.2000.279.1.H234)

38 Hanlon EC \& Van Cauter E. Quantification of sleep behavior and of its impact on the cross-talk between the brain and peripheral 
metabolism. PNAS 2011108 15609-15616. (https://doi.org/10.1073/ pnas.1101338108)

39 Shechter A. Obstructive sleep apnea and energy balance regulation: a systematic review. Sleep Medicine Reviews 201734 59-69. (https://doi. org/10.1016/j.smrv.2016.07.001)

40 Vgontzas AN, Papanicolaou DA, Bixler EO, Hopper K, Lotsikas A, Lin HM, Kales A \& Chrousos GP. Sleep apnea and daytime sleepiness and fatigue: relation to visceral obesity, insulin resistance, and hypercytokinemia. Journal of Clinical Endocrinology and Metabolism 200085 1151-1158. (https://doi.org/10.1210/jcem.85.3.6484)

41 Quan SF, O'Connor GT, Quan JS, Redline S, Resnick HE, Shahar E, Siscovick D \& Sherrill DL. Association of physical activity with sleepdisordered breathing. Sleep and Breathing 200711 149-157. (https:// doi.org/10.1007/s11325-006-0095-5)

42 Chasens ER, Sereika SM, Weaver TE \& Umlauf MG. Daytime sleepiness, exercise, and physical function in older adults. Journal of Sleep Research 200716 60-65. (https://doi.org/10.1111/j.13652869.2007.00576.x)

43 Chasens ER, Sereika SM, Houze MP \& Strollo PJ. Subjective and objective appraisal of activity in adults with obstructive sleep apnea. Journal of Aging Research 20112011 751819. (https://doi. org/10.4061/2011/751819)

44 Cappuccio FP, Taggart FM, Kandala N-B, Currie A, Peile E, Stranges S $\&$ Miller MA. Meta-analysis of short sleep duration and obesity in children and adults. Sleep 200831 619-626. (https://doi.org/10.1093/ sleep/31.5.619)

45 Benedict C, Brooks SJ, O'daly OG, Almèn MS, Morell A, Åberg K, Gingnell M, Schultes B, Hallschmid M \& Broman J-E. Acute sleep deprivation enhances the brain's response to hedonic food stimuli: an fMRI study. Journal of Clinical Endocrinology and Metabolism 2012 97 E443-E447. (https://doi.org/10.1210/jc.2011-2759)

46 St-Onge M-P, McReynolds A, Trivedi ZB, Roberts AL, Sy M \& Hirsch J. Sleep restriction leads to increased activation of brain regions sensitive to food stimuli. American Journal of Clinical Nutrition 2012 95 818-824. (https://doi.org/10.3945/ajcn.111.027383)

47 Beebe DW, Miller N, Kirk S, Daniels SR \& Amin R. The association between obstructive sleep apnea and dietary choices among obese individuals during middle to late childhood. Sleep Medicine 201112 797-799. (https://doi.org/10.1016/j.sleep.2010.12.020)

48 Spruyt K, Capdevila OS, Serpero LD, Kheirandish-Gozal L \& Gozal D Dietary and physical activity patterns in children with obstructive sleep apnea. Journal of Pediatrics 2010156 724.e723-730.e723. (https://doi.org/10.1016/j.jpeds.2009.11.010)

49 Kim NH, Lee SK, Eun CR, Seo JA, Kim SG, Choi KM, Baik SH, Choi DS, Yun C-H \& Kim NH. Short sleep duration combined with obstructive sleep apnea is associated with visceral obesity in Korean adults. Sleep 201336 723-729. (https://doi.org/10.5665/sleep.2636)

50 Beccuti G \& Pannain S. Sleep and obesity. Current Opinion in Clinical Nutrition and Metabolic Care 201114 402. (https://doi.org/10.1097/ MCO.0b013e3283479109)

51 Kritikou I, Basta M, Vgontzas AN, Pejovic S, Fernandez-Mendoza J, Liao D, Bixler EO, Gaines J \& Chrousos GP. Sleep apnoea and the hypothalamic-pituitary-adrenal axis in men and women: effects of continuous positive airway pressure. European Respiratory Journal 201647 531-540. (https://doi.org/10.1183/13993003.00319-2015)

52 Kikuchi R, Tsuji T, Watanabe O, Yamaguchi K, Furukawa K, Nakamura H \& Aoshiba K. Hypercapnia accelerates adipogenesis: a novel role of high $\mathrm{CO} 2$ in exacerbating obesity. American Journal of Respiratory Cell and Molecular Biology 201757 570-580. (https://doi. org/10.1165/rcmb.2016-02780C)

53 Phillips BG, Hisel TM, Kato M, Pesek CA, Dyken ME, Narkiewicz K \& Somers VK. Recent weight gain in patients with newly diagnosed obstructive sleep apnea. Journal of Hypertension 199917 1297-1300. (https://doi.org/10.1097/00004872-199917090-00009)

54 Drager LF, Brunoni AR, Jenner R, Lorenzi-Filho G, Benseñor IM $\&$ Lotufo PA. Effects of CPAP on body weight in patients with obstructive sleep apnoea: a meta-analysis of randomised trials. Thorax 201570 258-264. (https://doi.org/10.1136/thoraxjnl-2014-205361)

55 Drager LF, Jun JC \& Polotsky VY. Metabolic consequences of intermittent hypoxia: relevance to obstructive sleep apnea. Best Practice and Research Clinical Endocrinology and Metabolism 201024 843-851. (https://doi.org/10.1016/j.beem.2010.08.011)

56 Tamisier R, Tan CO, Pepin JL, Levy P \& Taylor JA. Blood pressure increases in OSA due to maintained neurovascular sympathetic transduction: impact of CPAP. Sleep 201538 1973-1980. (https://doi. org/10.5665/sleep.5252)

57 Tentolouris N, Liatis S \& Katsilambros N. Sympathetic system activity in obesity and metabolic syndrome. Annals of the New York Academy of Sciences 20061083 129-152. (https://doi.org/10.1196/ annals.1367.010)

58 Spraul M, Ravussin E, Fontvieille AM, Rising R, Larson DE \& Anderson EA. Reduced sympathetic nervous activity. A potential mechanism predisposing to body weight gain. Journal of Clinical Investigation 199392 1730-1735. (https://doi.org/10.1172/ JCI116760)

59 Chopra S, Rathore A, Younas H, Pham LV, Gu C, Beselman A, Kim IY, Wolfe RR, Perin J, Polotsky VY et al. Obstructive sleep apnea dynamically increases nocturnal plasma free fatty acids, glucose, and cortisol during sleep. Journal of Clinical Endocrinology and Metabolism 2017102 3172-3181. (https://doi.org/10.1210/jc.2017-00619)

60 Henderson LA, Fatouleh RH, Lundblad LC, McKenzie DK \& Macefield VG. Effects of 12 months continuous positive airway pressure on sympathetic activity related brainstem function and structure in obstructive sleep apnea. Frontiers in Neuroscience 201610 90. (https://doi.org/10.3389/fnins.2016.00090)

61 Harsch I, Konturek P, Koebnick C, Kuehnlein P, Fuchs F, Schahin SP, Wiest G, Hahn E, Lohmann T \& Ficker J. Leptin and ghrelin levels in patients with obstructive sleep apnoea: effect of CPAP treatment. European Respiratory Journal 200322 251-257. (https://doi.org/10.118 3/09031936.03.00010103)

$62 \mathrm{Gu}$ C, Younas H \& Jun JC. Sleep apnea: an overlooked cause of lipotoxicity? Medical Hypotheses 2017108 161-165. (https://doi. org/10.1016/j.mehy.2017.09.007)

63 Mahat B, Chasse E, Mauger JF \& Imbeault P. Effects of acute hypoxia on human adipose tissue lipoprotein lipase activity and lipolysis. Journal of Translational Medicine 201614 212. (https://doi. org/10.1186/s12967-016-0965-y)

64 Cooper BG, White JE, Ashworth LA, Alberti KG \& Gibson GJ. Hormonal and metabolic profiles in subjects with obstructive sleep apnea syndrome and the acute effects of nasal continuous positive airway pressure (CPAP) treatment. Sleep 199518 172-179. (https:// doi.org/10.1093/sleep/18.3.172)

65 Tahrani AA. Diabetes and sleep apnea. In International Textbook of Diabetes Mellitus, 4th ed., pp 316-336. 2015 John Wiley \& Sons, West Sussex, UK. (https://doi.org/10.1002/9781118387658.ch22)

66 Pamidi S \& Tasali E. Obstructive sleep apnea and type 2 diabetes: is there a link? Frontiers in Neurology 20123 126. (https://doi. org/10.3389/fneur.2012.00126)

67 Amin A, Ali A, Altaf QA, Piya MK, Barnett AH, Raymond NT \& Tahrani AA. Prevalence and associations of obstructive sleep apnea in south asians and white europeans with type 2 diabetes: a crosssectional study. Journal of Clinical Sleep Medicine 201713 583-589. (https://doi.org/10.5664/jcsm.6548)

68 West SD, Nicoll DJ \& Stradling JR. Prevalence of obstructive sleep apnoea in men with type 2 diabetes. Thorax $2006 \mathbf{6 1} 945-950$ (https://doi.org/10.1136/thx.2005.057745)

69 Lam DC, Lui MM, Lam JC, Ong LH, Lam KS \& Ip MS. Prevalence and recognition of obstructive sleep apnea in Chinese patients with type 2 diabetes mellitus. Chest 2010138 1101-1107. (https://doi. org/10.1378/chest.10-0596)

70 Heffner JE, Rozenfeld Y, Kai M, Stephens EA \& Brown LK. Prevalence of diagnosed sleep apnea among patients with type 2 diabetes in 
primary care. Chest 2012141 1414-1421. (https://doi.org/10.1378/ chest.11-1945)

71 Tahrani AA. Obstructive sleep apnoea: a diabetologist's perspective. British Journal of Diabetes 201616 107-113. (https://doi. org/10.15277/bjd.2016.088)

72 Anothaisintawee T, Reutrakul S, Van Cauter E \& Thakkinstian A. Sleep disturbances compared to traditional risk factors for diabetes development: systematic review and meta-analysis. Sleep Medicine Reviews 201630 11-24. (https://doi.org/10.1016/j.smrv.2015.10.002)

73 Salord N, Fortuna AM, Monasterio C, Gasa M, Perez A, Bonsignore MR, Vilarrasa N, Montserrat JM \& Mayos M. A randomized controlled trial of continuous positive airway pressure on glucose tolerance in obese patients with obstructive sleep apnea. Sleep 201639 35-41. (https://doi.org/10.5665/sleep.5312)

74 Pamidi S, Wroblewski K, Broussard J, Day A, Hanlon EC, Abraham V $\&$ Tasali E. Obstructive sleep apnea in young lean men: impact on insulin sensitivity and secretion. Diabetes Care 201235 2384-2389. (https://doi.org/10.2337/dc12-0841)

75 Lin Q-C, Zhang X-B, Chen G-P, Huang D-Y, Din H-B \& Tang A$\mathrm{Z}$. Obstructive sleep apnea syndrome is associated with some components of metabolic syndrome in nonobese adults. Sleep and Breathing 201216 571-578. (https://doi.org/10.1007/s11325-0110544-7)

76 Barcelo A, Barbe F, de la Pena M, Martinez P, Soriano JB, Pierola J \& Agusti AG. Insulin resistance and daytime sleepiness in patients with sleep apnoea. Thorax 200863 946-950. (https://doi.org/10.1136/ thx.2007.093740)

77 Iftikhar IH, Hoyos CM, Phillips CL \& Magalang UJ. Meta-analyses of the association of sleep apnea with insulin resistance, and the effects of CPAP on HOMA-IR, adiponectin, and visceral adipose fat. Journal of Clinical Sleep Medicine 201511 475-485. (https://doi.org/10.5664/ jcsm.4610)

78 Punjabi NM \& Beamer BA. Alterations in glucose disposal in sleepdisordered breathing. American Journal of Respiratory and Critical Care Medicine 2009179 235-240. (https://doi.org/10.1164/rccm.2008091392OC)

79 Gu CJ, Li M, Li QY, Li N, Shi GC \& Wan HY. Obstructive sleep apnea is associated with impaired glucose metabolism in Han Chinese subjects. Chinese Medical Journal 2013126 5-10. (https://doi. org/10.3760/cma.j.issn.0366-6999.20121195)

80 Hermans MP, Ahn SA, Mahadeb YP \& Rousseau MF. Sleep apnoea syndrome and 10-year cardiovascular risk in females with type 2 diabetes: relationship with insulin secretion and insulin resistance. Diabetes/Metabolism Research and Reviews 201329 227-234. (https:// doi.org/10.1002/dmrr.2387)

81 Çuhadaroğlu Ç, Utkusavaş A, Öztürk L, Salman S \& Ece T. Effects of nasal CPAP treatment on insulin resistance, lipid profile, and plasma leptin in sleep apnea. Lung 2009187 75-81. (https://doi. org/10.1007/s00408-008-9131-5)

82 Pamidi S, Wroblewski K, Stepien M, Sharif-Sidi K, Kilkus J, Whitmore H \& Tasali E. Eight hours of nightly continuous positive airway pressure treatment of obstructive sleep apnea improves glucose metabolism in patients with prediabetes. A randomized controlled trial. American Journal of Respiratory and Critical Care Medicine 2015192 96-105. (https://doi.org/10.1164/rccm.2014081564OC)

83 Xu J, Long YS, Gozal D \& Epstein PN. Beta-cell death and proliferation after intermittent hypoxia: role of oxidative stress. Free Radical Biology and Medicine 200946 783-790. (https://doi. org/10.1016/j.freeradbiomed.2008.11.026)

84 Wang N, Khan SA, Prabhakar NR \& Nanduri J. Impairment of pancreatic beta-cell function by chronic intermittent hypoxia. Experimental Physiology 201398 1376-1385. (https://doi.org/10.1113/ expphysiol.2013.072454)

85 Louis M \& Punjabi NM. Effects of acute intermittent hypoxia on glucose metabolism in awake healthy volunteers. Journal of
Applied Physiology 2009106 1538-1544. (https://doi.org/10.1152/ japplphysiol.91523.2008)

86 Lavie L. Oxidative stress - a unifying paradigm in obstructive sleep apnea and comorbidities. Progress in Cardiovascular Diseases 200951 303-312. (https://doi.org/10.1016/j.pcad.2008.08.003)

87 Welsh N, Margulis B, Borg L, Wiklund HJ, Saldeen J \& FlodstrÃ M. Differences in the expression of heat-shock proteins and antioxidant enzymes between human and rodent pancreatic islets: implications for the pathogenesis of insulin-dependent diabetes mellitus. Molecular Medicine 19951 806. (https://doi.org/10.1007/BF03401895)

88 Grankvist K, Marklund SL \& Täljedal I. CuZn-superoxide dismutase, Mn-superoxide dismutase, catalase and glutathione peroxidase in pancreatic islets and other tissues in the mouse. Biochemical Journal 1981199 393-398. (https://doi.org/10.1042/bj1990393)

89 Tasali E \& Ip MS. Obstructive sleep apnea and metabolic syndrome: alterations in glucose metabolism and inflammation. Proceedings of the American Thoracic Society 20085 207-217. (https://doi. org/10.1513/pats.200708-139MG)

90 Ryan S. Adipose tissue inflammation by intermittent hypoxia: mechanistic link between obstructive sleep apnoea and metabolic dysfunction. Journal of Physiology 2017595 2423-2430. (https://doi. org/10.1113/JP273312)

91 Murphy AM, Thomas A, Crinion SJ, Kent BD, Tambuwala MM, Fabre A, Pepin J-L, Roche HM, Arnaud C \& Ryan S. Intermittent hypoxia in obstructive sleep apnoea mediates insulin resistance through adipose tissue inflammation. European Respiratory Journal 201749 1601731. (https://doi.org/10.1183/13993003.01731-2016)

92 Ban J-J, Ruthenborg RJ, Cho KW \& Kim J-W. Regulation of obesity and insulin resistance by hypoxia-inducible factors. Hypoxia 20142 171. (https://doi.org/10.2147/HP.S68771)

93 Sacramento JF, Ribeiro MJ, Rodrigues T, Guarino MP, Diogo LN, Seica R, Monteiro EC, Matafome P \& Conde SV. Insulin resistance is associated with tissue-specific regulation of HIF-1alpha and HIF-2alpha during mild chronic intermittent hypoxia. Respiratory Physiology and Neurobiology 2016228 30-38. (https://doi. org/10.1016/j.resp.2016.03.007)

94 Tasali E, Leproult R, Ehrmann DA \& Van Cauter E. Slow-wave sleep and the risk of type 2 diabetes in humans. PNAS $2008 \mathbf{1 0 5}$ 1044-1049. (https://doi.org/10.1073/pnas.0706446105)

95 Stamatakis KA \& Punjabi NM. Effects of sleep fragmentation on glucose metabolism in normal subjects. Chest 2010137 95-101. (https://doi.org/10.1378/chest.09-0791)

96 Gianotti L, Pivetti S, Lanfranco F, Tassone F, Navone F, Vittori E, Rossetto R, Gauna C, Destefanis S, Grottoli S et al. Concomitant impairment of growth hormone secretion and peripheral sensitivity in obese patients with obstructive sleep apnea syndrome. Journal of Clinical Endocrinology and Metabolism 200287 5052-5057. (https:// doi.org/10.1210/jc.2001-011441)

97 Vestergaard ET, Jessen N, Moller N \& Jorgensen JO. Acyl ghrelin induces insulin resistance independently of GH, cortisol, and free

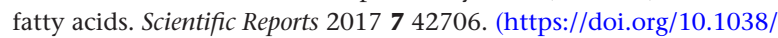
srep42706)

98 Segal KR, Landt M \& Klein S. Relationship between insulin sensitivity and plasma leptin concentration in lean and obese men. Diabetes 199645 988-991. (https://doi.org/10.2337/diab.45.7.988)

99 Lam JC, Xu A, Tam S, Khong PI, Yao TJ, Lam DC, Lai AY, Lam B, Lam KS \& Mary SM. Hypoadiponectinemia is related to sympathetic activation and severity of obstructive sleep apnea. Sleep $2008 \mathbf{3 1}$ 1721-1727. (https://doi.org/10.1093/sleep/31.12.1721)

100 Frankenberg ADV, Reis AF \& Gerchman F. Relationships between adiponectin levels, the metabolic syndrome, and type 2 diabetes: a literature review. Archives of Endocrinology and Metabolism 201761 614-622. (https://doi.org/10.1590/2359-3997000000316)

101 Luther JM. Effects of aldosterone on insulin sensitivity and secretion. Steroids 201491 54-60. (https://doi.org/10.1016/j. steroids.2014.08.016) 
102 Chen X, Niu X, Xiao Y, Dong J, Lu M \& Kong W. Effect of continuous positive airway pressure on leptin levels in patients with obstructive sleep apnea: a meta-analysis. Otolaryngology-Head and Neck Surgery 2015152 610-618. (https://doi.org/10.1177/0194599814562719)

103 Hobzova M, Salzman R, Stejskal D, Zapletalova J \& Kolek V. Serum adiponectin level in obstructive sleep apnea: relation of adiponectin to obesity and long-term continuous positive airway pressure therapy. Advances in Medical Sciences 201661 130-134. (https://doi. org/10.1016/j.advms.2015.10.004)

104 Ng SS, Liu EK, Ma RC, Chan TO, To KW, Chan KK, Ngai J, Yip WH, Ko FW, Wong CK et al. Effects of CPAP therapy on visceral fat thickness, carotid intima-media thickness and adipokines in patients with obstructive sleep apnoea. Respirology 201722 786-792. (https:// doi.org/10.1111/resp.12963)

105 Chen LD, Liu JN, Lin L, Wu Z, Li H, Ye YM, Xu QZ \& Lin QC. Effect of continuous positive airway pressure on adiponectin in patients with obstructive sleep apnea: a meta-analysis. PLOS ONE $2015 \mathbf{1 0}$ e0136837. (https://doi.org/10.1371/journal.pone.0136837)

106 Kritikou I, Basta M, Vgontzas AN, Pejovic S, Liao D, Tsaoussoglou M, Bixler EO, Stefanakis Z \& Chrousos GP. Sleep apnoea, sleepiness, inflammation and insulin resistance in middle-aged males and females. European Respiratory Journal 201443 145-155. (https://doi. org/10.1183/09031936.00126712)

107 Hoyos CM, Killick R, Yee BJ, Phillips CL, Grunstein RR \& Liu PY. Cardiometabolic changes after continuous positive airway pressure for obstructive sleep apnoea: a randomised sham-controlled study. Thorax 201267 1081-1089. (https://doi.org/10.1136/ thoraxjnl-2011-201420)

108 Fisher VL \& Tahrani AA. Cardiac autonomic neuropathy in patients with diabetes mellitus: current perspectives. Diabetes, Metabolic Syndrome and Obesity: Targets and Therapy 201710 419. (https://doi. org/10.2147/DMSO.S129797)

109 Semenza GL \& Prabhakar NR. The role of hypoxia-inducible factors in carotid body (patho) physiology. Journal of Physiology 2018596 2977-2983. (https://doi.org/10.1113/JP275696)

110 Kahal H, Tahrani AA, George JT, Barlow IM \& Malik MA. Obstructive sleep apnoea; a rare cause of pseudophaeochromocytoma. QJM 2013 106 1133-1136. (https://doi.org/10.1093/qjmed/hcr216)

111 Narkiewicz K \& Somers VK. Sympathetic nerve activity in obstructive sleep apnoea. Acta Physiologica Scandinavica 2003177 385-390. (https://doi.org/10.1046/j.1365-201X.2003.01091.x)

112 Mishra P, Nugent C, Afendy A, Bai C, Bhatia P, Afendy M, Fang Y, Elariny H, Goodman Z \& Younossi ZM. Apnoeic-hypopnoeic episodes during obstructive sleep apnoea are associated with histological nonalcoholic steatohepatitis. Liver International $2008 \mathbf{2 8}$ 1080-1086. (https://doi.org/10.1111/j.1478-3231.2008.01822.x)

113 Jin S, Jiang S \& Hu A. Association between obstructive sleep apnea and non-alcoholic fatty liver disease: a systematic review and metaanalysis. Sleep Breath 201822 841-851. (https://doi.org/10.1007/ s11325-018-1625-7)

114 Huang T, Lin BM, Stampfer MJ, Tworoger SS, Hu FB \& Redline S. A population-based study of the bidirectional association between obstructive sleep apnea and type 2 diabetes in three prospective U.S. cohorts. Diabetes Care 201841 2111-2119. (https://doi.org/10.2337/ dc18-0675)

115 Balkau B, Vol S, Loko S, Andriamboavonjy T, Lantieri O, Gusto G, Meslier N, Racineux JL \& Tichet J. High baseline insulin levels associated with 6-year incident observed sleep apnea. Diabetes Care 201033 1044-1049. (https://doi.org/10.2337/dc09-1901)

116 Evlice A, Ugurel B, Baklan B \& Oztura I. Neuropathy and Dysautonomia in Patients with Obstructive Sleep Apnea Syndrome. Nöropsikiyatri Arşivi 201552 24-28. (https://doi.org/10.5152/ npa.2015.7288)

117 Tantucci C, Scionti L, Bottini P, Dottorini ML, Puxeddu E, Casucci G $\&$ Sorbini CA. Influence of autonomic neuropathy of different severities on the hypercapnic drive to breathing in diabetic patients. Chest 1997112 145-153. (https://doi.org/10.1378/chest.112.1.145)

118 Vojtkova J, Ciljakova M, Michnova Z \& Turcan T. Chronic complications of diabetes mellitus related to the respiratory system. Pediatric Endocrinology Diabetes and Metabolism 201218 112-115.

119 Lecube A, Simó R, Pallayova M, Punjabi NM, López-Cano C, Turino C, Hernández C \& Barbé F. Pulmonary function and sleep breathing: two new targets for type 2 diabetes care. Endocrine Reviews 201738 550-573. (https://doi.org/10.1210/er.2017-00173)

120 Dharwadkar AR, Dharwadkar AA, Banu G \& Bagali S. Reduction in lung functions in type- 2 diabetes in Indian population: correlation with glycemic status. Indian Journal of Physiology and Pharmacology 201155 170-175.

121 Klein OL, Aviles-Santa L, Cai J, Collard HR, Kanaya AM, Kaplan RC, Kinney GL, Mendes E, Smith L \& Talavera G. Hispanics/Latinos with type 2 diabetes have functional and symptomatic pulmonary impairment mirroring kidney microangiopathy: findings from the Hispanic Community Health Study/Study of Latinos (HCHS/SOL). Diabetes Care 201639 2051-2057. (https://doi.org/10.2337/dc16-1170)

122 Oda E \& Kawai R. A cross-sectional relationship between vital capacity and metabolic syndrome and between vital capacity and diabetes in a sample Japanese population. Environmental Health and Preventive Medicine 200914 284. (https://doi.org/10.1007/s12199009-0098-5)

123 Kim H-K, Kim C-H, Jung Y, Bae S, Choe J, Park J \& Lee K-U. Association of restrictive ventilatory dysfunction with insulin resistance and type 2 diabetes in Koreans. Experimental and Clinical Endocrinology and Diabetes 2011119 47-52. (https://doi. org/10.1055/s-0030-1268467)

124 Huang H, Guo Q, Li L, Lin S, Lin Y, Gong X, Yao J, Liang J, Lin L \& Wen J. Effect of type 2 diabetes mellitus on pulmonary function. Experimental and Clinical Endocrinology and Diabetes 2014122 322-326. (https://doi.org/10.1055/s-0034-1372579)

125 Lange P, Parner J, Schnohr P \& Jensen G. Copenhagen City Heart Study: longitudinal analysis of ventilatory capacity in diabetic and nondiabetic adults. European Respiratory Journal 200220 1406-1412. (https://doi.org/10.1183/09031936.02.00050502)

126 Walter RE, Beiser A, Givelber RJ, O'connor GT \& Gottlieb DJ. Association between glycemic state and lung function: the Framingham Heart Study. American Journal of Respiratory and Critical Care Medicine 2003167 911-916. (https://doi.org/10.1164/ rccm.2203022)

127 Lawlor D, Ebrahim S \& Smith GD. Associations of measures of lung function with insulin resistance and type 2 diabetes: findings from the British Women's Heart and Health Study. Diabetologia 200447 195-203. (https://doi.org/10.1007/s00125-003-1310-6)

128 Yeh H-C, Punjabi NM, Wang N-Y, Pankow JS, Duncan BB, Cox CE, Selvin E \& Brancati FL. Cross-sectional and prospective study of lung function in adults with type 2 diabetes: the Atherosclerosis Risk in Communities (ARIC) study. Diabetes Care 200831 741-746. (https:// doi.org/10.2337/dc07-1464)

129 van den Borst B, Gosker HR, Zeegers MP \& Schols AMWJ. Pulmonary function in diabetes. Chest 138 393-406. (https://doi.org/10.1378/ chest.09-2622)

130 Klein O, Krishnan J, Glick S \& Smith L. Systematic review of the association between lung function and Type 2 diabetes mellitus. Diabetic Medicine 201027 977-987. (https://doi.org/10.1111/j.14645491.2010.03073.x)

131 Tahrani AA, Barnett AH \& Bailey CJ. Pharmacology and therapeutic implications of current drugs for type 2 diabetes mellitus. Nature Reviews Endocrinology 201612 566-592. (https://doi.org/10.1038/ nrendo.2016.86)

132 Newman AB, Foster G, Givelber R, Nieto FJ, Redline S \& Young T. Progression and regression of sleep-disordered breathing with changes in weight: the Sleep Heart Health Study. Archives of 
Internal Medicine 2005165 2408-2413. (https://doi.org/10.1001/ archinte.165.20.2408)

133 Papanas N, Steiropoulos P, Nena E, Tzouvelekis A, Maltezos E, Trakada G \& Bouros D. HbA1c is associated with severity of obstructive sleep apnea hypopnea syndrome in nondiabetic men. Vascular Health and Risk Management 20095 751-756. (https://doi. org/10.2147/VHRM.S7057)

134 Pillai A, Warren G, Gunathilake W \& Idris I. Effects of sleep apnea severity on glycemic control in patients with type 2 diabetes prior to continuous positive airway pressure treatment. Diabetes Technology and Therapeutics 201113 945-949. (https://doi.org/10.1089/ dia.2011.0005)

135 Aronsohn RS, Whitmore H, Van Cauter E \& Tasali E. Impact of untreated obstructive sleep apnea on glucose control in type 2 diabetes. American Journal of Respiratory and Critical Care Medicine 2010181 507-513. (https://doi.org/10.1164/rccm.200909-1423OC)

136 Grimaldi D, Beccuti G, Touma C, Van Cauter E \& Mokhlesi B. Association of obstructive sleep apnea in rapid eye movement sleep with reduced glycemic control in type 2 diabetes: therapeutic implications. Diabetes Care 201437 355-363. (https://doi. org/10.2337/dc13-0933)

137 Guo LX, Zhao X, Pan Q, Sun X, Li H, Wang XX, Zhang LN \& Wang Y. Effect of continuous positive airway pressure therapy on glycemic excursions and insulin sensitivity in patients with obstructive sleep apnea-hypopnea syndrome and type 2 diabetes. Chinese Medical Journal 2015128 2301-2306. (https://doi.org/10.4103/03666999.163382)

138 West SD, Nicoll DJ, Wallace TM, Matthews DR \& Stradling JR. Effect of CPAP on insulin resistance and HbA1c in men with obstructive sleep apnoea and type 2 diabetes. Thorax 200762 969-974. (https:// doi.org/10.1136/thx.2006.074351)

139 Shaw JE, Punjabi NM, Naughton MT, Willes L, Bergenstal RM, Cistulli PA, Fulcher GR, Richards GN \& Zimmet PZ. The effect of treatment of obstructive sleep apnea on glycemic control in type 2 diabetes. American Journal of Respiratory and Critical Care Medicine 2016194 486-492. (https://doi.org/10.1164/rccm.201511-2260OC)

140 Martinez-Ceron E, Barquiel B, Bezos AM, Casitas R, Galera R, GarciaBenito C, Hernanz A, Alonso-Fernandez A \& Garcia-Rio F. Effect of continuous positive airway pressure on glycemic control in patients with obstructive sleep apnea and type 2 diabetes. A randomized clinical trial. American Journal of Respiratory and Critical Care Medicine 2016194 476-485. (https://doi.org/10.1164/rccm.201510-1942OC)

141 Altaf QA, Ali A, Piya MK, Raymond NT \& Tahrani AA. The relationship between obstructive sleep apnea and intra-epidermal nerve fiber density, PARP activation and foot ulceration in patients with type 2 diabetes. Journal of Diabetes and its Complications 201630 1315-1320. (https://doi.org/10.1016/j.jdiacomp.2016.05.025)

142 Tahrani AA \& Ali A. Oxidative stress, inflammation and endothelial dysfunction: the link between obstructive sleep apnoea and vascular disease in type 2 diabetes. In Studies in Diabetes, pp 149-171. Springer, USA, 2014.

143 Tahrani AA, Ali A, Raymond NT, Begum S, Dubb K, Mughal S, Jose B, Piya MK, Barnett AH \& Stevens MJ. Obstructive sleep apnea and diabetic neuropathy: a novel association in patients with type 2 diabetes. American Journal of Respiratory and Critical Care Medicine 2012186 434-441. (https://doi.org/10.1164/rccm.201112-2135OC)

144 Brownlee M. The pathobiology of diabetic complications: a unifying mechanism. Diabetes 200554 1615-1625. (https://doi.org/10.2337/ diabetes.54.6.1615)

145 Jullian-Desayes I, Joyeux-Faure M, Tamisier R, Launois S, Borel A-L, Levy P \& Pepin J-L. Impact of obstructive sleep apnea treatment by continuous positive airway pressure on cardiometabolic biomarkers: a systematic review from sham CPAP randomized controlled trials. Sleep Medicine Reviews 201521 23-38. (https://doi.org/10.1016/j. smrv.2014.07.004)
146 Tahrani AA \& Ali A. Obstructive sleep apnoea and type 2 diabetes. European Endocrinology 201410 43-50. (https://doi.org/10.17925/ EE.2014.10.01.43)

147 Prasad B, Carley DW, Krishnan JA, Weaver TE \& Weaver FM. Effects of positive airway pressure treatment on clinical measures of hypertension and type 2 diabetes. Journal of Clinical Sleep Medicine 20128 481-487. (https://doi.org/10.5664/jcsm.2136)

148 Myhill PC, Davis WA, Peters KE, Chubb SP, Hillman D \& Davis TM. Effect of continuous positive airway pressure therapy on cardiovascular risk factors in patients with type 2 diabetes and obstructive sleep apnea. Journal of Clinical Endocrinology and Metabolism 201297 4212-4218. (https://doi.org/10.1210/jc.2012-2107)

149 Rice TB, Foster GD, Sanders MH, Unruh M, Reboussin D, Kuna ST, Millman R, Zammit G, Wing RR, Wadden TA et al. The relationship between obstructive sleep apnea and self-reported stroke or coronary heart disease in overweight and obese adults with type 2 diabetes mellitus. Sleep 201235 1293-1298. (https://doi.org/10.5665/ sleep.2090)

150 Seicean S, Strohl KP, Seicean A, Gibby C \& Marwick TH. Sleep disordered breathing as a risk of cardiac events in subjects with diabetes mellitus and normal exercise echocardiographic findings. American Journal of Cardiology 2013111 1214-1220. (https://doi. org/10.1016/j.amjcard.2012.12.053)

151 Koo CY, Drager LF, Sethi R, Ho H-H, Hein T, Jim M-H, Tai BC, Zhang J-J \& Lee C-H. Obstructive sleep apnea and diabetes independently add to cardiovascular risk after coronary revascularization. Diabetes Care 201841 e12-e14. (https://doi. org/10.2337/dc17-0759)

152 Leong WB, Jadhakhan F, Taheri S, Chen YF, Adab P \& Thomas GN. Effect of obstructive sleep apnoea on diabetic retinopathy and maculopathy: a systematic review and meta-analysis. Diabetic Medicine 201633 158-168. (https://doi.org/10.1111/dme.12817)

153 Altaf QA, Dodson P, Ali A, Raymond NT, Wharton H, Fellows H, Hampshire-Bancroft R, Shah M, Shepherd E, Miah J et al. Obstructive sleep apnea and retinopathy in patients with type 2 diabetes. A longitudinal study. American Journal of Respiratory and Critical Care Medicine 2017196 892-900. (https://doi.org/10.1164/rccm.20170101750C)

154 Mason RH, Kiire CA, Groves DC, Lipinski HJ, Jaycock A, Winter BC, Smith L, Bolton A, Rahman NM, Swaminathan R et al. Visual improvement following continuous positive airway pressure therapy in diabetic subjects with clinically significant macular oedema and obstructive sleep apnoea: proof of principle study. Respiration 2012 84 275-282. (https://doi.org/10.1159/000334090)

155 Leong WB, Jadhakhan F, Taheri S, Thomas GN \& Adab P. The association between obstructive sleep apnea on diabetic kidney disease: a systematic review and meta-analysis. Sleep 201639 301-308. (https://doi.org/10.5665/sleep.5432)

156 Tahrani AA, Ali A, Raymond NT, Begum S, Dubb K, Altaf QA, Piya MK, Barnett AH \& Stevens MJ. Obstructive sleep apnea and diabetic nephropathy: a cohort study. Diabetes Care $2013 \mathbf{3 6}$ 3718-3725. (https://doi.org/10.2337/dc13-0450)

157 Chiang JL, Kirkman MS, Laffel LM \& Peters AL. Type 1 diabetes through the life span: a position statement of the American Diabetes Association. Diabetes Care 201437 2034-2054. (https://doi. org/10.2337/dc14-1140)

158 Reutrakul S \& Mokhlesi B. Obstructive sleep apnea and diabetes: a state of the art review. Chest 2017152 1070-1086. (https://doi. org/10.1016/j.chest.2017.05.009)

159 De Keukelaere M, Fieuws S, Reynaert N, Vandoorne E, Kerckhove KV, Asscherickx W \& Casteels K. Evolution of body mass index in children with type 1 diabetes mellitus. European Journal of Pediatrics 2018177 1661-1666. (https://doi.org/10.1007/s00431-018-3224-9)

160 Reutrakul S, Thakkinstian A, Anothaisintawee T, Chontong S, Borel A-L, Perfect MM, Janovsky CCPS, Kessler R, Schultes B \& 
Harsch IA. Sleep characteristics in type 1 diabetes and associations with glycemic control: systematic review and meta-analysis. Sleep Medicine 201623 26-45. (https://doi.org/10.1016/j. sleep.2016.03.019)

161 Banghoej AM, Nerild HH, Kristensen PL, Pedersen-Bjergaard U, Fleischer J, Jensen AEK, Laub M, Thorsteinsson B \& Tarnow L. Obstructive sleep apnoea is frequent in patients with type 1 diabetes. Journal of Diabetes and its Complications 201731 156-161. (https:// doi.org/10.1016/j.jdiacomp.2016.10.006)

162 Janovsky CCPS, Rolim LCdSP, Sá JRd, Poyares D, Tufik S, Silva AB $\&$ Dib SA. Cardiovascular autonomic neuropathy contributes to sleep apnea in young and lean type 1 diabetes mellitus patients. Frontiers in Endocrinology 20145 119. (https://doi.org/10.3389/ fendo.2014.00119)

163 Al-Saadi MM, Meo SA, Al-Drees AM, Mohamed S, Shaikh SA \& Al-Rubeaan K. Lung functions in poorly controlled type 1 Saudi diabetic children and adolescents. Saudi Medical Journal 201132 778-783.

164 Vojtková J, Michnová Z, Turčan T, Ďurdík P, Kryštofová J, Vojarová L, Čiljaková M \& Bánovčin P. Lung function tests in children with diabetes mellitus type 1. Acta Pneumologica et Allergologica Pediatrica 201013 5-8.

165 Villa MP, Montesano M, Barreto M, Pagani J, Stegagno M, Multari G \& Ronchetti R. Diffusing capacity for carbon monoxide in children with type 1 diabetes. Diabetologia 200447 1931-1935. (https://doi. org/10.1007/s00125-004-1548-7)

166 Stubbe B, Schipf S, Schäper C, Felix SB, Steveling A, Nauck M, Völzke H, Wallaschofski H, Friedrich N, Ewert R et al. The influence of type 1 diabetes mellitus on pulmonary function and exercise capacity - results from the Study of Health in Pomerania (SHIP). Experimental and Clinical Endocrinology and Diabetes 2017125 64-69. (https://doi.org/10.1055/s-0042-112219)

167 Sokolov EI \& Demidov Iu I. Gas exchange function of the lungs in patients with type 1 diabetes mellitus. Ter Arkh 200880 63-66.

168 Lee MJ, Coast JR, Hempleman SC \& Baldi JC. Type 1 diabetes duration decreases pulmonary diffusing capacity during exercise. Respiration 201691 164-170. (https://doi.org/10.1159/000443181)

169 Hla KM, Young T, Finn L, Peppard PE, Szklo-Coxe M \& Stubbs M. Longitudinal association of sleep-disordered breathing and nondipping of nocturnal blood pressure in the Wisconsin Sleep Cohort Study. Sleep 200831 795-800. (https://doi.org/10.1093/ sleep/31.6.795)

170 Nieto FJ, Young TB, Lind BK, Shahar E, Samet JM, Redline S, D'agostino RB, Newman AB, Lebowitz MD \& Pickering TG. Association of sleep-disordered breathing, sleep apnea, and hypertension in a large community-based study. JAMA 2000283 1829-1836. (https://doi.org/10.1001/jama.283.14.1829)

171 Peppard PE, Young T, Palta M \& Skatrud J. Prospective study of the association between sleep-disordered breathing and hypertension. New England Journal of Medicine 2000342 1378-1384. (https://doi. org/10.1056/NEJM200005113421901)

172 Ahmad M, Makati D \& Akbar S. Review of and updates on hypertension in obstructive sleep apnea. International Journal of Hypertension 20172017 1848375. (https://doi. org/10.1155/2017/1848375)

173 Prejbisz A, Kolodziejczyk-Kruk S, Lenders JWM \& Januszewicz A. Primary aldosteronism and obstructive sleep apnea: is this a bidirectional relationship? Hormone and Metabolic Research 201749 969-976. (https://doi.org/10.1055/s-0043-122887)

174 Jin Z-N \& Wei Y-X. Meta-analysis of effects of obstructive sleep apnea on the renin-angiotensin-aldosterone system. Journal of Geriatric Cardiology 201613 333. (https://doi.org/10.11909/j.issn.16715411.2016.03.020)

175 Zhang W, Zhang J, Wu K, Chen X, Wang Y, Zhou L, Wang H \& Chen S. Effect of aldosterone antagonists on obstructive sleep apnea in patients with resistant hypertension: a systematic review and meta-analysis. Journal of Human Hypertension 201731 855. (https:// doi.org/10.1038/jhh.2017.70)

176 Zhang X \& Li Y. Efficacy of continuous positive airway pressure therapy upon resistant hypertension in patients with obstructive sleep apnea hypopnea syndrome. Zhonghua Yi Xue Za Zhi 200989 1811-1814.

177 Lloberes P, Sampol G, Espinel E, Segarra A, Ferrer M, Romero O, Jurado MJ, Ramon MA, Untoria D \& Garcia MAM. Effect of 3-month CPAP treatment on blood pressure and serum aldosterone concentration in patients with resistant hypertension. European Respiratory Society 2013.

178 Lloberes P, Sampol G, Espinel E, Segarra A, Ramon M-A, Romero O, Ferrer R, Martínez-Garcia M-A \& Tovar J-L. A randomized controlled study of CPAP effect on plasma aldosterone concentration in patients with resistant hypertension and obstructive sleep apnea. Journal of Hypertension 201432 1650-1657. (https://doi.org/10.1097/ HJH.0000000000000238)

179 Møller DS, Lind P, Strunge B \& Pedersen EB. Abnormal vasoactive hormones and 24-hour blood pressure in obstructive sleep apnea. American Journal of Hypertension 200316 274-280. (https://doi. org/10.1016/S0895-7061(02)03267-3)

180 de Souza F, Muxfeldt ES, Margallo V, Cortez AF, Cavalcanti AH \& Salles GF. Effects of continuous positive airway pressure treatment on aldosterone excretion in patients with obstructive sleep apnoea and resistant hypertension: a randomized controlled trial. Journal of Hypertension 201735 837-844. (https://doi.org/10.1097/ HJH.0000000000001254)

181 Yang S-J, Jiang X-T, Zhang X-B, Yin X-W \& Deng W-X. Does continuous positive airway pressure reduce aldosterone levels in patients with obstructive sleep apnea? Sleep and Breathing 201620 921-928. (https://doi.org/10.1007/s11325-015-1311-y)

182 Fung ML, Tipoe GL \& Leung PS. Mechanisms of maladaptive responses of peripheral chemoreceptors to intermittent hypoxia in sleep-disordered breathing. Acta Physiologica Sinica 201466 23-29.

183 Lam SY, Liu Y, Ng KM, Liong EC, Tipoe GL, Leung PS \& Fung ML. Upregulation of a local renin-angiotensin system in the rat carotid body during chronic intermittent hypoxia. Experimental Physiology 201499 220-231. (https://doi.org/10.1113/ expphysiol.2013.074591)

184 Shimosawa T. Salt, the renin-angiotensin-aldosterone system and resistant hypertension. Hypertension Research 201336 657. (https:// doi.org/10.1038/hr.2013.69)

185 Wolley M, Pimenta E, Calhoun D, Gordon R, Cowley D \& Stowasser M. Treatment of primary aldosteronism is associated with a reduction in the severity of obstructive sleep apnoea. Journal of Human Hypertension 201731 561. (https://doi.org/10.1038/ jhh.2017.28)

186 Sim JJ, Yan EH, Liu ILA, Rasgon SA, Kalantar-Zadeh K, Calhoun DA \& Derose SF. Positive relationship of sleep apnea to hyperaldosteronism in an ethnically diverse population. Journal of Hypertension 201129 1553-1559. (https://doi.org/10.1097/ HJH.Ob013e3283492219)

187 Ke X, Guo W, Peng H, Hu C, Zhang H, Peng C \& Wang X. Association of aldosterone excess and apnea-hypopnea index in patients with resistant hypertension. Scientific Reports $2017 \mathbf{7} 45241$. (https://doi.org/10.1038/srep45241)

188 Gaddam K, Pimenta E, Thomas SJ, Cofield SS, Oparil S, Harding SM $\&$ Calhoun DA. Spironolactone reduces severity of obstructive sleep apnoea in patients with resistant hypertension: a preliminary report. Journal of Human Hypertension 201024 532. (https://doi.org/10.1038/ jhh.2009.96)

189 Hoy LJ, Emery M, Wedzicha JA, Davison AG, Chew SL, Monson JP \& Metcalfe KA. Obstructive sleep apnea presenting as pseudopheochromocytoma: a case report. Journal of Clinical Endocrinology and Metabolism 200489 2033-2038. (https://doi. org/10.1210/jc.2003-031348) 
190 Cheezum MK \& Lettieri CJ. Obstructive sleep apnea presenting as pseudopheochromocytoma. Journal of Clinical Sleep Medicine 20106 190-191.

191 Brainard T. Obstructive sleep apnea and tricyclic antidepressant use presenting as a pseudopheochromocytoma in an active duty sailor: a case report. Military Medicine 2014179 e120-e123. (https://doi. org/10.7205/MILMED-D-13-00333)

192 Grossman AB. The diagnosis and management of central hypoadrenalism. Journal of Clinical Endocrinology and Metabolism 2010 95 4855-4863. (https://doi.org/10.1210/jc.2010-0982)

193 Copinschi G \& Challet E. Chapter 9 - Endocrine rhythms, the sleep-wake cycle, and biological clocks A2 - Jameson, J. Larry. In Endocrinology: Adult and Pediatric, 7th ed., pp 147.e149-173.e149. Eds LJD Groot, DMd Kretser, LC Giudice, AB Grossman, S Melmed, JT Potts \& GC Weir. Philadelphia, USA : W.B. Saunders, 2016.

194 Gardner D \& Shoback D. Greenspan's Basic and Clinical Endocrinology, 9th ed. Mcgraw-Hill, 2011.

195 Grunstein RR, Handelsman DJ, Lawrence SJ, Blackwell C, Caterson ID $\&$ Sullivan CE. Neuroendocrine dysfunction in sleep apnea: reversal by continuous positive airways pressure therapy. Journal of Clinical Endocrinology and Metabolism 198968 352-358. (https://doi. org/10.1210/jcem-68-2-352)

196 Carneiro G, Togeiro SM, Hayashi LF, Ribeiro-Filho FF, Ribeiro AB, Tufik S \& Zanella MT. Effect of continuous positive airway pressure therapy on hypothalamic-pituitary-adrenal axis function and 24-h blood pressure profile in obese men with obstructive sleep apnea syndrome. American Journal of Physiology: Endocrinology and Metabolism 2008295 E380-E384. (https://doi.org/10.1152/ ajpendo.00780.2007)

197 Karaca Z, Ismailogullari S, Korkmaz S, Cakir I, Aksu M, Baydemir R, Tanriverdi F \& Bayram F. Obstructive sleep apnoea syndrome is associated with relative hypocortisolemia and decreased hypothalamo-pituitary-adrenal axis response to 1 and $250 \mu \mathrm{g}$ ACTH and glucagon stimulation tests. Sleep Medicine 201314 160-164. (https://doi.org/10.1016/j.sleep.2012.10.013)

198 Bozic J, Galic T, Supe-Domic D, Ivkovic N, Kurir TT, Valic Z, Lesko J \& Dogas Z. Morning cortisol levels and glucose metabolism parameters in moderate and severe obstructive sleep apnea patients. Endocrine 201653 730-739. (https://doi.org/10.1007/s12020-016-0925-6)

199 Tomfohr LM, Edwards KM \& Dimsdale JE. Is obstructive sleep apnea associated with cortisol levels? A systematic review of the research evidence. Sleep Medicine Reviews 201216 243-249. (https://doi. org/10.1016/j.smrv.2011.05.003)

200 Dadoun F, Darmon P, Achard V, Boullu-Ciocca S, Philip-Joet F, Alessi M-C, Rey M, Grino M \& Dutour A. Effect of sleep apnea syndrome on the circadian profile of cortisol in obese men. American Journal of Physiology: Endocrinology and Metabolism 2007293 E466-E474. (https://doi.org/10.1152/ajpendo.00126.2007)

201 Vgontzas A, Pejovic S, Zoumakis E, Lin H-M, Bentley C, Bixler E, Sarrigiannidis A, Basta M \& Chrousos G. Hypothalamic-pituitaryadrenal axis activity in obese men with and without sleep apnea: effects of continuous positive airway pressure therapy. Journal of Clinical Endocrinology and Metabolism 200792 4199-4207. (https:// doi.org/10.1210/jc.2007-0774)

202 Lanfranco F, Gianotti L, Pivetti S, Navone F, Rossetto R, Tassone F, Gai V, Ghigo E \& Maccario M. Obese patients with obstructive sleep apnoea syndrome show a peculiar alteration of the corticotroph but not of the thyrotroph and lactotroph function. Clinical Endocrinology 200460 41-48. (https://doi.org/10.1111/j.1365-2265.2004.01938.x)

203 Chin K, Shimizu K, Nakamura T, Narai N, Masuzaki H, Ogawa Y, Mishima M, Nakamura T, Nakao K \& Ohi M. Changes in intraabdominal visceral fat and serum leptin levels in patients with obstructive sleep apnea syndrome following nasal continuous positive airway pressure therapy. Circulation 1999100 706-712. (https://doi.org/10.1161/01.CIR.100.7.706)
204 Follenius M, Krieger J, Krauth M, Sforza F \& Brandenberger G. Obstructive sleep apnea treatment: peripheral and central effects on plasma renin activity and aldosterone. Sleep 199114 211-217.

205 Meston N, Davies R, Mullins R, Jenkinson C, Wass J \& Stradling J. Endocrine effects of nasal continuous positive airway pressure in male patients with obstructive sleep apnoea. Journal of Internal Medicine 2003254 447-454. (https://doi.org/10.1046/j.13652796.2003.01212.x)

206 Schmoller A, Eberhardt F, Jauch-Chara K, Schweiger U, Zabel P, Peters A, Schultes B \& Oltmanns KM. Continuous positive airway pressure therapy decreases evening cortisol concentrations in patients with severe obstructive sleep apnea. Metabolism-Clinical and Experimental 200958 848-853. (https://doi.org/10.1016/j. metabol.2009.02.014)

207 Henley DE, Russell GM, Douthwaite JA, Wood SA, Buchanan F, Gibson R, Woltersdorf WW, Catterall JR \& Lightman SL. Hypothalamic-pituitary-adrenal axis activation in obstructive sleep apnea: the effect of continuous positive airway pressure therapy. Journal of Clinical Endocrinology and Metabolism 200994 4234-4242. (https://doi.org/10.1210/jc.2009-1174)

208 Mokhlesi B, Grimaldi D, Beccuti G \& Van Cauter E. Effect of one week of CPAP treatment of obstructive sleep apnoea on 24-hour profiles of glucose, insulin and counter-regulatory hormones in type 2 diabetes. Diabetes, Obesity and Metabolism 201719 452-456. (https://doi.org/10.1111/dom.12823)

209 Raff H, Ettema SL, Eastwood DC \& Woodson BT. Salivary cortisol in obstructive sleep apnea: the effect of CPAP. Endocrine 201140137. (https://doi.org/10.1007/s12020-011-9474-1)

210 Yanovski JA \& Cutler JG. Glucocorticoid action and the clinical features of Cushing's syndrome. Endocrinology and Metabolism Clinics of North America 199423 487-509. (https://doi.org/10.1016/S08898529(18)30080-X)

211 Vgontzas AN, Zoumakis M, Bixler EO, Lin H-M, Prolo P, VelaBueno A, Kales A \& Chrousos GP. Impaired nighttime sleep in healthy old versus young adults is associated with elevated plasma interleukin-6 and cortisol levels: physiologic and therapeutic implications. Journal of Clinical Endocrinology and Metabolism 200388 2087-2095. (https://doi.org/10.1210/jc.2002-021176)

212 Ekstedt M, Åkerstedt T \& Söderström M. Microarousals during sleep are associated with increased levels of lipids, cortisol, and blood pressure. Psychosomatic Medicine 200466 925-931. (https://doi. org/10.1097/01.psy.0000145821.25453.f7)

213 Van Cauter E, Van Coevorden A \& Blackman J. Modulation of neuroendocrine release by sleep and circadian rhythmicity. Advances in Neuroendocrine Regulation of Reproduction 1990 113-122.

214 Follenius M, Brandenberger G, Bandesapt J, Libert J \& Ehrhart J. Nocturnal cortisol release in relation to sleep structure. Sleep $1992 \mathbf{1 5}$ 21-27. (https://doi.org/10.1093/sleep/15.1.21)

215 Pruessner JC, Wolf OT, Hellhammer DH, Buske-Kirschbaum A, Von Auer K, Jobst S, Kaspers F \& Kirschbaum C. Free cortisol levels after awakening: a reliable biological marker for the assessment of adrenocortical activity. Life Sciences 199761 2539-2549. (https://doi. org/10.1016/S0024-3205(97)01008-4)

216 Caufriez A, Moreno-Reyes R, Leproult R, Vertongen F, Van Cauter E \& Copinschi G. Immediate effects of an 8-h advance shift of the rest-activity cycle on 24-h profiles of cortisol. American Journal of Physiology: Endocrinology and Metabolism 2002282 E1147-E1153. (https://doi.org/10.1152/ajpendo.00525.2001)

217 McCarthy V \& Caruso A. Sleep apnoea in endocrine diseases Felix Rosenow. Journal of Sleep Research 19987 3-12. (https://doi. org/10.1046/j.1365-2869.1998.00086.x)

218 Gokosmanoğlu F, Güzel A, Kan EK \& Atmaca H. Increased prevalence of obstructive sleep apnea in patients with Cushing's syndrome compared with weight and age-matched controls. European Journal of Endocrinology 2017176 267-272. (https://doi.org/10.1530/EJE-16-0815) 
219 Wang L-U, Wang T-Y, Bai Y-M, Hsu J-W, Huang K-L, Su T-P, Li C-T, Lin W-C, Chen T-J \& Chen M-H. Risk of obstructive sleep apnea among patients with Cushing's syndrome: a nationwide longitudinal study. Sleep Medicine 201736 44-47. (https://doi.org/10.1016/j. sleep.2017.04.016)

220 Berger G, Hardak E, Shaham B, Avitan E \& Yigla M. Preliminary prospective explanatory observation on the impact of 3-month steroid therapy on the objective measures of sleep-disordered breathing. Sleep and Breathing 201216 549-553. (https://doi. org/10.1007/s11325-011-0541-x)

221 Feelders RA, Pulgar SJ, Kempel A \& Pereira AM. MANAGEMENT OF ENDOCRINE DISEASE: The burden of Cushing's disease: clinical and health-related quality of life aspects. European Journal of Endocrinology 2012167 311-326. (https://doi.org/10.1530/EJE-11-1095)

222 Ceccato F, Bernkopf E \& Scaroni C. Sleep apnea syndrome in endocrine clinics. Journal of Endocrinological Investigation 201538 827-834. (https://doi.org/10.1007/s40618-015-0338-z)

223 Van Cauter E, Latta F, Nedeltcheva A, Spiegel K, Leproult R, Vandenbril C, Weiss R, Mockel J, Legros J-J \& Copinschi G. Reciprocal interactions between the GH axis and sleep. Growth Hormone and IGF Research 200414 10-17. (https://doi.org/10.1016/j.ghir.2004.03.006)

224 Parker DC, Sassin JF, Mace JW, Gotlin RW \& Rossman LG. Human growth hormone release during sleep: electroencephalographic correlation. Journal of Clinical Endocrinology and Metabolism 196929 871-874. (https://doi.org/10.1210/jcem-29-6-871)

225 Lanfranco F, Motta G, Minetto M, Ghigo E \& Maccario M. Growth hormone/insulin-like growth factor-I axis in obstructive sleep apnea syndrome: an update. Journal of Endocrinological Investigation 201033 192-196. (https://doi.org/10.1007/BF03346580)

226 Xu NY, Chen XQ, Du JZ, Wang TY \& Duan C. Intermittent hypoxia causes a suppressed pituitary growth hormone through somatostatin. Neuro Enocrinology Letters 200425 361-367.

227 Saini J, Krieger J, Brandenberger G, Wittersheim G, Simon C \& Follenius M. Continuous positive airway pressure treatment. Effects on growth hormone, insulin and glucose profiles in obstructive sleep apnea patients. Hormone and Metabolic Research 199325 375-381. (https://doi.org/10.1055/s-2007-1002123)

228 Hoyos CM, Killick R, Keenan DM, Baxter RC, Veldhuis JD \& Liu PY. Continuous positive airway pressure increases pulsatile growth hormone secretion and circulating insulin-like growth factor-1 in a time-dependent manner in men with obstructive sleep apnea: a randomized sham-controlled study. Sleep 201437 733-741. (https:// doi.org/10.5665/sleep.3580)

229 Nieminen P, Löppönen T, Tolonen U, Lanning P, Knip M \& Löppönen H. Growth and biochemical markers of growth in children with snoring and obstructive sleep apnea. Pediatrics 2002109 e55-e55. (https://doi.org/10.1542/peds.109.4.e55)

230 Rasmussen $\mathrm{MH}$. Obesity, growth hormone and weight loss. Molecular and Cellular Endocrinology 2010316 147-153. (https://doi. org/10.1016/j.mce.2009.08.017)

231 Castellani C, Francia G, Dalle Carbonare L, Ferrari M, Viva E, Cerini R, Zaccarella A, Trevisiol L \& Davi MV. Morphological study of upper airways and long-term follow-up of obstructive sleep apnea syndrome in acromegalic patients. Endocrine $201651308-316$. (https://doi.org/10.1007/s12020-015-0659-x)

232 Attal P \& Chanson P. Endocrine aspects of obstructive sleep apnea. Journal of Clinical Endocrinology and Metabolism 201095 483-495. (https://doi.org/10.1210/jc.2009-1912)

233 Roemmler J, Gutt B, Fischer R, Vay S, Wiesmeth A, Bidlingmaier M, Schopohl J \& Angstwurm M. Elevated incidence of sleep apnoea in acromegaly - correlation to disease activity. Sleep and Breathing 2012 16 1247-1253. (https://doi.org/10.1007/s11325-011-0641-7)

234 Katznelson L, Laws ER Jr, Melmed S, Molitch ME, Murad MH, Utz A \& Wass JA. Acromegaly: an Endocrine Society Clinical Practice Guideline. Journal of Clinical Endocrinology and Metabolism 201499 3933-3951. (https://doi.org/10.1210/jc.2014-2700)
235 De Menis E, Giustina A, Colao A, Degli Uberti E, Ghigo E, Minuto F, Bogazzi F, Drigo R, Cattaneo A \& Aimaretti G. Assessment of the awareness and management of sleep apnea syndrome in acromegaly. The COM.E.TA (Comorbidities Evaluation and Treatment in Acromegaly) Italian Study Group. Journal of Endocrinological Investigation 201134 60-64. (https://doi.org/10.1007/BF03346696)

236 Davi MV, Dalle Carbonare L, Giustina A, Ferrari M, Frigo A, Lo Cascio V \& Francia G. Sleep apnoea syndrome is highly prevalent in acromegaly and only partially reversible after biochemical control of the disease. European Journal of Endocrinology 2008159 533-540. (https://doi.org/10.1530/EJE-08-0442)

237 Duarte FH, Jallad RS, Amaro AC, Drager LF, Lorenzi-Filho G \& Bronstein MD. The impact of sleep apnea treatment on carbohydrate metabolism in patients with acromegaly. Pituitary 201316 341-350. (https://doi.org/10.1007/s11102-012-0430-8)

238 Sharma MD, Nguyen AV, Brown S \& Robbins RJ. Cardiovascular disease in acromegaly. Methodist DeBakey Cardiovascular Journal 2017 13 64. (https://doi.org/10.14797/mdcj-13-2-64)

239 Heinrich DA, Reinholz C, Bauer M, Tufman A, Frohner R, Schopohl J, Bidlingmaier M, Kosilek RP, Reincke M \& Schneider HJ. IGF-1-based screening reveals a low prevalence of acromegaly in patients with obstructive sleep apnea. Endocrine 2018 1-6.

240 Colao A, Ferone D, Marzullo P \& Lombardi G. Systemic complications of acromegaly: epidemiology, pathogenesis, and management. Endocrine Reviews 200425 102-152. (https://doi. org/10.1210/er.2002-0022)

241 Hochban W, Ehlenz K, Conradt R \& Brandenburg U. Obstructive sleep apnoea in acromegaly: the role of craniofacial changes. European Respiratory Journal 199914 196-202. (https://doi. org/10.1034/j.1399-3003.1999.14a33.x)

242 Kamenicky P, Viengchareun S, Blanchard A, Meduri G, Zizzari P, Imbert-Teboul M, Doucet A, Chanson P \& Lombes M. Epithelial sodium channel is a key mediator of growth hormone-induced sodium retention in acromegaly. Endocrinology 2008149 3294-3305. (https://doi.org/10.1210/en.2008-0143)

243 Kamenicky P, Blanchard A, Frank M, Salenave S, Letierce A, Azizi M, Lombès $\mathrm{M} \&$ Chanson $\mathrm{P}$. Body fluid expansion in acromegaly is related to enhanced epithelial sodium channel (ENaC) activity. Journal of Clinical Endocrinology and Metabolism 201196 2127-2135. (https://doi.org/10.1210/jc.2011-0078)

244 Quatresooz P, Hermanns-Le T, Ciccarelli A, Beckers A \& Pierard GE. Tensegrity and type 1 dermal dendrocytes in acromegaly. European Journal of Clinical Investigation 200535 133-139. (https://doi. org/10.1111/j.1365-2362.2005.01461.x)

245 Chanson P \& Salenave S. Acromegaly. Orphanet Journal of Rare Diseases 20083 17. (https://doi.org/10.1186/1750-1172-3-17)

246 Herrmann B, Wessendorf T, Ajaj W, Kahlke S, Teschler H \& Mann K. Effects of octreotide on sleep apnoea and tongue volume (magnetic resonance imaging) in patients with acromegaly. European Journal of Endocrinology 2004151 309-315. (https://doi.org/10.1530/ eje.0.1510309)

247 Dostalova S, Sonka K, Smahel Z, Weiss V, Marek J \& Horinek D. Craniofacial abnormalities and their relevance for sleep apnoea syndrome aetiopathogenesis in acromegaly. European Journal of Endocrinology 2001144 491-497. (https://doi.org/10.1530/ eje.0.1440491)

248 van Haute FR, Taboada GF, Corrêa LL, Lima GA, Fontes R, Riello AP, Dominici M \& Gadelha MR. Prevalence of sleep apnea and metabolic abnormalities in patients with acromegaly and analysis of cephalometric parameters by magnetic resonance imaging. European Journal of Endocrinology 2008158 459-465. (https://doi.org/10.1530/ EJE-07-0753)

249 Ip M, Tan K, Peh W \& Lam K. Effect of Sandostatin ${ }^{\circledR}$ LAR® on sleep apnoea in acromegaly: correlation with computerized tomographic cephalometry and hormonal activity. Clinical Endocrinology 200155 477-483. (https://doi.org/10.1046/j.1365-2265.2001.01358.x) 
250 Isono S, Saeki N, Tanaka A \& Nishino T. Collapsibility of passive pharynx in patients with acromegaly. American Journal of Respiratory and Critical Care Medicine 1999160 64-68. (https://doi.org/10.1164/ ajrccm.160.1.9806054)

251 Attal P, Claes V, Bobin S, Chanson P, Kamenicky P, Zizzari P \& Lecarpentier Y. Growth hormone excess and sternohyoid muscle mechanics in rats. European Respiratory Journal 200934 967-974. (https://doi.org/10.1183/09031936.00171808)

252 Wolinski K, Stangierski A, Gurgul E, Brominska B, Czarnywojtek A, Lodyga M \& Ruchala M. Thyroid lesions in patients with acromegaly - case-control study and update to the meta-analysis. Endokrynologia Polska 201768 2-6. (https://doi.org/10.5603/EP.2017.0001)

253 Gasperi M, Martino E, Manetti L, Arosio M, Porretti S, Faglia G, Mariotti S, Colao A, Lombardi G \& Baldelli R. Prevalence of thyroid diseases in patients with acromegaly: results of an Italian multicenter study. Journal of Endocrinological Investigation 200225 240-245. (https://doi.org/10.1007/BF03343997)

254 Amado A, Araujo F \& Carvalho D. Cardiovascular risk factors in acromegaly: what's the impact of disease control? Experimental and Clinical Endocrinology and Diabetes 2018126 505-512. (https://doi. org/10.1055/s-0043-124668)

255 Sze L, Schmid C, Bloch KE, Bernays R \& Brändle M. Effect of transsphenoidal surgery on sleep apnoea in acromegaly. European Journal of Endocrinology 2007156 321-329. (https://doi.org/10.1530/ eje.1.02340)

256 Zhang Z, Li Q, He W, Qiu H, Ye H, Wang Y, Shen M, He M, Yu Y $\&$ Shou X. The comprehensive impact on human body induced by resolution of growth hormone excess. European Journal of Endocrinology 2018178 365-375. (https://doi.org/10.1530/EJE-170872)

257 Tolis G, Angelopoulos NG, Katounda E, Rombopoulos G, Kaltzidou V, Kaltsas D, Protonotariou A \& Lytras A. Medical treatment of acromegaly: comorbidities and their reversibility by somatostatin analogs. Neuroendocrinology 200683 249-257. (https://doi. org/10.1159/000095535)

258 Grunstein RR, Ho KK \& Sullivan CE. Effect of octreotide, a somatostatin analog, on sleep apnea in patients with acromegaly. Annals of Internal Medicine 1994121 478-483. (https://doi. org/10.7326/0003-4819-121-7-199410010-00002)

259 Chanson P, Timsit J, Benoit O, Augendre B, Moulonguet M, Guillausseau P-J, Warnet A \& Lubetzki J. Rapid improvement in sleep apnoea of acromegaly after short-term treatment with somatostatin analogue SMS 201-995. Lancet 1986327 1270-1271. (https://doi. org/10.1016/S0140-6736(86)91405-4)

260 Leibowitz G, Shapiro M, Salameh M \& Glaser B. Improvement of sleep apnoea due to acromegaly during short-term treatment with octreotide. Journal of Internal Medicine 1994236 231-235. (https:// doi.org/10.1111/j.1365-2796.1994.tb01288.x)

261 Berg C, Wessendorf T, Mortsch F, Forsting M, Teschler H, Weischer T, Mann K, Saller B \& Herrmann B. Influence of disease control with pegvisomant on sleep apnoea and tongue volume in patients with active acromegaly. European Journal of Endocrinology 2009161 829-835. (https://doi.org/10.1530/EJE-09-0694)

262 Kuhn E, Maione L, Bouchachi A, Rozière M, Salenave S, BraillyTabard S, Young J, Kamenicky P, Assayag P \& Chanson P. Long-term effects of pegvisomant on comorbidities in patients with acromegaly: a retrospective single-center study. European Journal of Endocrinology 2015173 693-702. (https://doi.org/10.1530/EJE-15-0500)

263 Chemla D, Attal P, Maione L, Veyer A-S, Mroue G, Baud D, Salenave S, Kamenicky P, Bobin S \& Chanson P. Impact of successful treatment of acromegaly on overnight heart rate variability and sleep apnea. Journal of Clinical Endocrinology and Metabolism 201499 2925-2931. (https://doi.org/10.1210/jc.2013-4288)

264 Melmed S, Casanueva F, Klibanski A, Bronstein M, Chanson P, Lamberts S, Strasburger C, Wass J \& Giustina A. A consensus on the diagnosis and treatment of acromegaly complications. Pituitary 2013 16 294-302. (https://doi.org/10.1007/s11102-012-0420-x)

265 Peker Y, Svensson J, Hedner J, Grote L \& Johannsson G. Sleep apnoea and quality of life in growth hormone (GH)-deficient adults before and after 6 months of GH replacement therapy. Clinical Endocrinology 200665 98-105. (https://doi.org/10.1111/j.1365-2265.2006.02555.x)

266 Ottosson M, Lönnroth P, Björntorp P \& Edén S. Effects of cortisol and growth hormone on lipolysis in human adipose tissue. Journal of Clinical Endocrinology and Metabolism 200085 799-803. (https://doi. org/10.1210/jcem.85.2.6358)

267 Bergan-Roller HE \& Sheridan MA. The growth hormone signaling system: insights into coordinating the anabolic and catabolic actions of growth hormone. General and Comparative Endocrinology 2018258 119-133. (https://doi.org/10.1016/j.ygcen.2017.07.028)

268 Nolte W, Rädisch C, Rodenbeck A, Wiltfang J \& Hüfner M. Polysomnographic findings in five adult patients with pituitary insufficiency before and after cessation of human growth hormone replacement therapy. Clinical Endocrinology 200256 805-810. (https://doi.org/10.1046/j.1365-2265.2002.01531.x)

269 Hartman ML, Xu R, Crowe BJ, Robison LL, Erfurth EM, Kleinberg DL, Zimmermann AG, Woodmansee WW, Cutler GB Jr \& Chipman JJ. Prospective safety surveillance of GH-deficient adults: comparison of GH-treated vs untreated patients. Journal of Clinical Endocrinology and Metabolism 201398 980-988. (https://doi.org/10.1210/jc.2012-2684)

270 Karimi M, Koranyi J, Franco C, Peker Y, Eder DN, Angelhed J-E, Lönn L, Grote L, Bengtsson B- $\AA$ \& Svensson J. Increased neck soft tissue mass and worsening of obstructive sleep apnea after growth hormone treatment in men with abdominal obesity. Journal of Clinical Sleep Medicine 20106256.

271 Sedky K, Bennett DS \& Pumariega A. Prader Willi syndrome and obstructive sleep apnea: co-occurrence in the pediatric population. Journal of Clinical Sleep Medicine 201410 403-409. (https://doi. org/10.5664/jcsm.3616)

272 Salvatoni A, Veronelli E, Nosetti L, Berini J, de Simone S, Iughetti L, Bosio L, Chiumello G, Grugni G, Delù G et al. Short-term effects of growth hormone treatment on the upper airways of non severely obese children with Prader-Willi syndrome. Journal of Endocrinological Investigation 200932 601-605. (https://doi.org/10.1007/BF03346516)

273 Miller J, Silverstein J, Shuster J, Driscoll DJ \& Wagner M. Short-term effects of growth hormone on sleep abnormalities in Prader-Willi syndrome. Journal of Clinical Endocrinology and Metabolism 200691 413-417. (https://doi.org/10.1210/jc.2005-1279)

274 Berini J, Spica Russotto V, Castelnuovo P, Di Candia S, Gargantini L, Grugni G, Iughetti L, Nespoli L, Nosetti L, Padoan G et al. Growth hormone therapy and respiratory disorders: long-term follow-up in PWS children. Journal of Clinical Endocrinology and Metabolism 2013 98 E1516-E1523. (https://doi.org/10.1210/jc.2013-1831)

275 Al-Saleh S, Al-Naimi A, Hamilton J, Zweerink A, Iaboni A \& Narang I. Longitudinal evaluation of sleep-disordered breathing in children with Prader-Willi Syndrome during 2 years of growth hormone therapy. Journal of Pediatrics 2013162 263.e261-268.e261. (https:// doi.org/10.1016/j.jpeds.2012.07.042)

276 Deal CL, Tony M, Hoybye C, Allen DB, Tauber M \& Christiansen JS. GrowthHormone Research Society workshop summary: consensus guidelines for recombinant human growth hormone therapy in Prader-Willi syndrome. Journal of Clinical Endocrinology and Metabolism 201398 E1072-E1087. (https://doi.org/10.1210/jc.20123888)

277 Stafler P \& Wallis C. Prader-Willi syndrome: who can have growth hormone? Archives of Disease in Childhood 200893 341-345. (https:// doi.org/10.1136/adc.2007.126334)

278 Nixon GM, Rodda CP \& Davey MJ. Longitudinal association between growth hormone therapy and obstructive sleep apnea in a child with Prader-Willi syndrome. Journal of Clinical Endocrinology and Metabolism 201196 29-33. (https://doi.org/10.1210/jc.2010-1445) 
279 Riedl S, Blumel P, Zwiauer K \& Frisch H. Death in two female Prader-Willi syndrome patients during the early phase of growth hormone treatment. Acta Paediatrica 200594 974-977. (https://doi. org/10.1080/08035250510027110)

280 Grugni G, Livieri C, Corrias A, Sartorio A \& Crino A. Death during GH therapy in children with Prader-Willi syndrome: description of two new cases. Journal of Endocrinological Investigation $2005 \mathbf{2 8}$ 554-557. (https://doi.org/10.1007/BF03347245)

281 Sorensen JR, Winther KH, Bonnema SJ, Godballe C \& Hegedus L. Respiratory manifestations of hypothyroidism: a systematic review. Thyroid 201626 1519-1527. (https://doi.org/10.1089/thy.2015.0642)

282 Jha A, Sharma SK, Tandon N, Lakshmy R, Kadhiravan T, Handa KK, Gupta R, Pandey RM \& Chaturvedi PK. Thyroxine replacement therapy reverses sleep-disordered breathing in patients with primary hypothyroidism. Sleep Medicine 20067 55-61. (https://doi. org/10.1016/j.sleep.2005.05.003)

283 Resta O, Carratu P, Carpagnano G, Maniscalco M, Di Gioia G, Lacedonia D, Giorgino R \& De Pergola G. Influence of subclinical hypothyroidism and $\mathrm{T} \sim 4$ treatment on the prevalence and severity of obstructive sleep apnoea syndrome (OSAS). Journal of Endocrinological Investigation 200528 893. (https://doi.org/10.1007/ BF03345320)

284 Al-Jawder SE \& BaHammam AS. Hypothyroidism and obstructive sleep apnea. In Hypothyroidism-Influences and Treatments. InTech Open: London, UK, 2012.

285 Mete T, Yalcin Y, Berker D, Ciftci B, Firat SG, Topaloglu O, Yavuz HC \& Guler S. Relationship between obstructive sleep apnea syndrome and thyroid diseases. Endocrine 201344 723-728. (https://doi. org/10.1007/s12020-013-9927-9)

286 Bielicki P, Przybyłowski T, Kumor M, Barnaś M, Wiercioch M \& Chazan R. Thyroid hormone levels and TSH activity in patients with obstructive sleep apnea syndrome. In Advances in Clinical Science, pp 67-71. Springer International: Switzerland, 2015

287 Resta O, Pannacciulli N, Di Gioia G, Stefano A, Barbaro MF \& De Pergola G. High prevalence of previously unknown subclinical hypothyroidism in obese patients referred to a sleep clinic for sleep disordered breathing. Nutrition, Metabolism and Cardiovascular Diseases 200414 248-253. (https://doi.org/10.1016/S09394753(04)80051-6)

288 Bahammam SA, Sharif MM, Jammah AA \& BaHammam AS. Prevalence of thyroid disease in patients with obstructive sleep apnea. Respiratory Medicine 2011105 1755-1760. (https://doi. org/10.1016/j.rmed.2011.07.007)

289 Ozcan KM, Selcuk A, Ozcan I, Ozdas T, Ozdogan F, Acar M \& Dere H. Incidence of hypothyroidism and its correlation with polysomnography findings in obstructive sleep apnea. European Archives of Oto-Rhino-Laryngology 2014271 2937-2941. (https://doi. org/10.1007/s00405-014-2962-1)

290 Takeuchi S, Kitamura T, Ohbuchi T, Koizumi H, Takahashi R, Hohchi N \& Suzuki H. Relationship between sleep apnea and thyroid function. Sleep and Breathing 201519 85-89. (https://doi. org/10.1007/s11325-014-0966-0)

291 Bozkurt NC, Karbek B, Cakal E, Firat H, Ozbek M \& Delibasi T. The association between severity of obstructive sleep apnea and prevalence of Hashimoto's thyroiditis. Endocrine Journal 201259 981-988. (https://doi.org/10.1507/endocrj.EJ12-0106)

292 Hegedüs L, Hansen JM, Feldt-Rasmussen U, Hansen BM \& Høier-Madsen M. Influence of thyroxine treatment on thyroid size and anti-thyroid peroxidase antibodies in Hashimoto's thyroiditis. Clinical Endocrinology 199135 235-238. (https://doi. org/10.1111/j.1365-2265.1991.tb03528.x)

293 Gutierrez T, Leong A, Pang L, Chevretton E, Jeannon J \& Simo R. Multinodular thyroid goitre causing obstructive sleep apnoea syndrome. Journal of Laryngology and Otology 2012126 190. (https:// doi.org/10.1017/S0022215111002714)
294 Menon SK, Jagtap VS, Sarathi V, Lila AR, Bandgar TR, Menon PS \& Shah NS. Prevalence of upper airway obstruction in patients with apparently asymptomatic euthyroid multi nodular goitre. Indian Journal of Endocrinology and Metabolism 201115 S127. (https://doi. org/10.4103/2230-8210.83351)

295 Schlenker EH \& Schultz HD. Hypothyroidism attenuates SCH 23390-mediated depression of breathing and decreases D1 receptor expression in carotid bodies, PVN and striatum of hamsters. Brain Research 20111401 40-51. (https://doi.org/10.1016/j. brainres.2011.05.034)

296 Petrof BJ, Kelly AM, Rubinstein NA \& Pack AI. Effect of hypothyroidism on myosin heavy chain expression in rat pharyngeal dilator muscles. Journal of Applied Physiology (1985) 199273 179-187. (https://doi.org/10.1152/jappl.1992.73.1.179)

297 Geiger PC, Cody MJ, Han YS, Hunter LW, Zhan W-Z \& Sieck GC. Effects of hypothyroidism on maximum specific force in rat diaphragm muscle fibers. Journal of Applied Physiology 200292 1506-1514. (https://doi.org/10.1152/japplphysiol.00095.2001)

298 Laurberg P, Knudsen N, Andersen S, Carlé A, Pedersen IB \& Karmisholt J. Thyroid function and obesity. European Thyroid Journal 20121 159-167. (https://doi.org/10.1159/000342994)

299 Sánchez A, Carretto H, Ulla MR \& Capozza R. Body composition of patients with primary hypothyroidism evaluated by dual-energy $\mathrm{X}$-ray absorptiometry and its changes after treatment with levothyroxine. Endocrinologist 200414 321-327.

300 Karmisholt J, Andersen S \& Laurberg P. Weight loss after therapy of hypothyroidism is mainly caused by excretion of excess body water associated with myxoedema. Journal of Clinical Endocrinology and Metabolism 201196 E99-E103. (https://doi.org/10.1210/jc.2010-1521)

301 Petrone A, Mormile F, Bruni G, Quartieri M, Bonsignore MR \& Marrone O. Abnormal thyroid hormones and non-thyroidal illness syndrome in obstructive sleep apnea, and effects of CPAP treatment. Sleep Medicine 201623 21-25. (https://doi.org/10.1016/j. sleep.2016.07.002)

302 Peeters RP, Wouters PJ, Kaptein E, Van Toor H, Visser TJ \& Van den Berghe G. Reduced activation and increased inactivation of thyroid hormone in tissues of critically ill patients. Journal of Clinical Endocrinology and Metabolism 200388 3202-3211. (https://doi. org/10.1210/jc.2002-022013)

303 DeGroot LJ. The Non-Thyroidal Illness Syndrome, 2015 Elsevier: Philadelphia, PA: USA.

$304 \mathrm{Xu} \mathrm{G}$, Yan W \& Li J. An update for the controversies and hypotheses of regulating nonthyroidal illness syndrome in chronic kidney diseases. Clinical and Experimental Nephrology 201418 837-843. (https://doi.org/10.1007/s10157-014-0974-1)

305 Punjabi NM. The epidemiology of adult obstructive sleep apnea. Proceedings of the American Thoracic Society 20085 136-143. (https:// doi.org/10.1513/pats.200709-155MG)

306 Lanfranco F, Motta G, Minetto MA, Baldi M, Balbo M, Ghigo E, Arvat E \& Maccario M. Neuroendocrine alterations in obese patients with sleep apnea syndrome. International Journal of Endocrinology 20102010 474518. (https://doi.org/10.1155/2010/474518)

307 Barrett-Connor E, Dam T-T, Stone K, Harrison SL, Redline S, Orwoll E $\&$ Group OFiMS. The association of testosterone levels with overall sleep quality, sleep architecture, and sleep-disordered breathing. Journal of Clinical Endocrinology and Metabolism 200893 2602-2609. (https://doi.org/10.1210/jc.2007-2622)

308 Luboshitzky R, Aviv A, Hefetz A, Herer P, Shen-Orr Z, Lavie L \& Lavie P. Decreased pituitary-gonadal secretion in men with obstructive sleep apnea. Journal of Clinical Endocrinology and Metabolism 200287 3394-3398. (https://doi.org/10.1210/ jcem.87.7.8663)

309 Yee B, Liu P, Phillips C \& Grunstein R. Neuroendocrine changes in sleep apnea. Current Opinion in Pulmonary Medicine 200410 475-481. (https://doi.org/10.1097/01.mcp.0000143967.34079.27) 
310 Gambineri A, Pelusi Ca \& Pasquali R. Testosterone levels in obese male patients with obstructive sleep apnea syndrome: relation to oxygen desaturation, body weight, fat distribution and the metabolic parameters. Journal of Endocrinological Investigation 200326 493-498. (https://doi.org/10.1007/BF03345209)

311 Luboshitzky R, Lavie L, Shen-Orr Z \& Herer P. Altered luteinizing hormone and testosterone secretion in middle-aged obese men with obstructive sleep apnea. Obesity 200513 780-786. (https://doi. org/10.1038/oby.2005.88)

312 Cole AP, Hanske J, Jiang W, Kwon NK, Lipsitz SR, Kathrins M, Learn PA, Sun M, Haider AH \& Basaria S. Impact of testosterone replacement therapy on thromboembolism, heart disease and obstructive sleep apnoea in men. BJU International $2018 \mathbf{1 2 1}$ 811-818. (https://doi.org/10.1111/bju.14149)

313 Liu PY, Yee B, Wishart SM, Jimenez M, Jung DG, Grunstein RR \& Handelsman DJ. The short-term effects of high-dose testosterone on sleep, breathing, and function in older men. Journal of Clinical Endocrinology and Metabolism 200388 3605-3613. (https://doi. org/10.1210/jc.2003-030236)

314 Snyder PJ, Peachey H, Hannoush P, Berlin JA, Loh L, Holmes JH, Dlewati A, Staley J, Santanna J \& Kapoor SC. Effect of testosterone treatment on bone mineral density in men over 65 years of age. Journal of Clinical Endocrinology and Metabolism 199984 1966-1972. (https://doi.org/10.1210/jcem.84.6.5741)

315 Schneider BK, Pickett CK, Zwillich CW, Weil JV, McDermott MT, Santen RJ, Varano LA \& White DP. Influence of testosterone on breathing during sleep. Journal of Applied Physiology $1986 \mathbf{6 1}$ 618-623. (https://doi.org/10.1152/jappl.1986.61.2.618)

316 Matsumoto A, Sandblom R, Schoene R, Lee KA, Giblin EC, Pierson D \& Bremner W. Testosterone replacement in hypogonadal men: effects on obstructive sleep apnoea, respiratory drives, and sleep. Clinical Endocrinology 198522 713-721. (https://doi. $\operatorname{org} / 10.1111 /$ j.1365-2265.1985.tb00161.x)

317 Sandblom RE, Matsumoto AM, Schoene RB, Lee KA, Giblin EC, Bremner WJ \& Pierson DJ. Obstructive sleep apnea syndrome induced by testosterone administration. New England Journal of Medicine 1983308 508-510. (https://doi.org/10.1056/ NEJM198303033080908)

318 Bhasin S, Brito JP, Cunningham GR, Hayes FJ, Hodis HN, Matsumoto AM, Snyder PJ, Swerdloff RS, Wu FC \& Yialamas MA Testosterone therapy in men with hypogonadism: an Endocrine Society Clinical Practice Guideline. Journal of Clinical Endocrinology and Metabolism 2018103 1715-1744. (https://doi.org/10.1210/ jc.2018-00229)

319 Hoyos CM, Killick R, Yee BJ, Grunstein RR \& Liu PY. Effects of testosterone therapy on sleep and breathing in obese men with severe obstructive sleep apnoea: a randomized placebo-controlled trial. Clinical Endocrinology 201277 599-607. (https://doi. org/10.1111/j.1365-2265.2012.04413.x)

320 Killick R, Wang D, Hoyos CM, Yee BJ, Grunstein RR \& Liu PY. The effects of testosterone on ventilatory responses in men with obstructive sleep apnea: a randomised, placebo-controlled trial. Journal of Sleep Research 201322 331-336. (https://doi.org/10.1111/jsr.12027)

321 Yuki A, Otsuka R, Kozakai R, Kitamura I, Okura T, Ando F \& Shimokata H. Relationship between low free testosterone levels and loss of muscle mass. Scientific Reports 20133 1818. (https://doi. org/10.1038/srep01818)

322 Kelly DM \& Jones TH. Testosterone and obesity. Obesity Reviews 2015 16 581-606. (https://doi.org/10.1111/obr.12282)

323 Andersen ML \& Tufik S. The effects of testosterone on sleep and sleep-disordered breathing in men: its bidirectional interaction with erectile function. Sleep Medicine Reviews 200812 365-379. (https:// doi.org/10.1016/j.smrv.2007.12.003)

324 Burschtin O \& Wang J. Testosterone deficiency and sleep apnea. Sleep Medicine Clinics 201611 525-529. (https://doi.org/10.1016/j. jsmc.2016.08.003)
325 Stewart DA, Grunstein RR, Berthon-Jones M, Handelsman DJ \& Sullivan CE. Androgen blockade does not affect sleep-disordered breathing or chemosensitivity in men with obstructive sleep apnea. American Review of Respiratory Disease 1992146 1389-1393. (https:// doi.org/10.1164/ajrccm/146.6.1389)

326 Luboshitzky R, Zabari Z, Shen-Orr Z, Herer P \& Lavie P. Disruption of the nocturnal testosterone rhythm by sleep fragmentation in normal men. Journal of Clinical Endocrinology and Metabolism 200186 1134-1139. (https://doi.org/10.1210/jcem.86.3.7296)

327 Zhang X-B, Jiang X-T, Du Y-P, Yuan Y-T \& Chen B. Efficacy of continuous positive airway pressure on testosterone in men with obstructive sleep apnea: a meta-analysis. PLoS ONE 20149 e115033. (https://doi.org/10.1371/journal.pone.0115033)

328 Bratel T, Wennlund A \& Carlström K. Pituitary reactivity, androgens and catecholamines in obstructive sleep apnoea. Effects of continuous positive airway pressure treatment (CPAP). Respiratory Medicine 199993 1-7. (https://doi.org/10.1016/S09546111(99)90068-9)

329 Luboshitzky R, Lavie L, Shen-Orr Z \& Lavie P. Pituitary-gonadal function in men with obstructive sleep apnea. Neuro Enocrinology Letters 200324 463-467.

330 Celec P, Mucska I, Ostatnikova D \& Hodosy J. Testosterone and estradiol are not affected in male and female patients with obstructive sleep apnea treated with continuous positive airway pressure. Journal of Endocrinological Investigation 2014 37 9-12. (https://doi.org/10.1007/s40618-013-0003-3)

331 Knapp A, Myhill PC, Davis WA, Peters KE, Hillman D, Hamilton EJ, Lim EM \& Davis TM. Effect of continuous positive airway pressure therapy on sexual function and serum testosterone in males with type 2 diabetes and obstructive sleep apnoea. Clinical Endocrinology 201481 254-258. (https://doi.org/10.1111/cen.12401)

332 Hoekema A, Stel AL, Stegenga B, Van Der Hoeven JH, Wijkstra PJ, Van Driel MF \& De Bont LG. Sexual function and obstructive sleep apnea-hypopnea: a randomized clinical trial evaluating the effects of oral-appliance and continuous positive airway pressure therapy. Journal of Sexual Medicine 20074 1153-1162. (https://doi. org/10.1111/j.1743-6109.2006.00341.x)

333 Zhang X-B, Lin Q-C, Zeng H-Q, Jiang X-T, Chen B \& Chen X. Erectile dysfunction and sexual hormone levels in men with obstructive sleep apnea: efficacy of continuous positive airway pressure. Archives of Sexual Behavior 201645 235-240. (https://doi.org/10.1007/s10508015-0593-2)

334 Li Z, Tang T, Wu W, Gu L, Du J, Zhao T, Zhou X, Wu H \& Qin G. Efficacy of nasal continuous positive airway pressure on patients with OSA with erectile dysfunction and low sex hormone levels. Respiratory Medicine 2016119 130-134. (https://doi.org/10.1016/j. rmed.2016.09.001)

335 Santamaria J, Prior J \& Fleetham J. Reversible reproductive dysfunction in men with obstructive sleep apnoea. Clinical Endocrinology 198828 461-470. (https://doi. org/10.1111/j.1365-2265.1988.tb03680.x)

336 Pastore A, Palleschi G, Ripoli A, Silvestri L, Maggioni C, Pagliuca G, Nobili Benedetti F, Gallo A, Zucchi A \& Maurizi A. Severe obstructive sleep apnoea syndrome and erectile dysfunction: a prospective randomised study to compare sildenafil vs nasal continuous positive airway pressure. International Journal of Clinical Practice 201468 995-1000. (https://doi.org/10.1111/ijcp.12463)

337 Perimenis P, Karkoulias K, Markou S, Gyftopoulos K, Athanasopoulos A, Barbalias G, Kiriazopoulou V \& Spiropoulos K. Erectile dysfunction in men with obstructive sleep apnea syndrome: a randomized study of the efficacy of sildenafil and continuous positive airway pressure. International Journal of Impotence Research 200416 256. (https://doi.org/10.1038/sj.ijir.3901219)

338 Behan M \& Wenninger JM. Sex steroidal hormones and respiratory control. Respiratory Physiology and Neurobiology 2008164 213-221. (https://doi.org/10.1016/j.resp.2008.06.006) 
339 Potvin C, Rossignol O, Uppari N, Dallongeville A, Bairam A \& Joseph $\mathrm{V}$. Reduced hypoxic ventilatory response in newborn mice knocked-out for the progesterone receptor. Experimental Physiology 201499 1523-1537. (https://doi.org/10.1113/ expphysiol.2014.080986)

340 Driver HS, Mclean H, Kumar DV, Farr N, Day AG \& Fitzpatrick MF. The influence of the menstrual cycle on upper airway resistance and breathing during sleep. Sleep 200528 449-456. (https://doi. org/10.1093/sleep/28.4.449)

341 Netzer NC, Eliasson AH \& Strohl KP. Women with sleep apnea have lower levels of sex hormones. Sleep and Breathing $2003725-29$. (https://doi.org/10.1007/s11325-003-0025-8)

342 Shahar E, Redline S, Young T, Boland LL, Baldwin CM, Nieto FJ, O'Connor GT, Rapoport DM \& Robbins JA. Hormone replacement therapy and sleep-disordered breathing. American Journal of Respiratory and Critical Care Medicine 2003167 1186-1192. (https:// doi.org/10.1164/rccm.200210-12380C)

343 Subramanian S, Bopparaju S, Desai A, Wiggins T, Rambaud C \& Surani S. Sexual dysfunction in women with obstructive sleep apnea Sleep and Breathing 201014 59-62. (https://doi.org/10.1007/s11325009-0280-4)

344 Petersen M, Kristensen E, Berg S, Giraldi A \& Midgren B. Sexual function in female patients with obstructive sleep apnea. Journal of Sexual Medicine 20118 2560-2568. (https://doi.org/10.1111/j.17436109.2011.02358.x)

345 Stavaras C, Pastaka C, Papala M, Gravas S, Tzortzis V, Melekos M, Seitanidis G \& Gourgoulianis K. Sexual function in pre-and postmenopausal women with obstructive sleep apnea syndrome. International Journal of Impotence Research 201224 228. (https://doi. org/10.1038/ijir.2012.20)

346 Steinke E, Palm Johansen P, Fridlund B \& Brostrom A. Determinants of sexual dysfunction and interventions for patients with obstructive sleep apnoea: a systematic review. International Journal of Clinical Practice 201670 5-19. (https://doi.org/10.1111/ijcp.12751)

347 Kahal H, Kyrou I, Uthman O, Brown A, Johnson S, Wall P, Metcalfe A, Tahrani A \& Randeva H. The prevalence of obstructive sleep apnoea in women with polycystic ovary syndrome: a systematic review and meta-analysis. 2017. (https://doi.org/10.1530/ endoabs.50.P339)

348 Kang K-T, Chou C-H, Weng W-C, Lee P-L \& Hsu W-C. Associations between adenotonsillar hypertrophy, age, and obesity in children with obstructive sleep apnea. PLoS ONE 20138 e78666. (https://doi. org/10.1371/journal.pone.0078666)

349 Kahal H, Kyrou I, Uthman O, Brown A, Johnson S, Wall P, Metcalfe A, Tahrani AA \& Randeva HS. The association between obstructive sleep apnoea and metabolic abnormalities in women with polycystic ovary syndrome: a systematic review and metaanalysis. Sleep 2018 zsy085.

350 Kahal H, Kyrou I, Tahrani AA \& Randeva HS. Obstructive sleep apnoea and polycystic ovary syndrome; a comprehensive review of clinical interactions and underlying pathophysiology. Clinical Endocrinology 201787 313-319. (https://doi.org/10.1111/cen.13392)

351 Uzkeser H, Yildirim K, Aktan B, Karatay S, Kaynar H, Araz O \& Kilic K. Bone mineral density in patients with obstructive sleep apnea syndrome. Sleep and Breathing 201317 339-342. (https://doi. org/10.1007/s11325-012-0698-y)

352 Terzi R \& Yllmaz Z. Bone mineral density and changes in bone metabolism in patients with obstructive sleep apnea syndrome. Journal of Bone and Mineral Metabolism 201634 475-481. (https://doi. org/10.1007/s00774-015-0691-1)

353 Mariani S, Fiore D, Varone L, Basciani S, Persichetti A, Watanabe M, Saponara M, Spera G, Moretti C \& Gnessi L. Obstructive sleep apnea and bone mineral density in obese patients. Diabetes, Metabolic Syndrome and Obesity: Targets and Therapy 20125 395. (https://doi. org/10.2147/DMSO.S37761)
354 Sforza E, Thomas T, Barthelemy JC, Collet P \& Roche F. Obstructive sleep apnea is associated with preserved bone mineral density in healthy elderly subjects. Sleep 201336 1509-1515. (https://doi. org/10.5665/sleep.3046)

355 Chen Y-L, Weng S-F, Shen Y-C, Chou C-W, Yang C-Y, Wang JJ \& Tien K-J. Obstructive sleep apnea and risk of osteoporosis: a population-based cohort study in Taiwan. Journal of Clinical Endocrinology and Metabolism 201499 2441-2447. (https://doi. org/10.1210/jc.2014-1718)

356 Yen C-M, Kuo C-L, Lin M-C, Lee C-F, Lin K-Y, Lin C-L, Chang S-N, Sung F-C \& Kao C-H. Sleep disorders increase the risk of osteoporosis: a nationwide population-based cohort study. Sleep Medicine 201415 1339-1344. (https://doi.org/10.1016/j.sleep.2014.07.005)

357 Cauley JA, Blackwell TL, Redline S, Ensrud KE, Ancoli-Israel S, Fink HA, Orwoll ES \& Stone KL. Hypoxia during sleep and the risk of falls and fractures in older men: the Osteoporotic Fractures in Men Sleep Study. Journal of the American Geriatrics Society 201462 1853-1859. (https://doi.org/10.1111/jgs.13069)

358 Stone KL, Ewing SK, Lui LY, Ensrud KE, Ancoli-Israel S, Bauer DC, Cauley JA, Hillier TA \& Cummings SR. Self-reported sleep and nap habits and risk of falls and fractures in older women: the study of osteoporotic fractures. Journal of the American Geriatrics Society 200654 1177-1183. (https://doi.org/10.1111/j.15325415.2006.00818.x)

359 Choi SB, Lyu IS, Lee W \& Kim DW. Increased fragility fracture risk in Korean women who snore: a 10-year population-based prospective cohort study. BMC Musculoskeletal Disorders 201718 236. (https:// doi.org/10.1186/s12891-017-1587-0)

360 Tomiyama H, Okazaki R, Inoue D, Ochiai H, Shiina K, Takata Y, Hashimoto H \& Yamashina A. Link between obstructive sleep apnea and increased bone resorption in men. Osteoporosis International 2008 19 1185-1192. (https://doi.org/10.1007/s00198-007-0556-0)

361 Maes C, Carmeliet G \& Schipani E. Hypoxia-driven pathways in bone development, regeneration and disease. Nature Reviews Rheumatology 20128 358. (https://doi.org/10.1038/nrrheum.2012.36)

362 Fan L, Li J, Yu Z, Dang X \& Wang K. The hypoxia-inducible factor pathway, prolyl hydroxylase domain protein inhibitors, and their roles in bone repair and regeneration. BioMed Research International 20142014 239356. (https://doi.org/10.1155/2014/239356)

363 Knowles HJ \& Athanasou NA. Acute hypoxia and osteoclast activity: a balance between enhanced resorption and increased apoptosis. Journal of Pathology 2009218 256-264. (https://doi.org/10.1002/ path.2534)

364 Frey JL, Stonko DP, Faugere M-C \& Riddle RC. Hypoxiainducible factor- $1 \alpha$ restricts the anabolic actions of parathyroid hormone. Bone Research 20142 14005. (https://doi.org/10.1038/ boneres.2014.5)

365 Zelzer E \& Olsen BR. Multiple roles of vascular endothelial growth factor (VEGF) in skeletal development, growth, and repair. Current Topics in Developmental Biology 200565 170-188. (https://doi. org/10.1016/S0070-2153(04)65006-X)

366 Barbour KE, Boudreau R, Danielson ME, Youk AO, Wactawski-Wende J, Greep NC, LaCroix AZ, Jackson RD, Wallace RB $\&$ Bauer DC. Inflammatory markers and the risk of hip fracture: the Women's Health Initiative. Journal of Bone and Mineral Research 2012 27 1167-1176. (https://doi.org/10.1002/jbmr.1559)

367 Cauley JA, Danielson ME, Boudreau RM, Forrest KY, Zmuda JM, Pahor M, Tylavsky FA, Cummings SR, Harris TB \& Newman AB. Inflammatory markers and incident fracture risk in older men and women: the Health Aging and Body Composition Study. Journal of Bone and Mineral Research 200722 1088-1095. (https://doi. org/10.1359/jbmr.070409)

368 Sheweita S \& Khoshhal K. Calcium metabolism and oxidative stress in bone fractures: role of antioxidants. Current Drug Metabolism 2007 8 519-525. (https://doi.org/10.2174/138920007780866852) 
369 Pan W \& Kastin AJ. Leptin: a biomarker for sleep disorders? Sleep Medicine Reviews 201418 283-290. (https://doi.org/10.1016/j. smrv.2013.07.003)

370 Swanson CM, Shea SA, Stone KL, Cauley JA, Rosen CJ, Redline S, Karsenty G \& Orwoll ES. Obstructive sleep apnea and metabolic bone disease: insights into the relationship between bone and sleep. Journal of Bone and Mineral Research 201530 199-211. (https://doi. org/10.1002/jbmr.2446)

371 Barnas M, Maskey-Warzechowska M, Bielicki P, Kumor M \& Chazan R. Diurnal and nocturnal serum melatonin concentrations after treatment with continuous positive airway pressure in patients with obstructive sleep apnea. Polish Archives of Internal Medicine 2017 127 589-596.(https://doi.org/10.20452/pamw.4062)

372 Amstrup AK, Sikjaer T, Heickendorff L, Mosekilde L \& Rejnmark L. Melatonin improves bone mineral density at the femoral neck in postmenopausal women with osteopenia: a randomized controlled trial. Journal of Pineal Research 201559 221-229. (https://doi. org/10.1111/jpi.12252)

373 Liguori C, Romigi A, Izzi F, Mercuri N, Cordella A, Tarquini E, Giambrone M, Marciani M \& Placidi F. Erratum: Continuous positive airway pressure treatment increases serum Vitamin D levels in male patients with obstructive sleep apnea (Journal of Clinical Sleep Medicine (2015) 11: 6 (603-607)). Journal of Clinical Sleep Medicine 201511 1349. (https://doi.org/10.5664/jcsm.5296)

374 Dede AD, Tournis S, Dontas I \& Trovas G. Type 2 diabetes mellitus and fracture risk. Metabolism 201463 1480-1490. (https://doi. org/10.1016/j.metabol.2014.09.002)

375 Tanaka H, Yamashita T, Yoneda M, Takagi S \& Miura T. Characteristics of bone strength and metabolism in type 2 diabetic model Tsumura, Suzuki, Obese Diabetes mice. Bone Reports 20189 74-83. (https://doi.org/10.1016/j.bonr.2018.07.004)

376 Chen FP, Kuo SF, Lin YC, Fan CM \& Chen JF. Status of bone strength and factors associated with vertebral fracture in postmenopausal women with type 2 diabetes. Menopause 2018. (https://doi. org/10.1097/GME.0000000000001185)

377 Ferrari SL, Abrahamsen B, Napoli N, Akesson K, Chandran M, Eastell R, El-Hajj Fuleihan G, Josse R, Kendler DL, Kraenzlin M et al. Diagnosis and management of bone fragility in diabetes: an emerging challenge. Osteoporosis International 201829 2585-2596. (https://doi.org/10.1007/s00198-018-4650-2)

Received 14 May 2018

Revised version received 29 October 2018

Accepted 10 December 2018 